\title{
Heterogeneity in outcome selection, definition and measurement in studies assessing the treatment of cryptoglandular anal fistula: findings from a systematic review
}

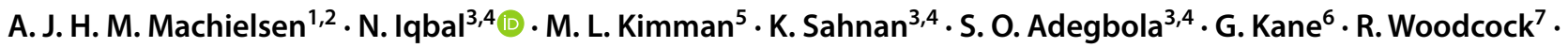 \\ J. Kleijnen ${ }^{8} \cdot$ U. Grossi ${ }^{9} \cdot$ S. O. Breukink ${ }^{10} \cdot$ P. J. Tozer $^{3,4}$
}

Received: 22 December 2020 / Accepted: 15 April 2021 / Published online: 8 May 2021

(c) The Author(s) 2021

\begin{abstract}
Background Treatment for cryptoglandular anal fistula (AF) is challenging and a lack of uniform outcomes in the literature prevents direct comparison of treatments. This can be addressed by developing a core outcome set, a standardised set of outcomes reported in all interventional studies for a specific condition. The aim of this systematic review is to assess the range of outcomes, their definitions, and the measurement instruments currently utilised in interventional studies for adult patients with AF. This will inform the development of an AF core outcome set.

Methods Medline, Embase and The Cochrane Library were searched to identify all patient- and clinician-reported outcomes in studies assessing medical, surgical or combination treatment of adult patients with AF published from January 2008 to May 2020. The resulting outcomes were categorized according to the Core Outcome Measurement in Effectiveness Trials (COMET) taxonomy to better understand their distribution.

Results In total, 155 studies were included, 552 outcomes were extracted, with a median of three outcomes (interquartile range 2-5) per study. Only $25 \%$ of studies demonstrated high-quality outcome reporting. The outcomes were merged into 52 unique outcomes and structured into four core areas and 14 domains, with the majority in the domain of physiological or clinical (gastrointestinal) outcomes. The most commonly reported outcomes were healing (77\%), incontinence (63\%), and recurrence (40\%), with no single outcome assessed across all studies. There was a wide variation in outcome definitions and measurement instruments used.

Conclusions There is substantial heterogeneity in outcomes, definitions, and measurement instruments reported in interventional studies for cryptoglandular anal fistula. This emphasises the need for standardised outcome reporting and measurement.
\end{abstract}

Keywords Cryptoglandular anal fistula $\cdot$ Systematic review $\cdot$ Outcome assessment $\cdot$ Core outcome set

\section{Introduction}

Cryptoglandular anal fistula (AF) is a challenging condition to manage. The symptom burden can be severe and can have wide-ranging impact on physical functioning and quality of life [1]. For clinicians, the difficulties of balancing treatment efficacy with minimal impairment of continence have been well documented [2,3], particularly for complex and

A. J. H. M. Machielsen and N. Iqbal should be considered joint first author.

N. Iqbal

niqbal@ doctors.org.uk

Extended author information available on the last page of the article recurrent cases. In an attempt to address the dichotomy in achieving these key treatment aims, numerous sphincter-preserving procedures have been developed in recent decades. These procedures have now made their way into common clinical practice, leading to wide variation in the techniques used according to surgical expertise, preference, and geographical area [4]. Along with the expansion of procedures, numerous interventional studies have been conducted to assess success rates and determine treatment superiority. Attempts have been made to meta-analyse data from multiple studies, however, difficulties in doing so reliably are frequently reported, due to inadequate follow-up, lack of randomized controlled trials, and non-uniform reporting of outcomes [4-6]. This limits the development of treatment guidelines for AF. 
The selection of relevant and appropriate outcomes is crucial to any study on treatment effectiveness [7], however, the lack of a systematic approach results in the reporting of numerous outcomes with varied definitions, multiple measurement instruments, and inconsistencies in the timing of assessment. Furthermore, selective reporting of outcomes based on significant results is a recognised problem and can overestimate the size of the treatment effect $[8,9]$. Such outcome reporting bias can lead to ill-informed decisions with the potential to cause patient harm [10].

One way of addressing such issues is to develop a core outcome set (COS); an agreed, standardised set of outcomes to be measured in all interventional studies for a specific health condition [9]. The importance and value of a COS in disease areas with heterogeneity in outcome reporting is being increasingly recognised. However, a COS has not yet been developed for cryptoglandular AF. We believe that this is an important step in addressing the challenges in developing evidence-based management strategies.

According to the Core Outcome Measurement in Effectiveness Trials (COMET) initiative, the first stage in the development of a COS is to determine what to measure, which can be partially achieved by identifying potential outcomes from the existing literature [7]. The primary aim of this systematic review was to identify all patient- and clinician-reported outcomes in studies assessing medical, surgical or combination treatment of adult patients with cryptoglandular AF, to inform the development of a cryptoglandular Anal Fistula Core Outcome Set (AFCOS) [11]. The secondary aim is to assess outcome definitions and identify the measurement instruments used.

\section{Materials and methods}

A systematic review of studies assessing medical, surgical, and combined interventions for cryptoglandular AF was performed in accordance with a registered protocol (PROSPERO-ID CRD42018102778).

\section{Search strategy}

An electronic search strategy was developed by an information specialist prior to execution. The following electronic databases were searched, adjusting vocabulary and syntax for each: Medline (Ovid), Embase (Ovid), and The Cochrane Library. Validated terms for 'Perianal Fistula' were used, ensuring that all interventional studies for AF could be captured. If MeSH terms or subject headings existed, these were included in the search strategy and supplemented with free-text searches of the same databases. To avoid limiting the scope of outcomes identified, no study design filter was applied. The search was restricted to full-text articles in English published from January 2008 to May 2020 and to studies conducted in human subjects aged $\geq 18$ years. The full search strategy can be found in Table 1 .
Table 1 Search strategy

\begin{tabular}{ll}
\hline Embase (Ovid) & \\
1 & Anus fistula/ \\
2 & Rectum fistula/ \\
3 & ((Anus or anal or anorectal or rectal or rectum or perianal) adj4 fistul*).m_titl \\
4 & Fistula ani_m_titl \\
5 & Fistula-in-ano.m_titl \\
6 & 1 or 2 or 3 or 4 or 5 \\
7 & Limit 6 to (full text and human and year= "2008-current") \\
The Cochrane library & \\
1 & MeSH descriptor: (rectal fistula) this term only \\
2 & (Anus or anal or anorectal or rectal or rectum or perianal) near/4 (fistul*):ti \\
3 & Fistula ani:ti \\
4 & Fistula-in-ano:ti \\
5 & \#1 or \#2 or \#3 or \#4 \\
Medline (Ovid) & Publication date from January 2008 to May 2020 \\
1 & \\
2 & Rectal fistula/ \\
3 & ((Anus or anal or anorectal or rectal or rectum or perianal) adj4 fistul*).m_titl \\
4 & Fistula ani.m_titl \\
5 & Fistula-in-ano.m_titl \\
6 & 1 or 2 or 3 or 4 \\
\hline & Limit 5 to (full text and humans and year = “2008-current") \\
\hline
\end{tabular}




\section{Study selection}

Four members of the study management group (AM, NI, KS, SA) identified and screened titles and abstracts using Covidence Systematic Review Software (Veritas Health Innovation, Melbourne, Australia, available at https://www. covidence.org/home), with each abstract and full-text publication screened by two independent group members. The following predefined selection criteria were used: (1) Prospective [including randomised controlled trials (RCTs), cohort comparisons, case controls and case series], retrospective, and observational studies including $\geq 10$ patients and systematic reviews published between January 2008 and May 2020; (2) including $\geq 10$ adult patients (aged $\geq 18$ years) with cryptoglandular AF; (3) assessing medical, surgical, or combined interventions for cryptoglandular AF; (4) and reporting $\geq$ one outcome. Studies were excluded if they were abstract only or if they reported on interventions that were only assessed on fistulas that were not perianal or not of cryptoglandular origin. Systematic reviews were included and individual studies were checked for eligibility. Disagreements were resolved through discussion with recourse to the senior authors (PT, SB) if necessary.

\section{Data extraction}

Two members of the study management group (AM, NI) extracted data from eligible studies using a predefined data extraction sheet created in Microsoft Excel. Extracted data included study publication year, design, interventions, patients, outcomes (primary and secondary), outcome definitions and measurement instruments used. In keeping with COMET recommendations, all data were extracted verbatim [7]. The quality of describing and reporting outcomes was assessed using Harman's criteria [12], which are presented in (Table 2). Disagreements were resolved through discussion with recourse to the senior authors (PT, SB) if necessary.

\section{Data synthesis}

\section{Outcome categorisation}

The resulting list of outcomes was reviewed by the study management group, including patient representatives (AM, NI, GK, RW, HG, MK, UG, PT, SB) to enable those with similar wording or meaning to be reduced to a single outcome. These were then mapped according to the COMET taxonomy developed for outcomes in medical research [13]. In this taxonomy, the measurable aspects of health conditions can be structured into five core areas, namely death, physiological or clinical, life impact, resource use, and adverse events, and further subdivided into 38 domains.

\section{Data analysis}

Primary, secondary, and overall outcome reporting were analysed. Results were summarized using frequencies and percentages. The frequency of outcome domain reporting was calculated. The interventions studied, number of outcome definitions and measurement instruments used were collated and analysed.

\section{Results}

\section{Search strategy and study selection}

The electronic databases Medline (Ovid), Embase (Ovid), and The Cochrane Library were searched in May 2018, followed by an updated search in May 2020, identifying a total of 2583 records. A schematic overview of the inclusion and exclusion of articles, including reasons provided for exclusion, is presented in Fig. 1. Full-text screening resulted in the inclusion of 143 articles, including 15 systematic reviews. The systematic reviews were individually screened for any additional studies that were not captured by the initial search and this yielded 27 articles, resulting in a final number of 155 articles from which data were extracted.

\section{Study characteristics}

An overview of the 155 included studies is presented in Table 2. Interventions for cryptoglandular AF were assessed on a total of 11,819 patients (mean 76, range 10-462 participants per study). The majority of studies were prospective studies (52\%) and assessed the effectiveness of sphincterpreserving procedures, of which fistula plugs (19\%) and ligation of intersphincteric fistula tract (LIFT) procedures (19\%) were assessed most frequently. The characteristics of the included studies are presented in Table 3 . The quality of outcome reporting for each individual study was assessed using Harman's criteria [12] and reported in Table 2. The criteria involve assessing whether: (1) The primary outcome for a study is clearly stated, (2) The primary outcome is clearly defined so that other researchers can reproduce its measurement, (3) The secondary outcomes are clearly stated, (4) The secondary outcomes are clearly defined, (5) The authors explain the use of the outcomes they have selected and (6) Any methods were used to enhance the quality of outcome measurement. The average number of criteria met across all studies was two, with only 38 of 155 studies (25\%) meeting $\geq$ four criteria, indicating high-quality outcome reporting in just a quarter of the studies assessed. 


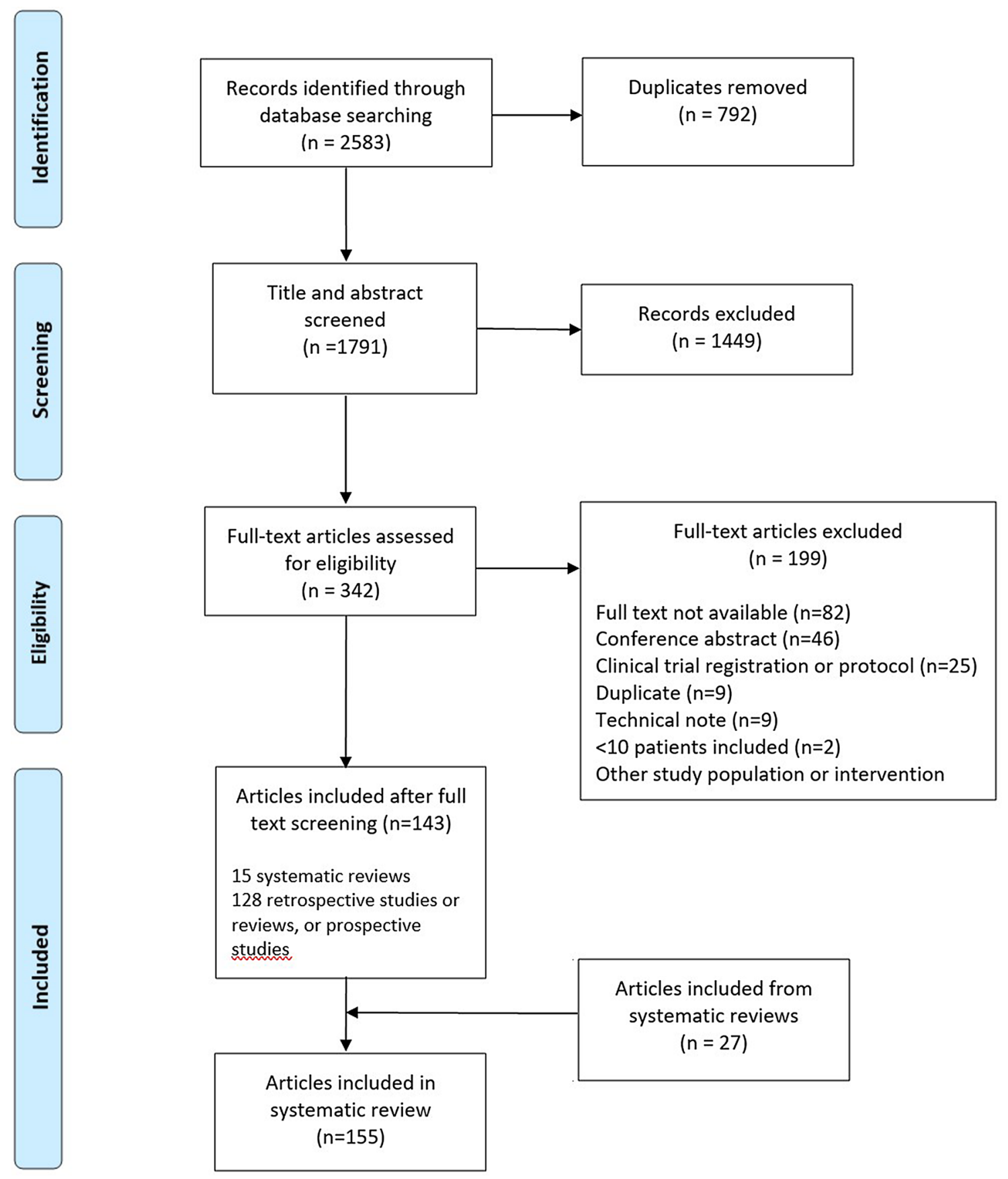

Fig. 1 Preferred reporting items for systematic reviews and meta-analyses flow chart of study selection

\section{Study outcomes}

In total, 552 patient- and clinician-reported outcomes were extracted from 155 studies, with studies reporting a median of three outcomes (interquartile range 2-5) per study. Duplicate and analogous terms were merged to form 52 outcomes, of which healing $(77 \%)$, incontinence $(63 \%)$, recurrence (40\%), and pain (26\%) were reported most frequently (Table 4). Outcomes such as healing and recurrence were sometimes measured at different time points within the same study but referred to as primary or secondary outcomes. This resulted in some studies reporting outcomes of healing and recurrence more than once. 


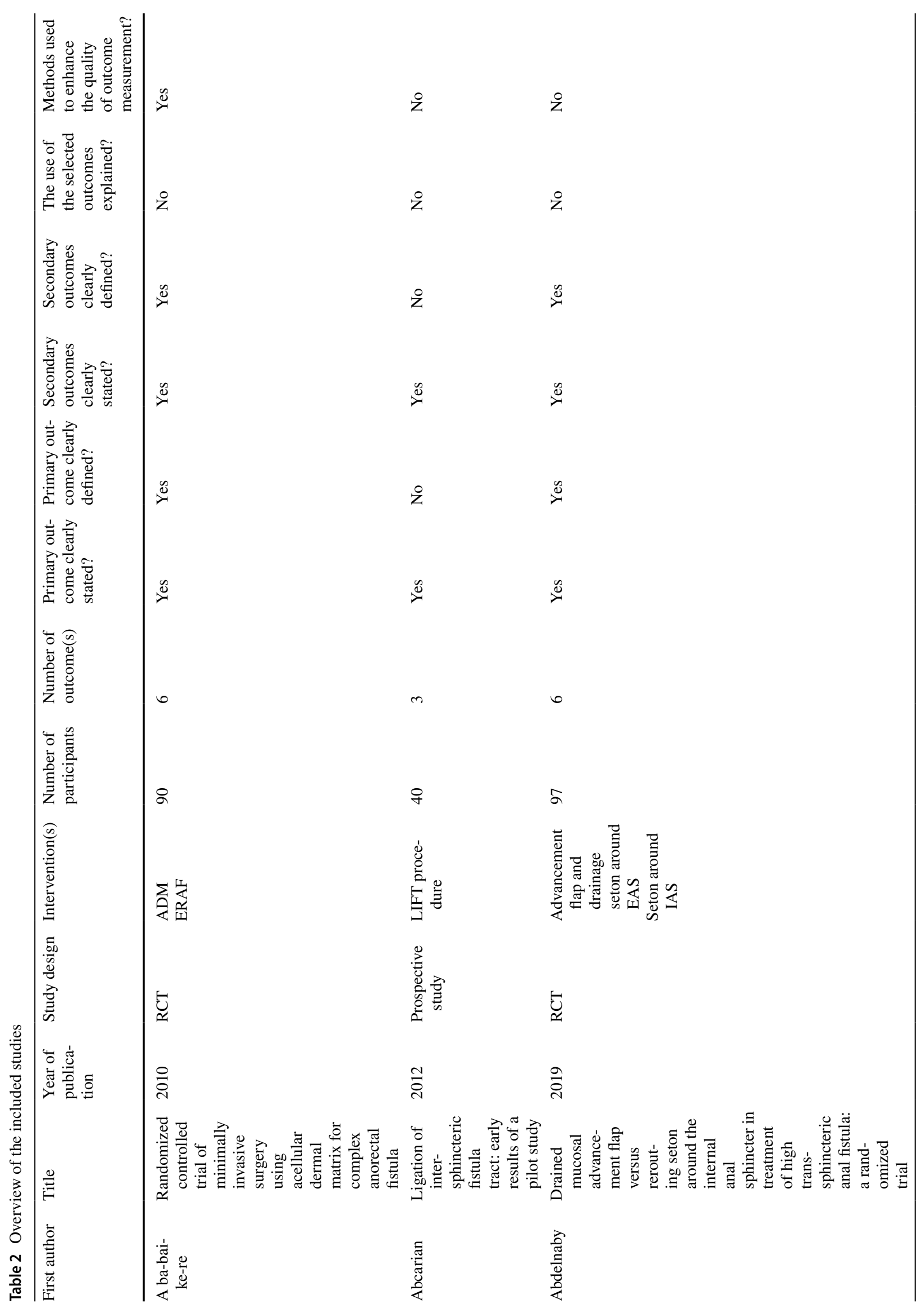




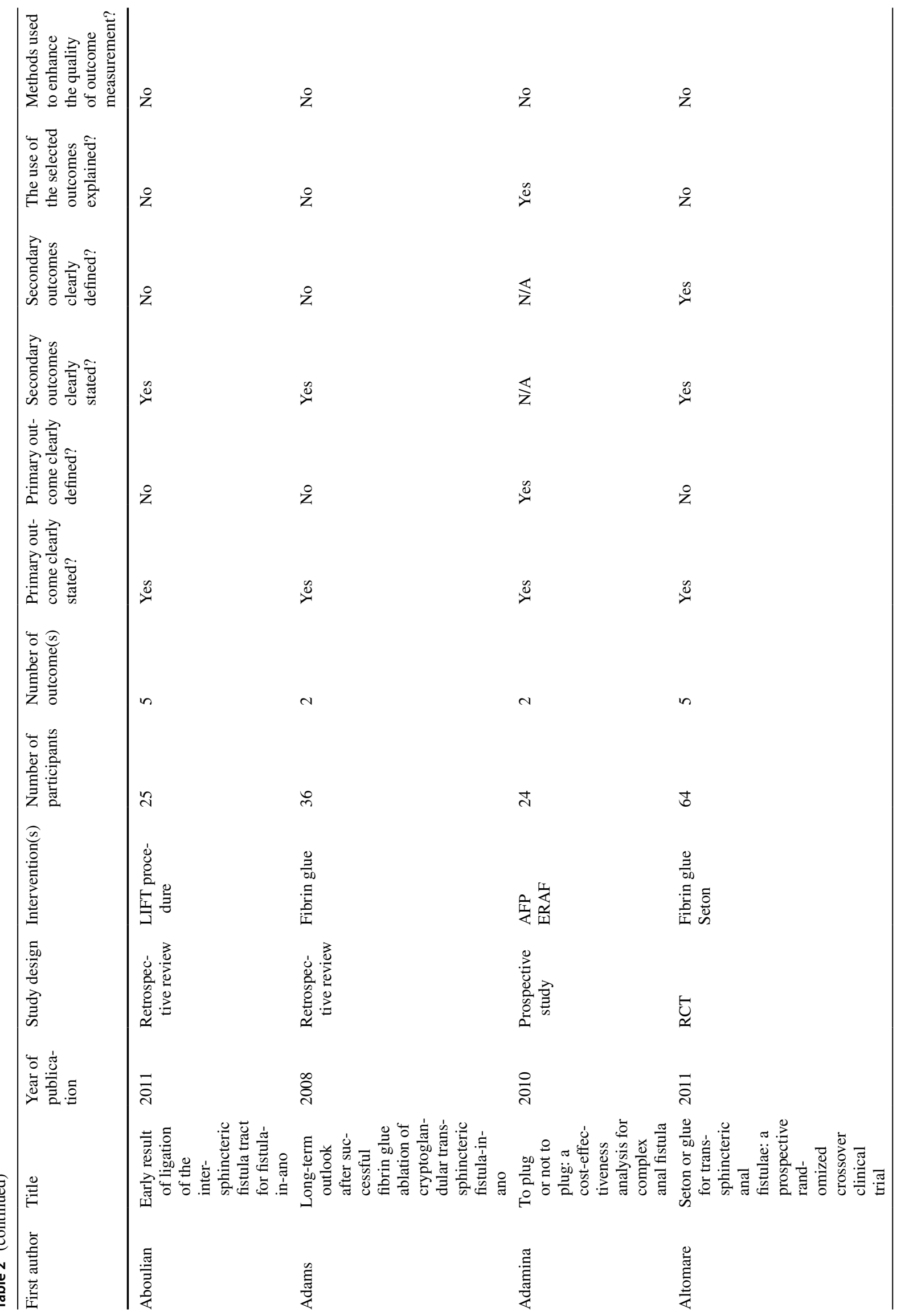




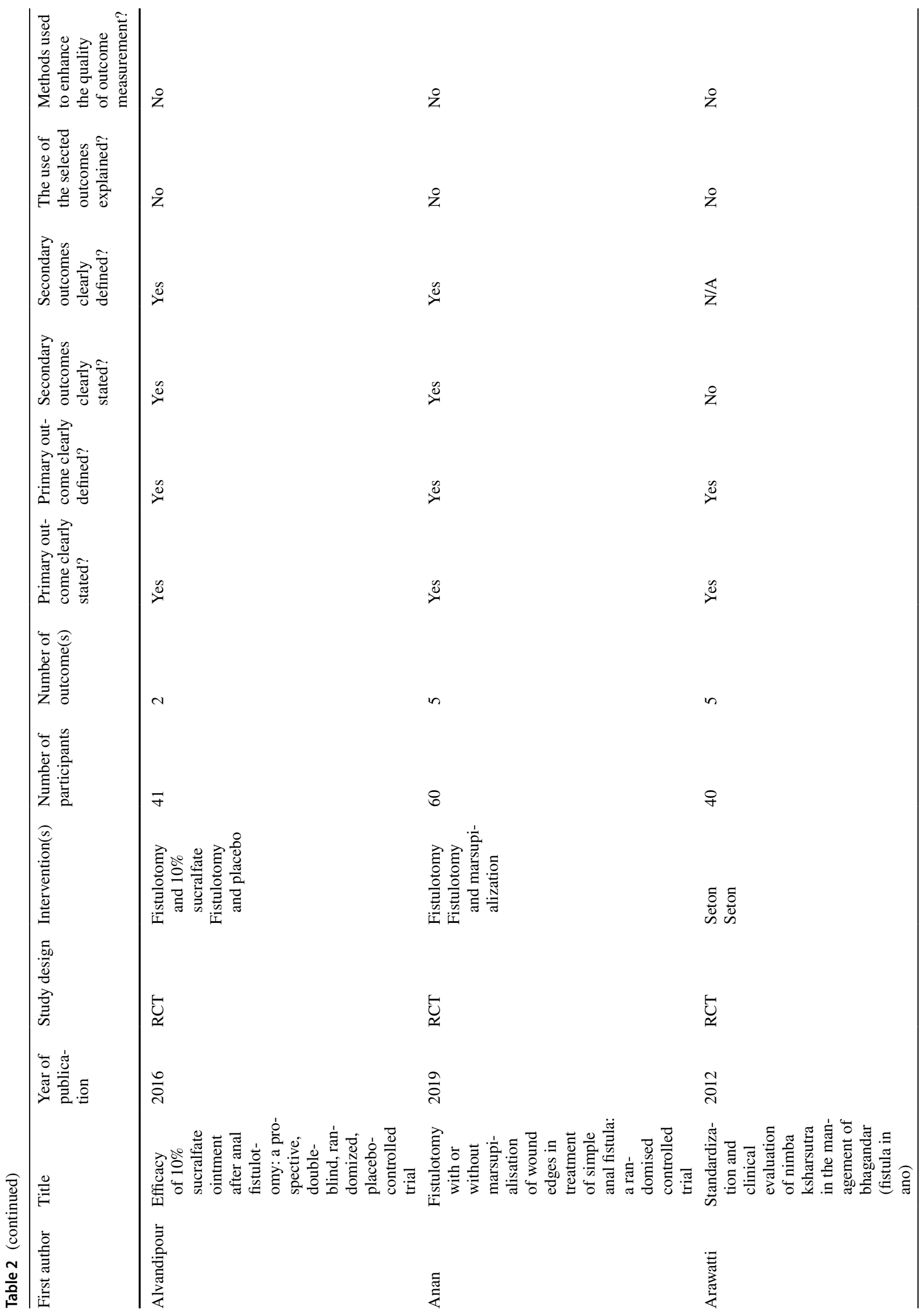




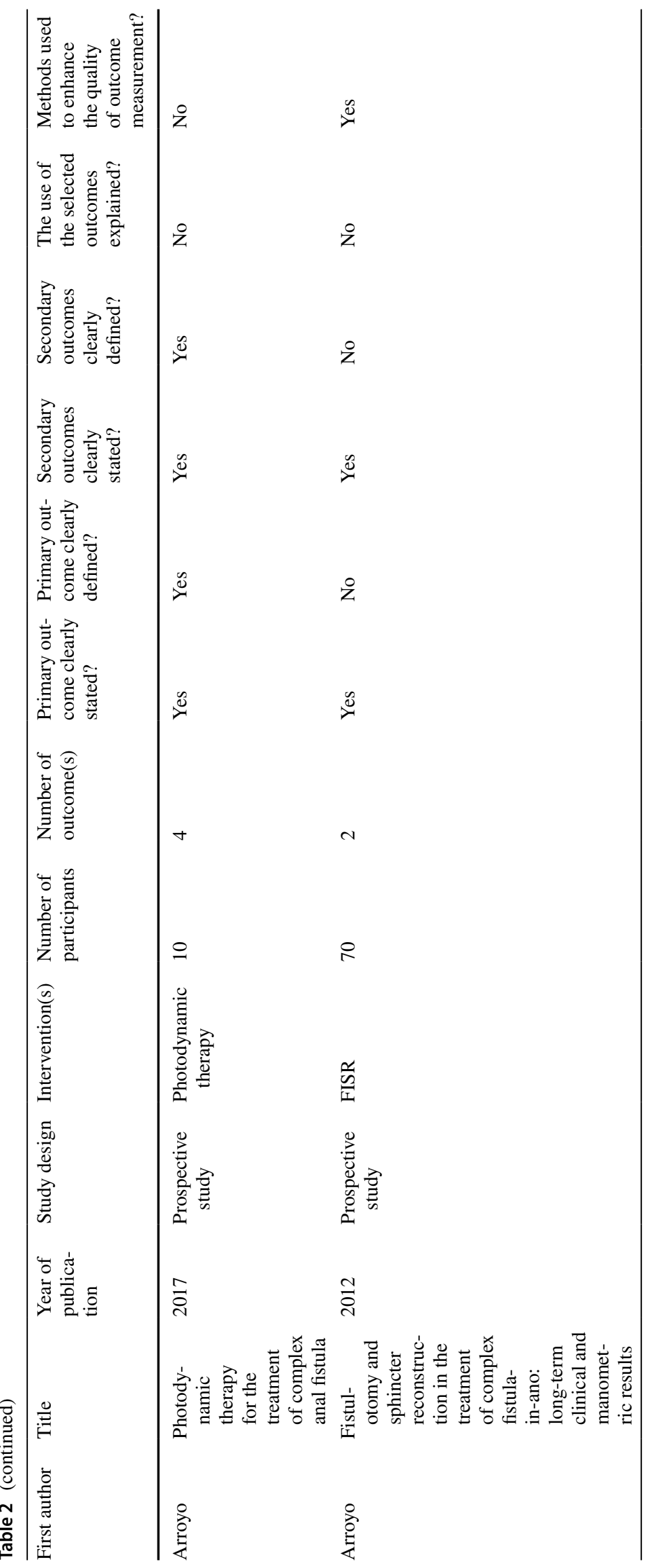




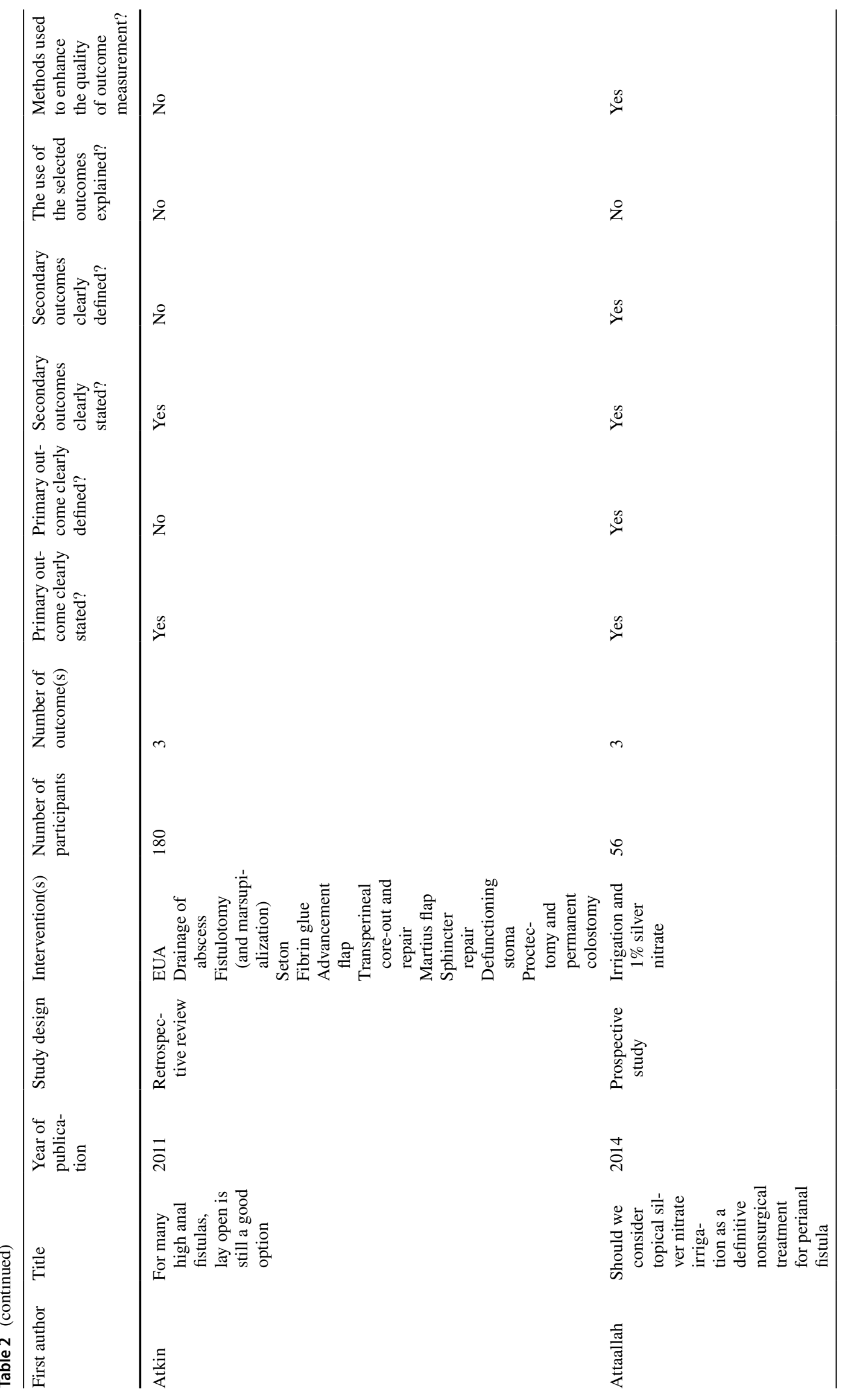




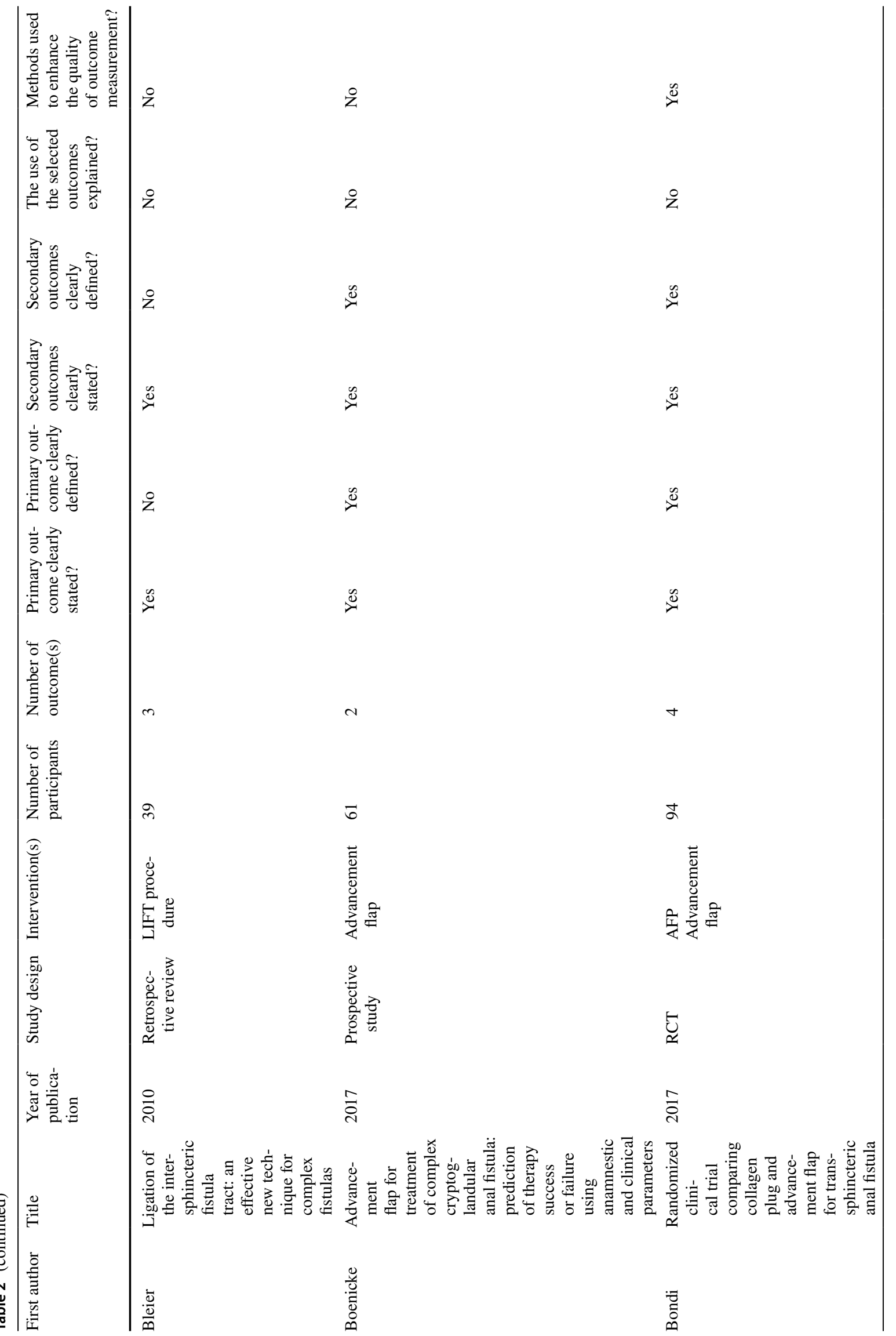




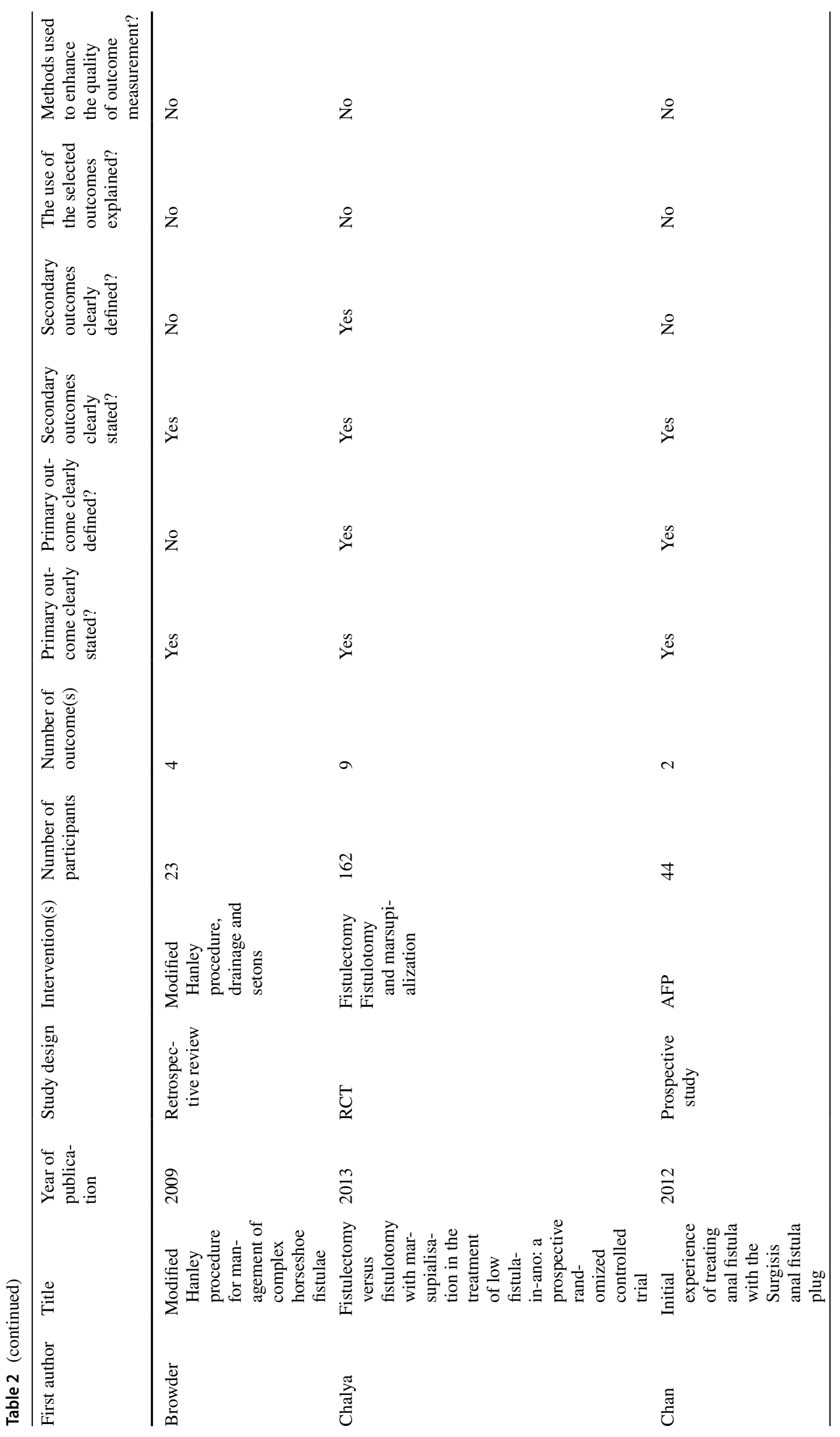




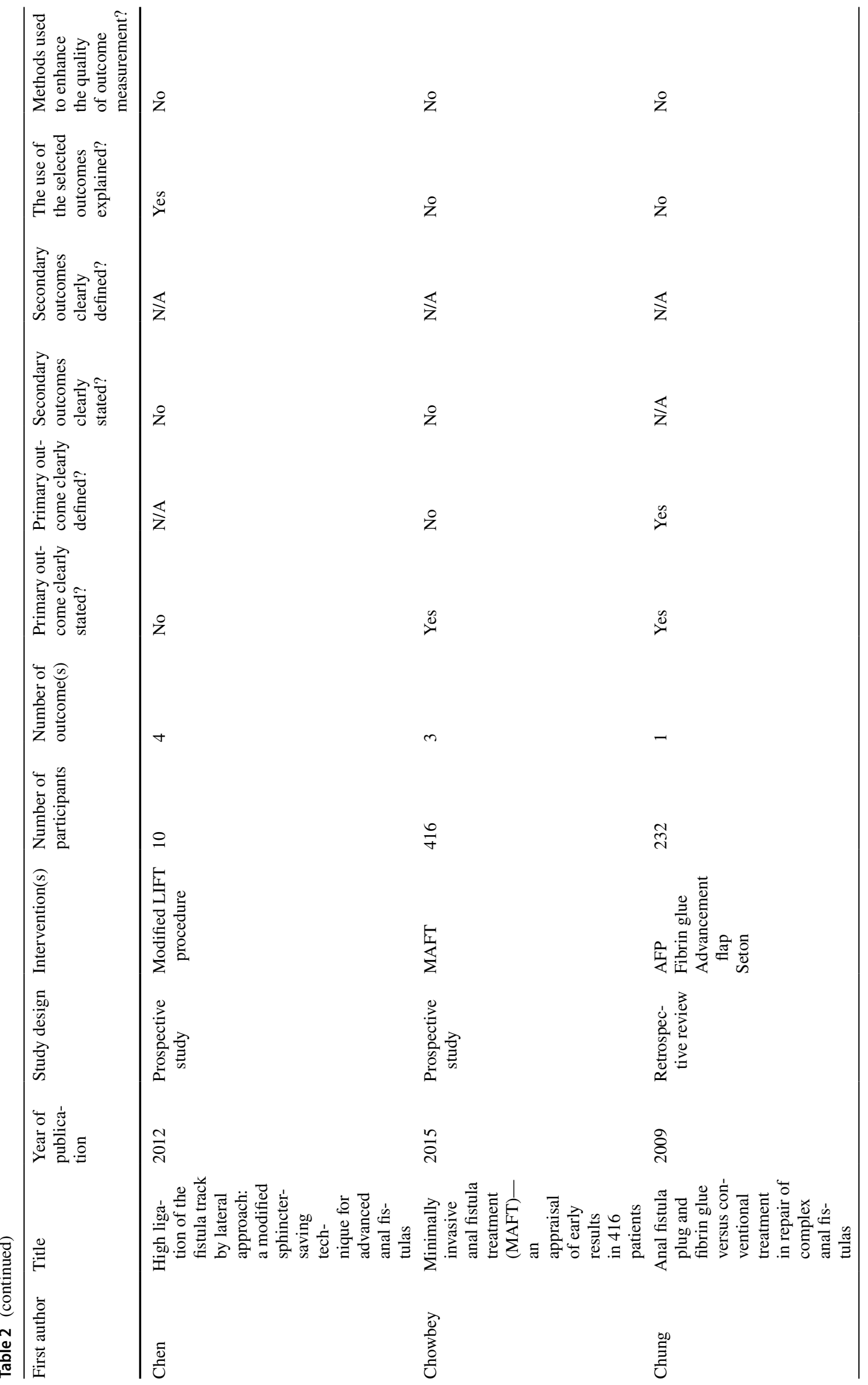




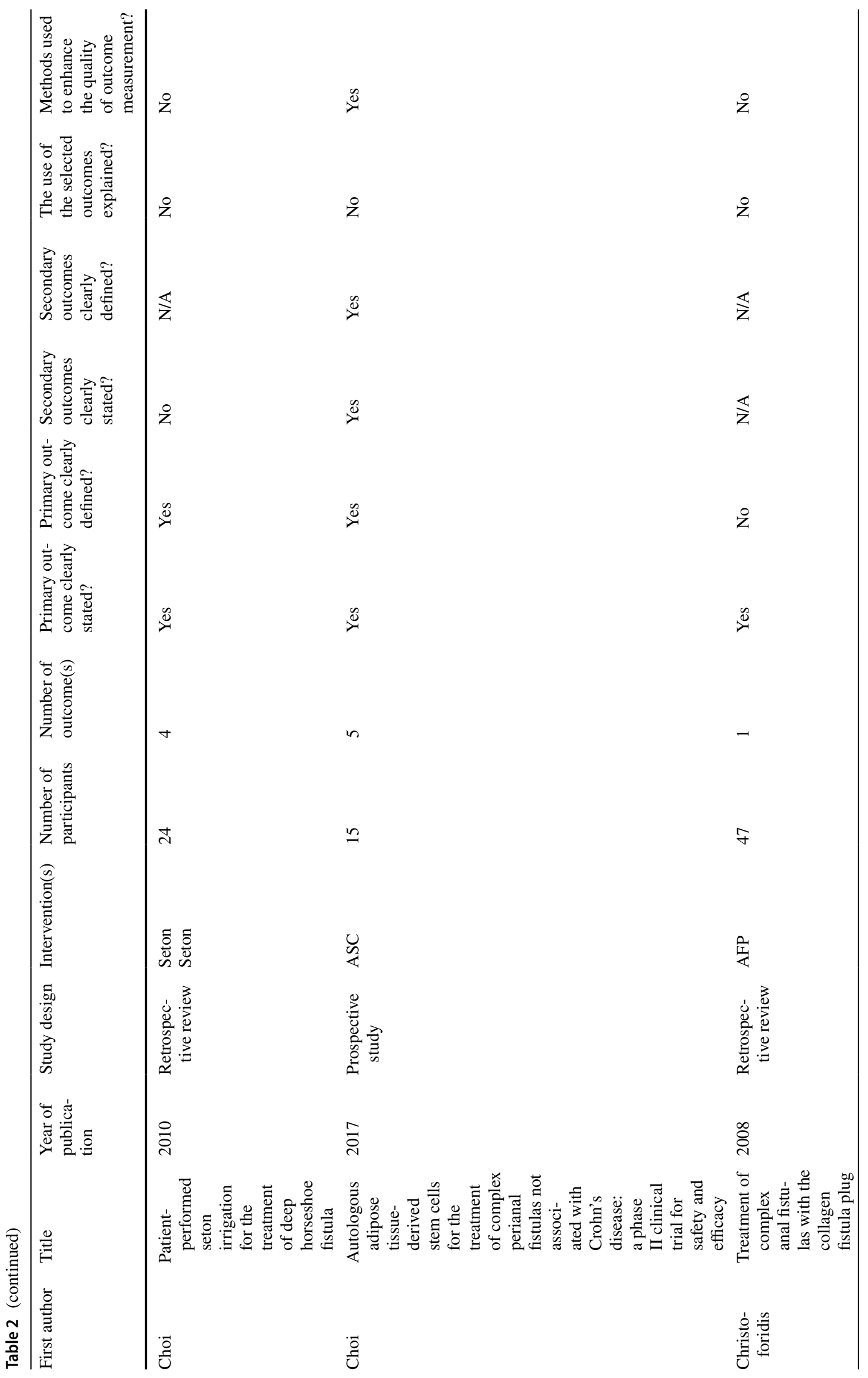




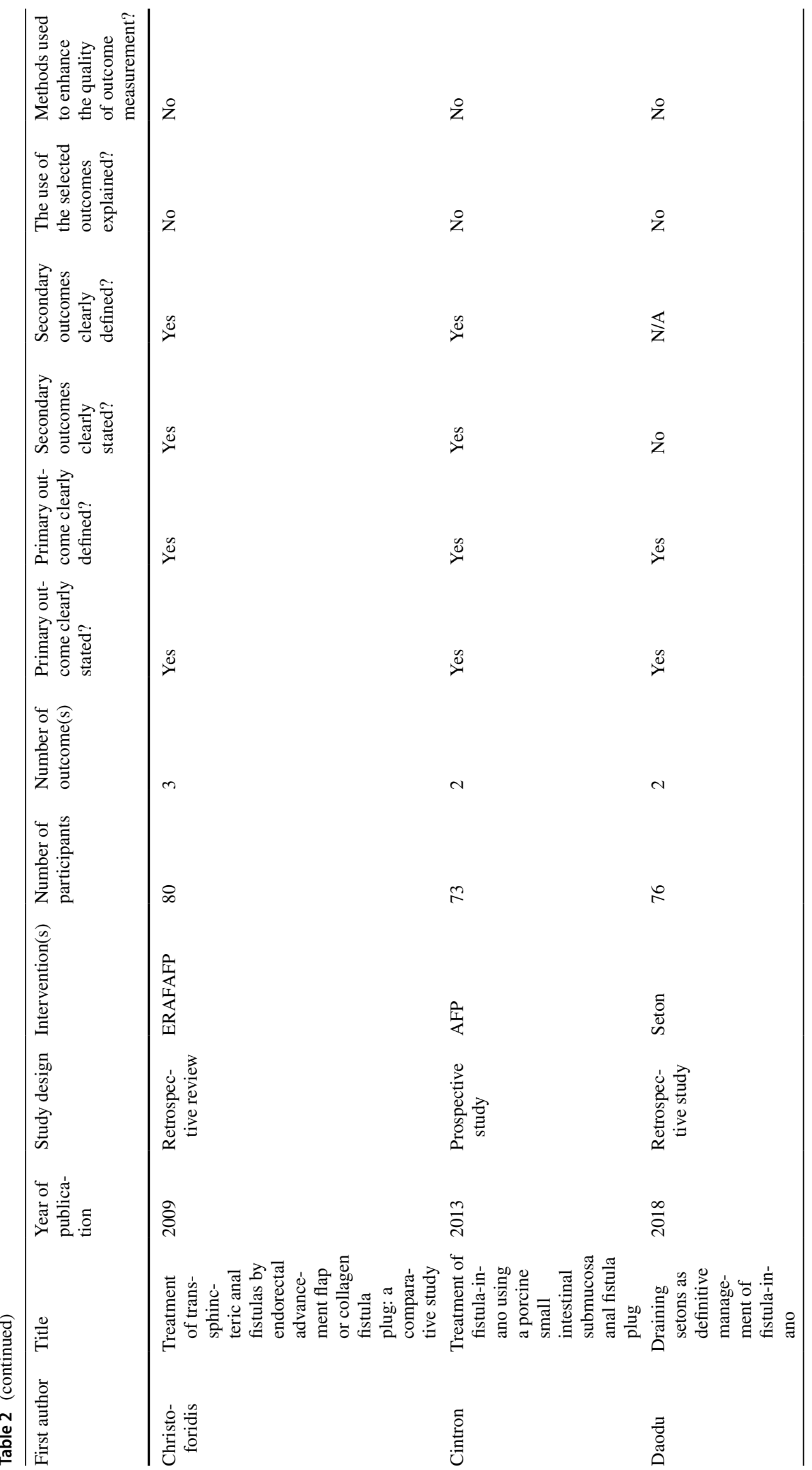




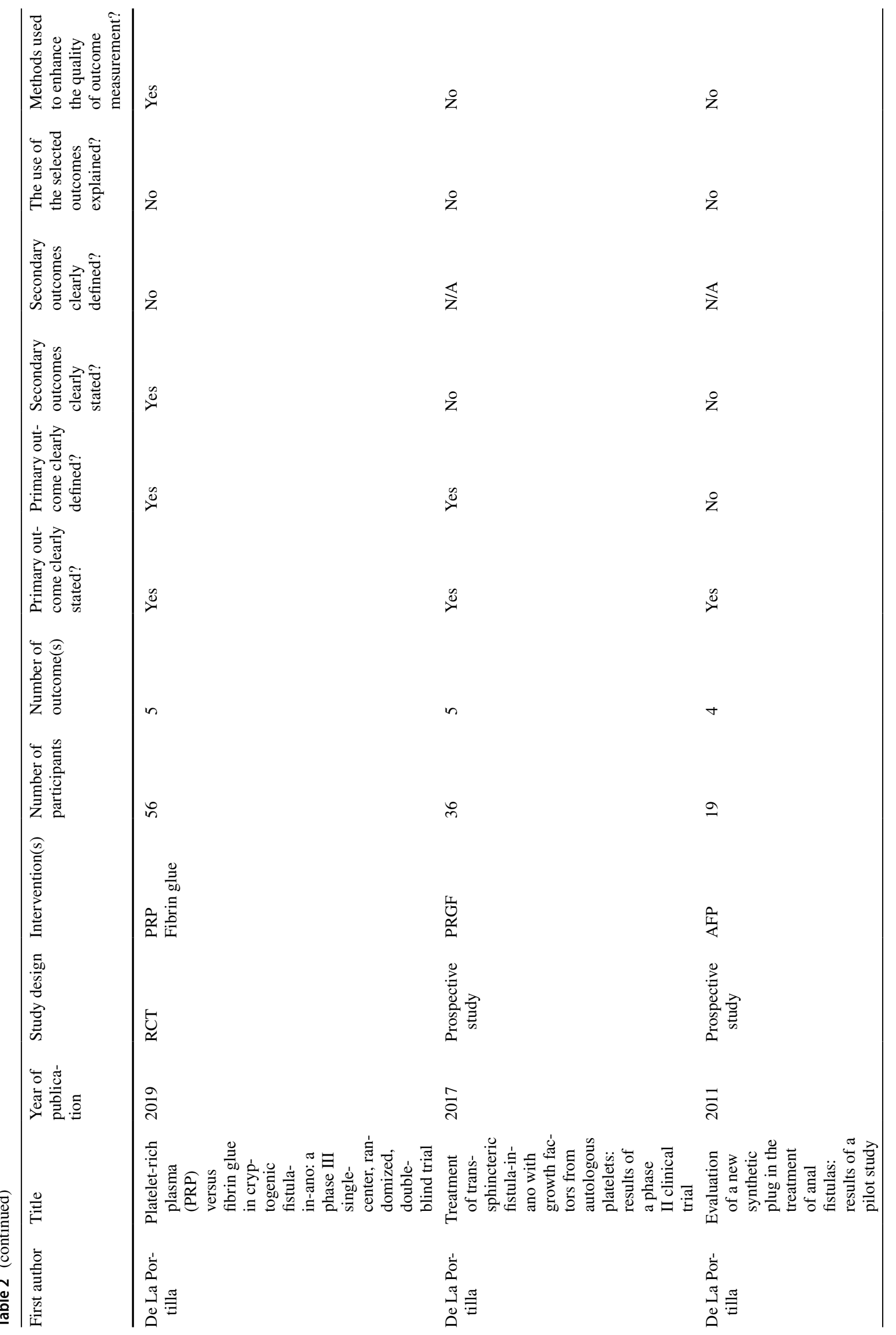




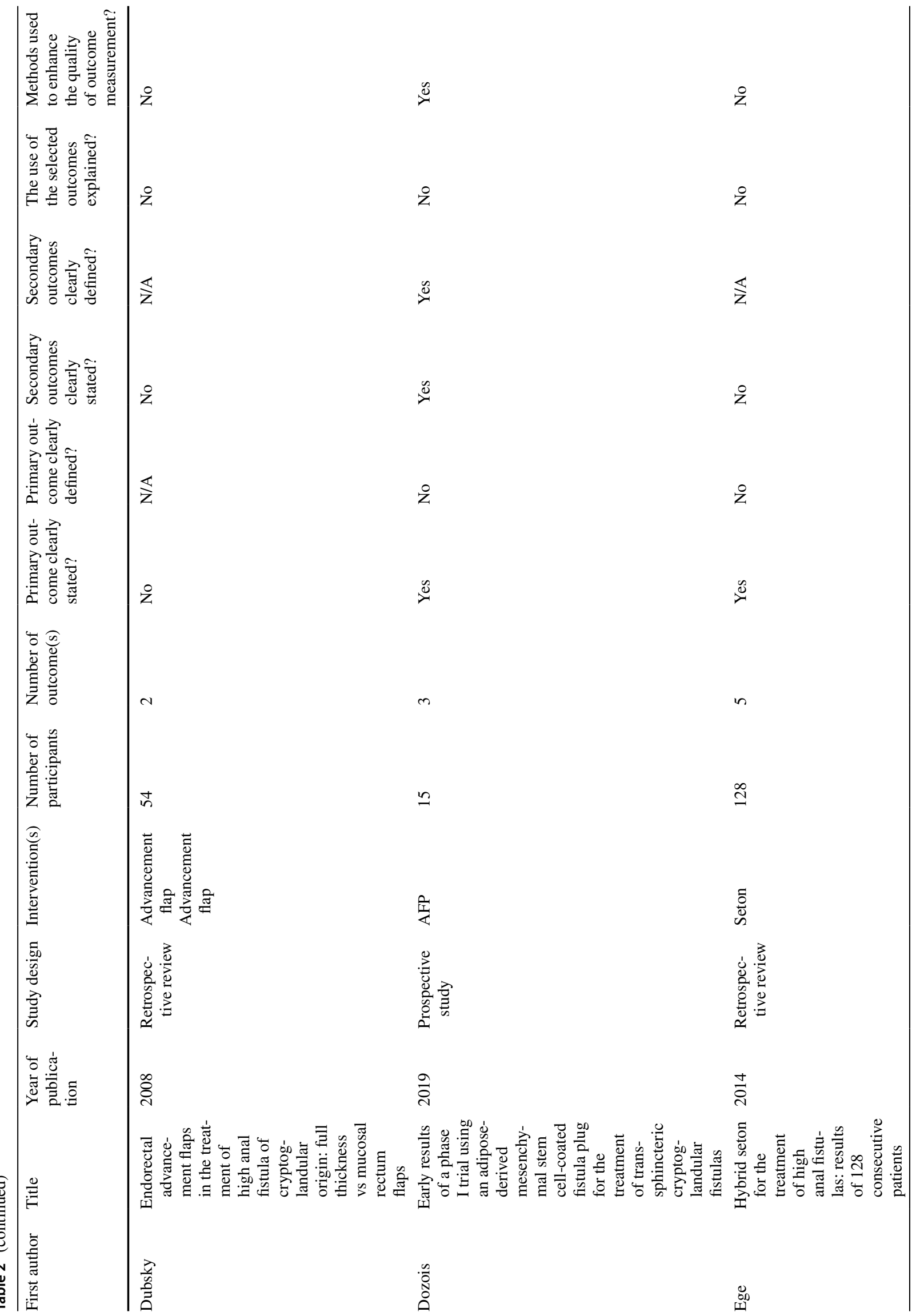




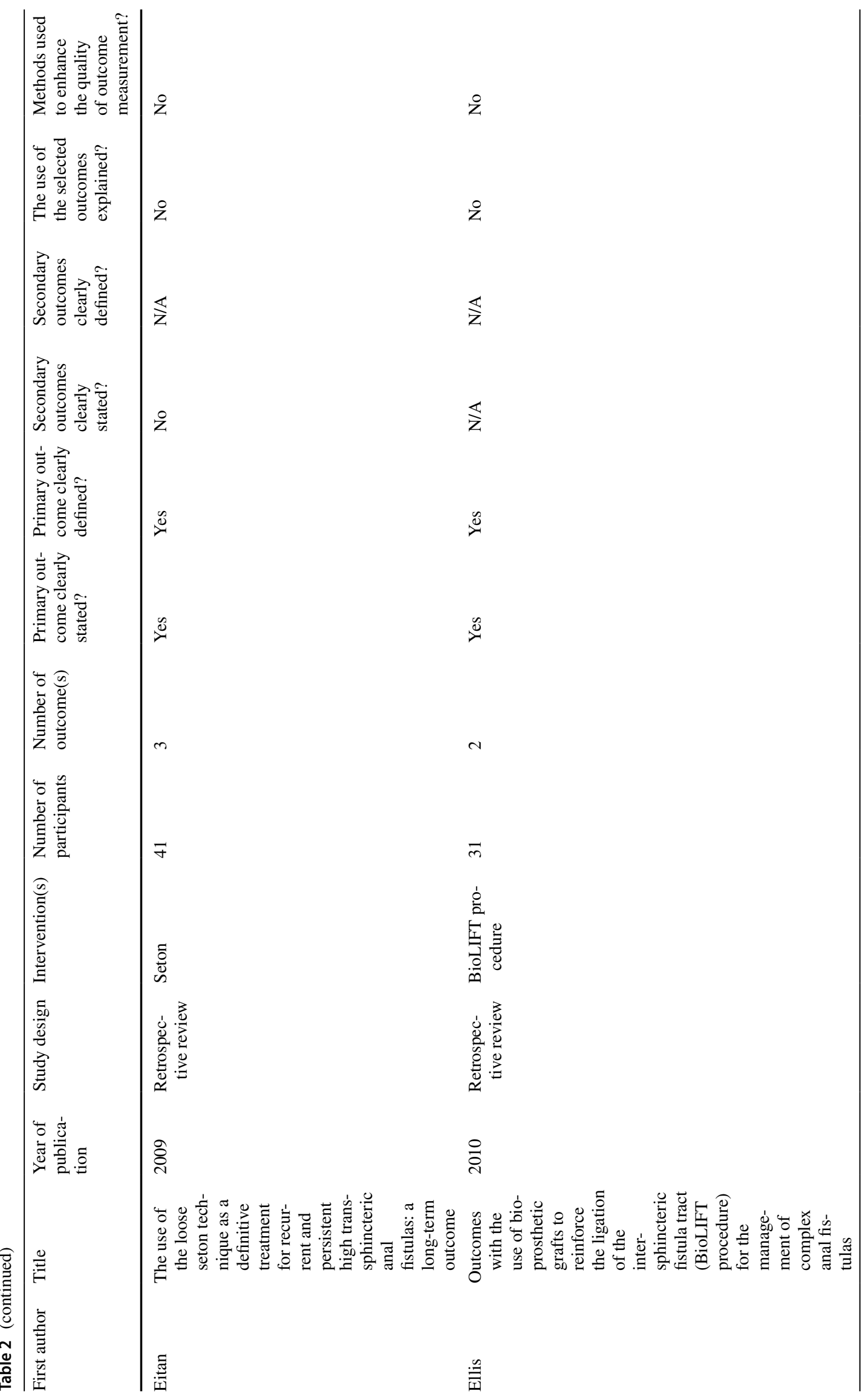




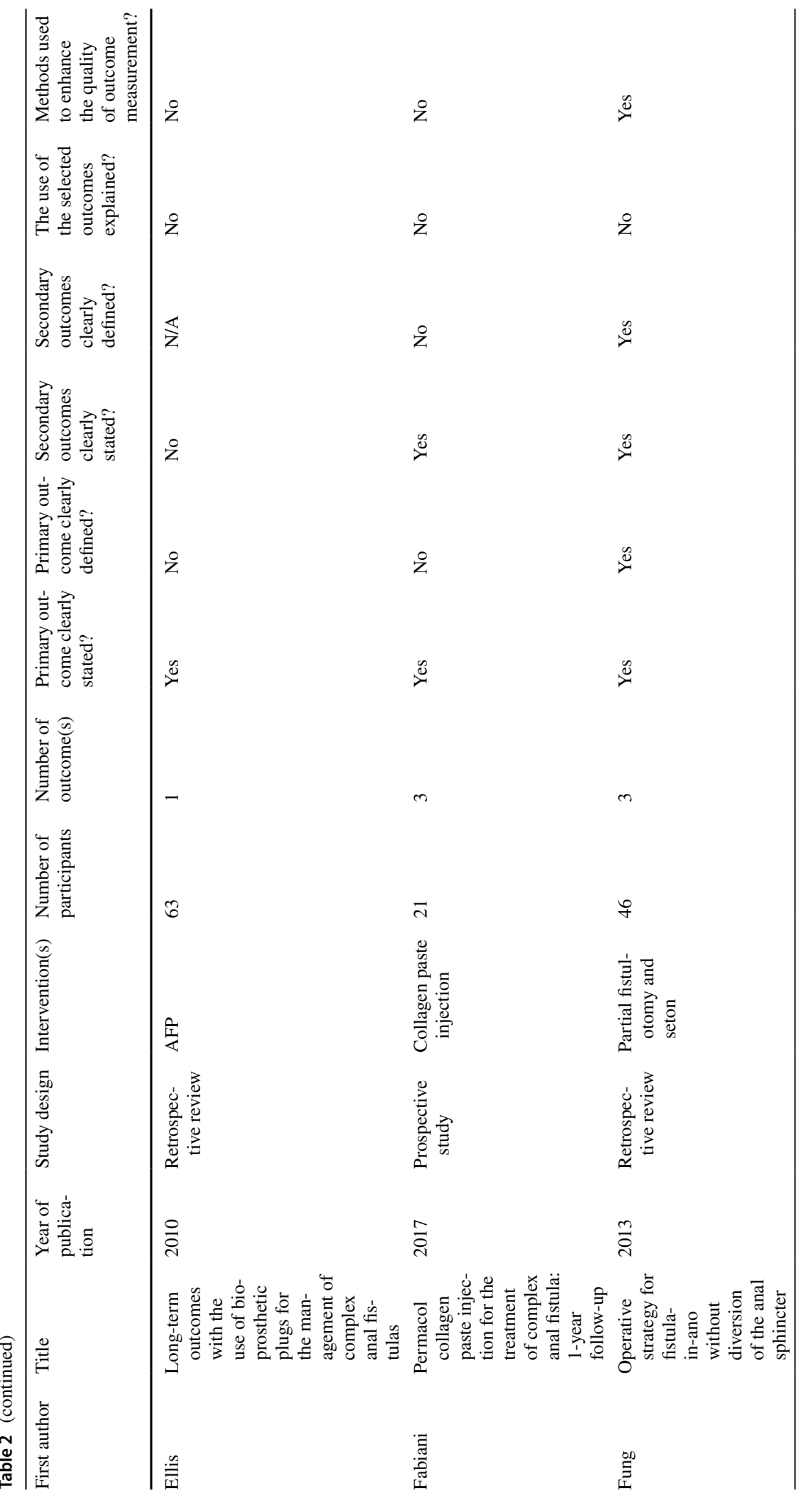




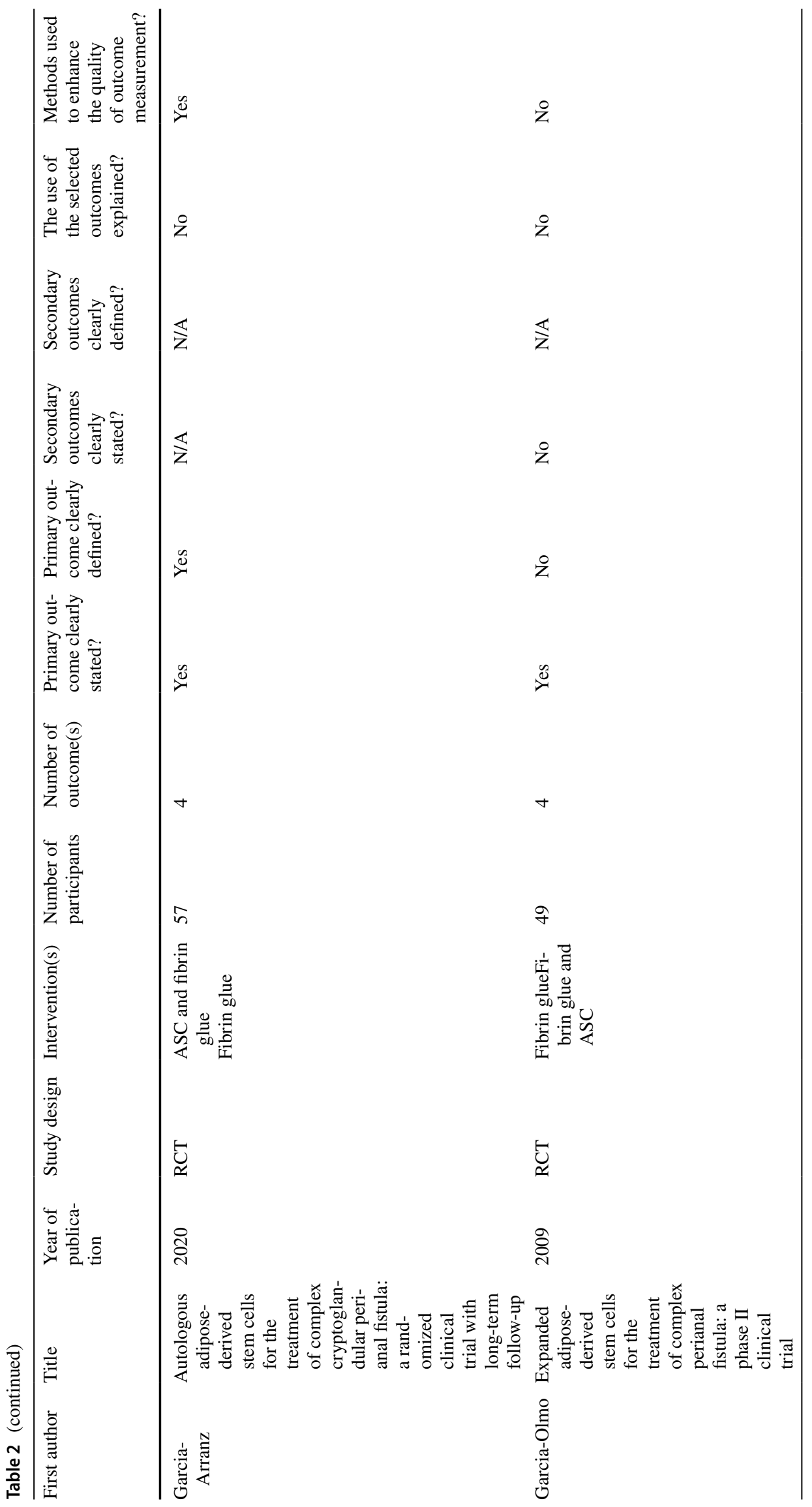




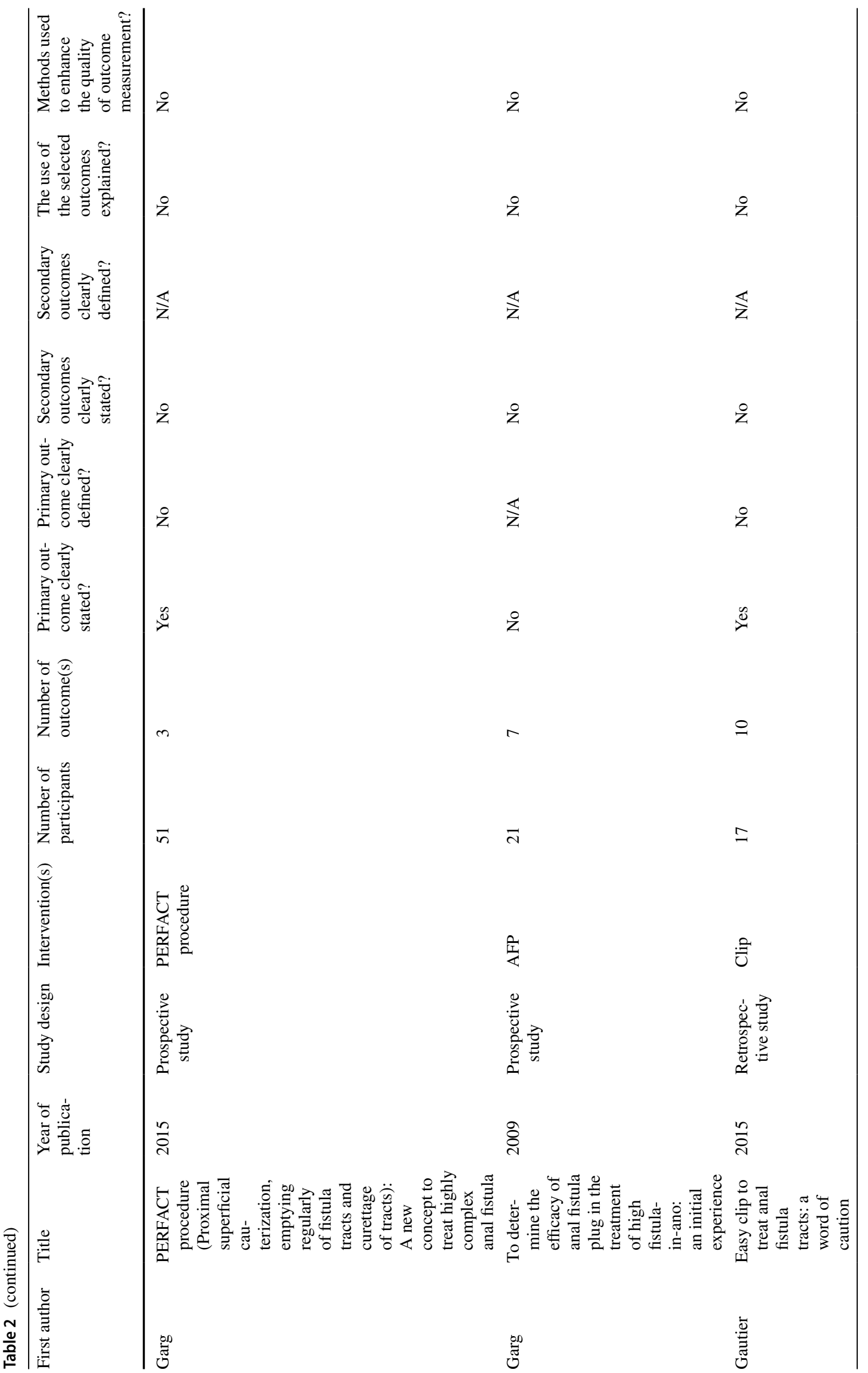




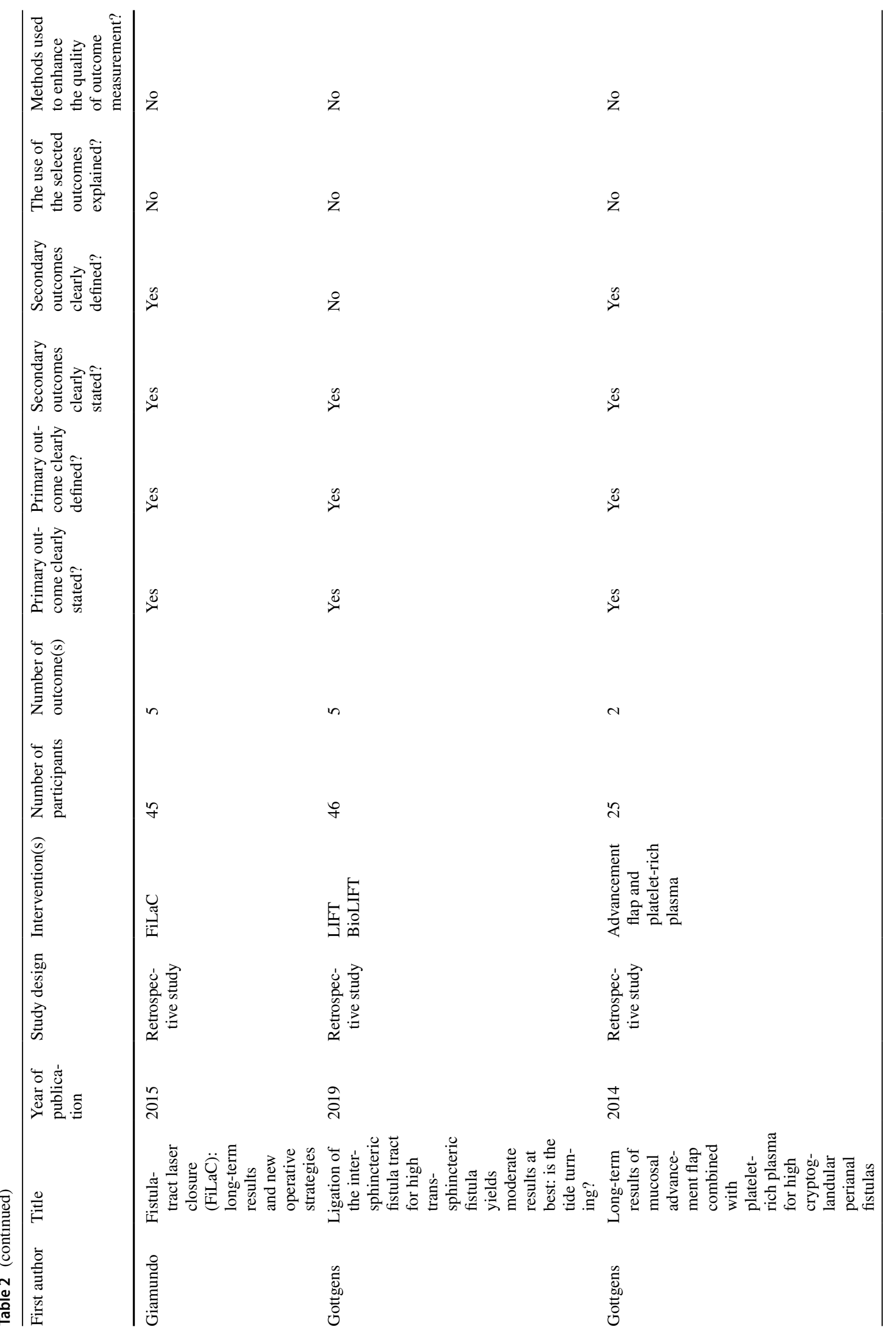




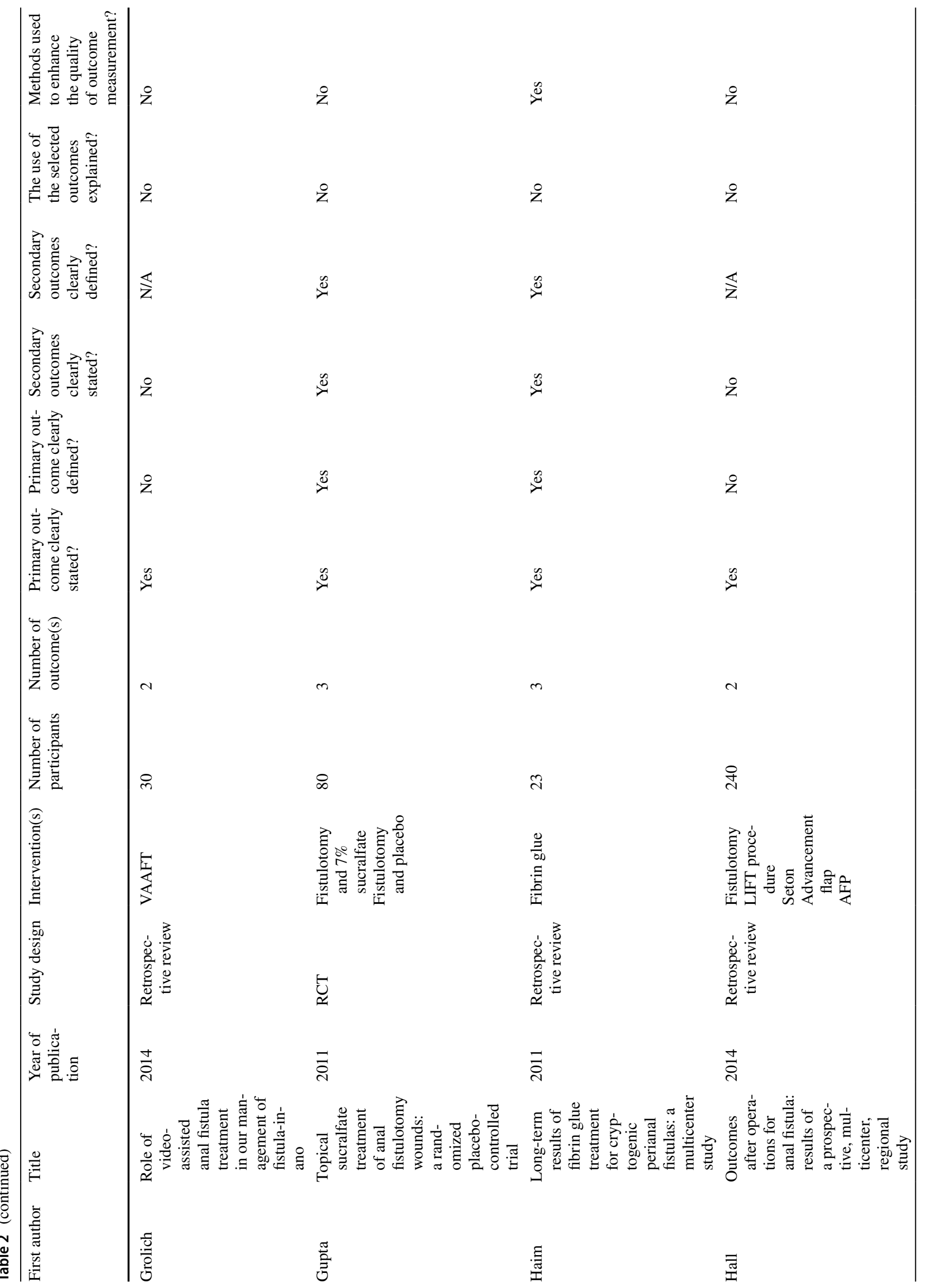




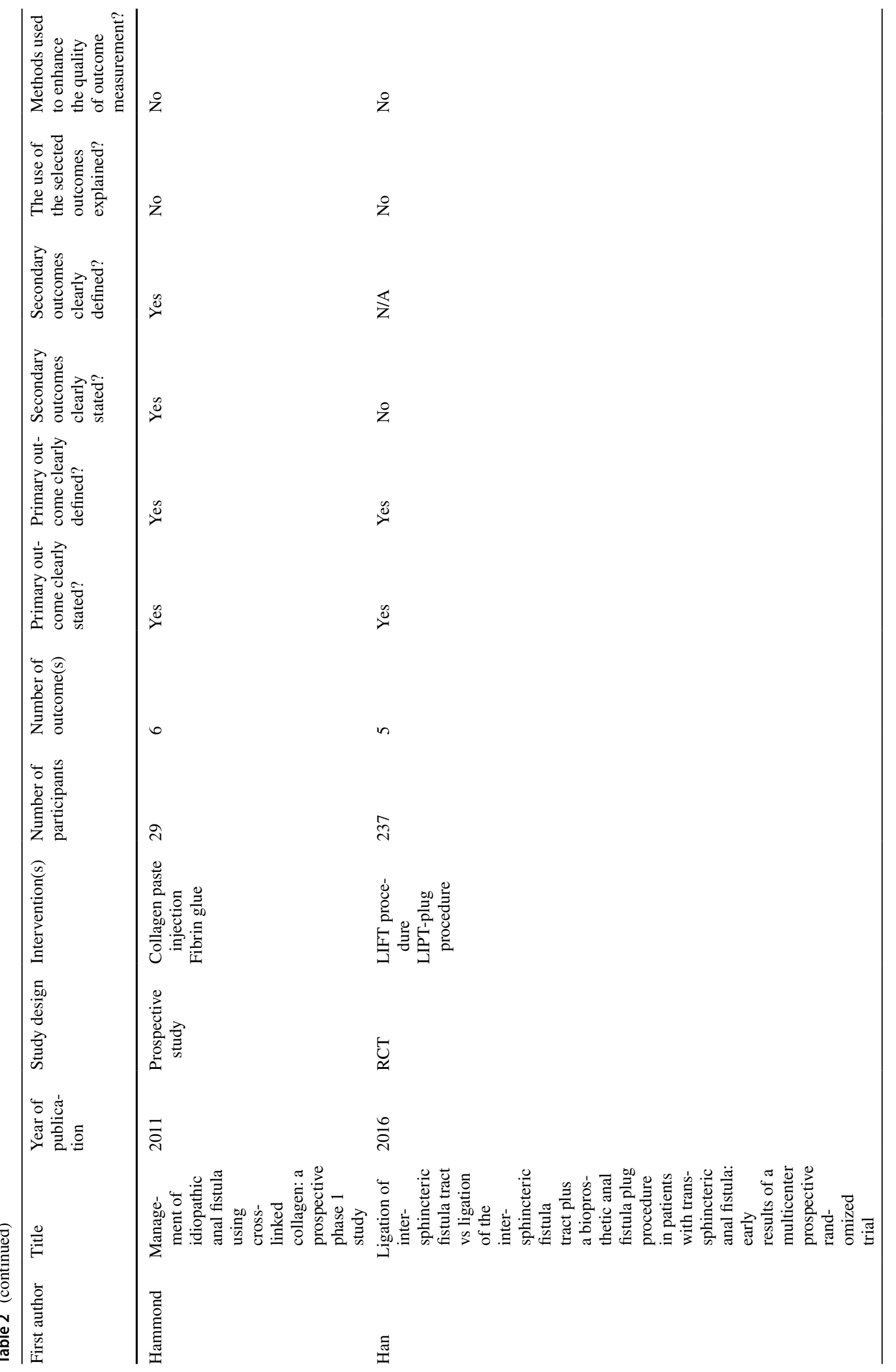




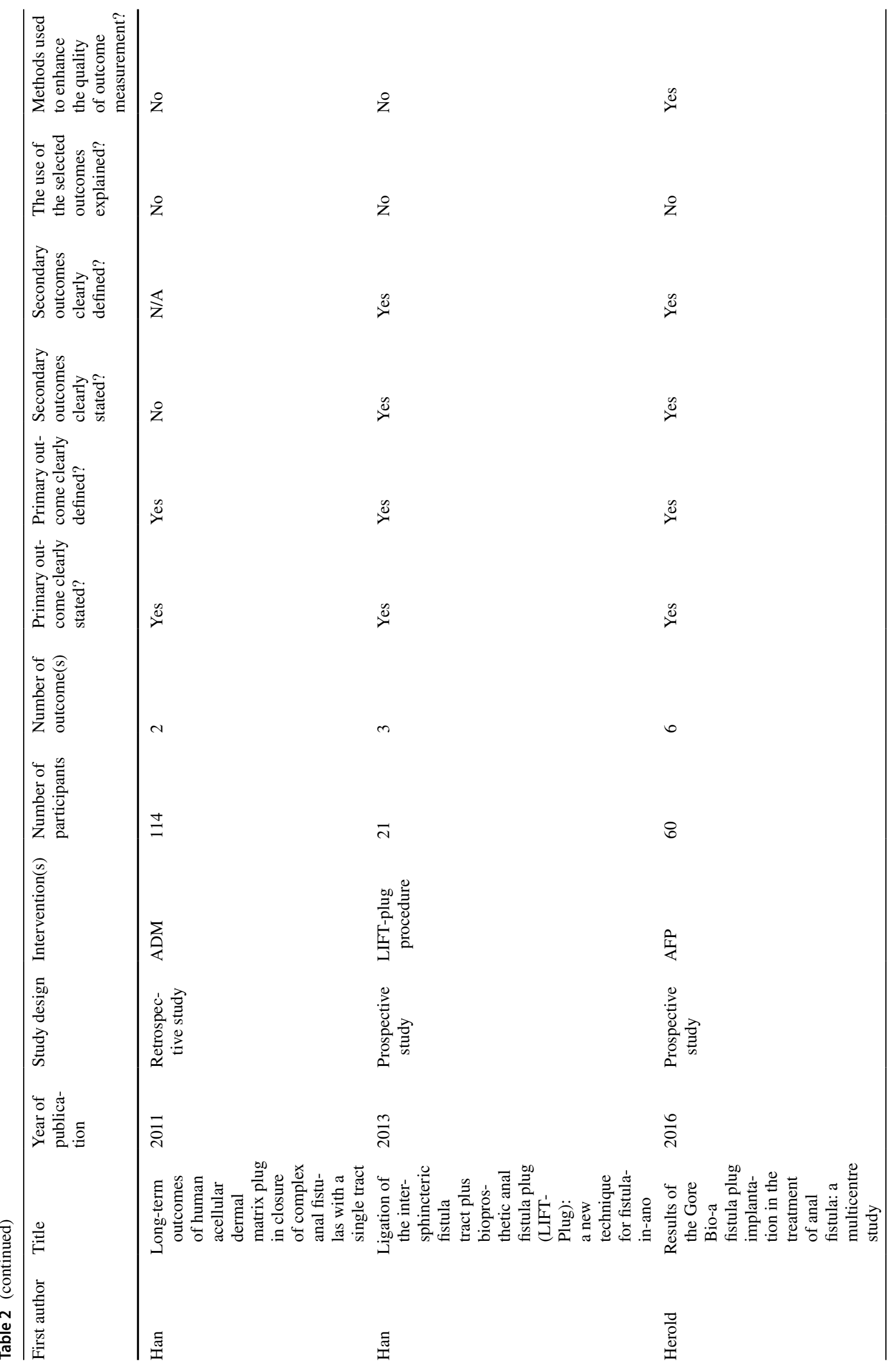




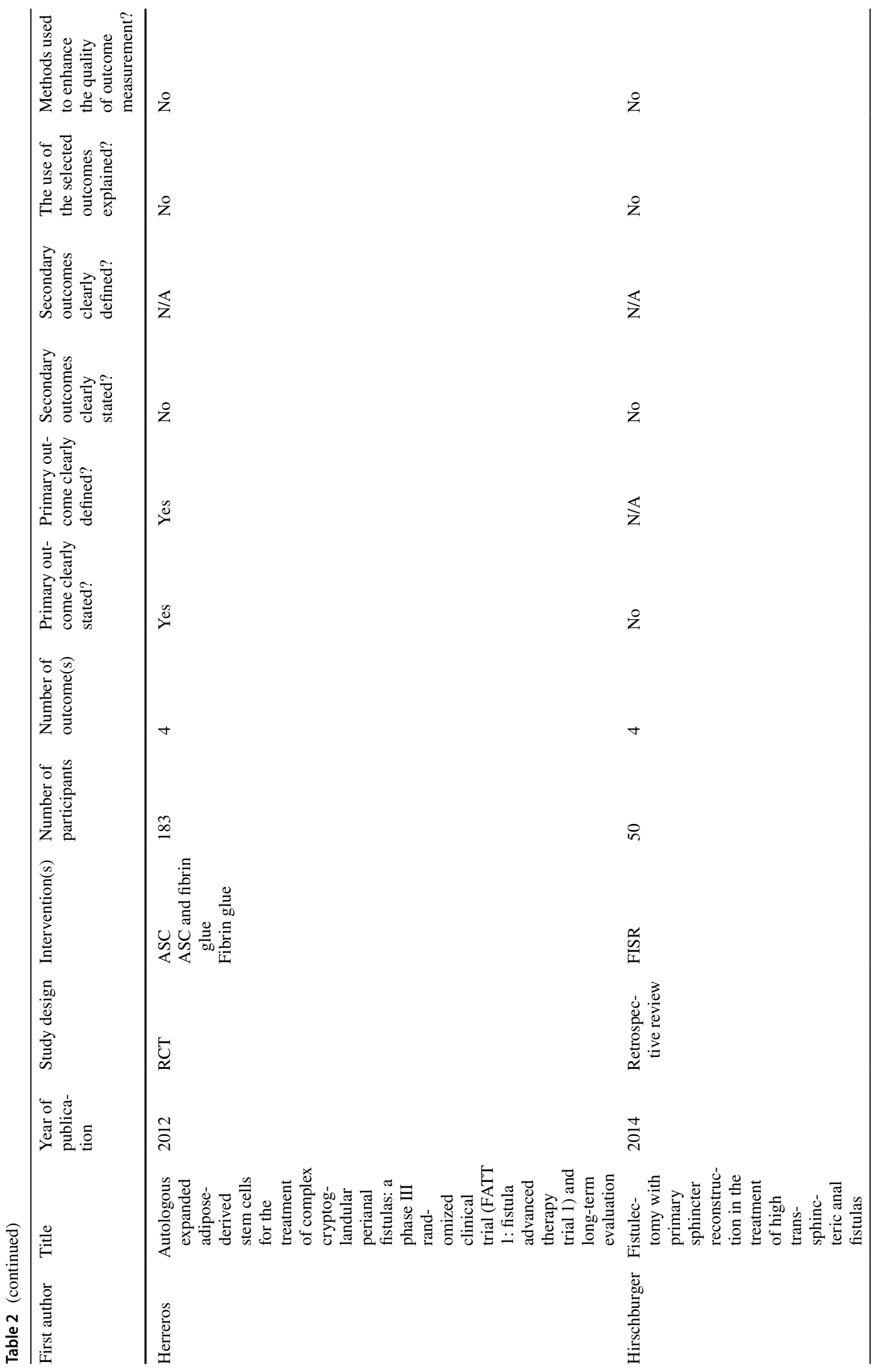




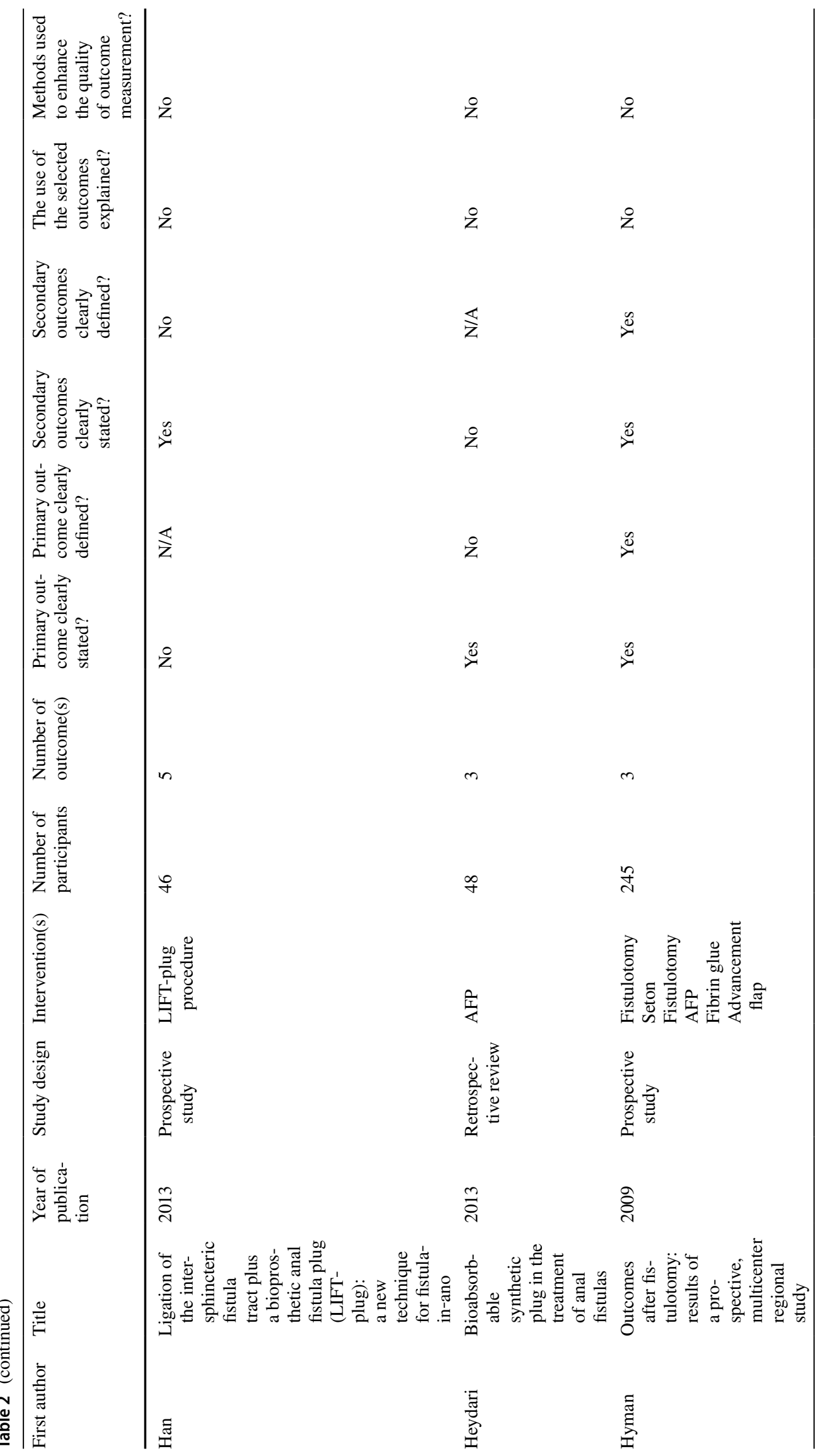




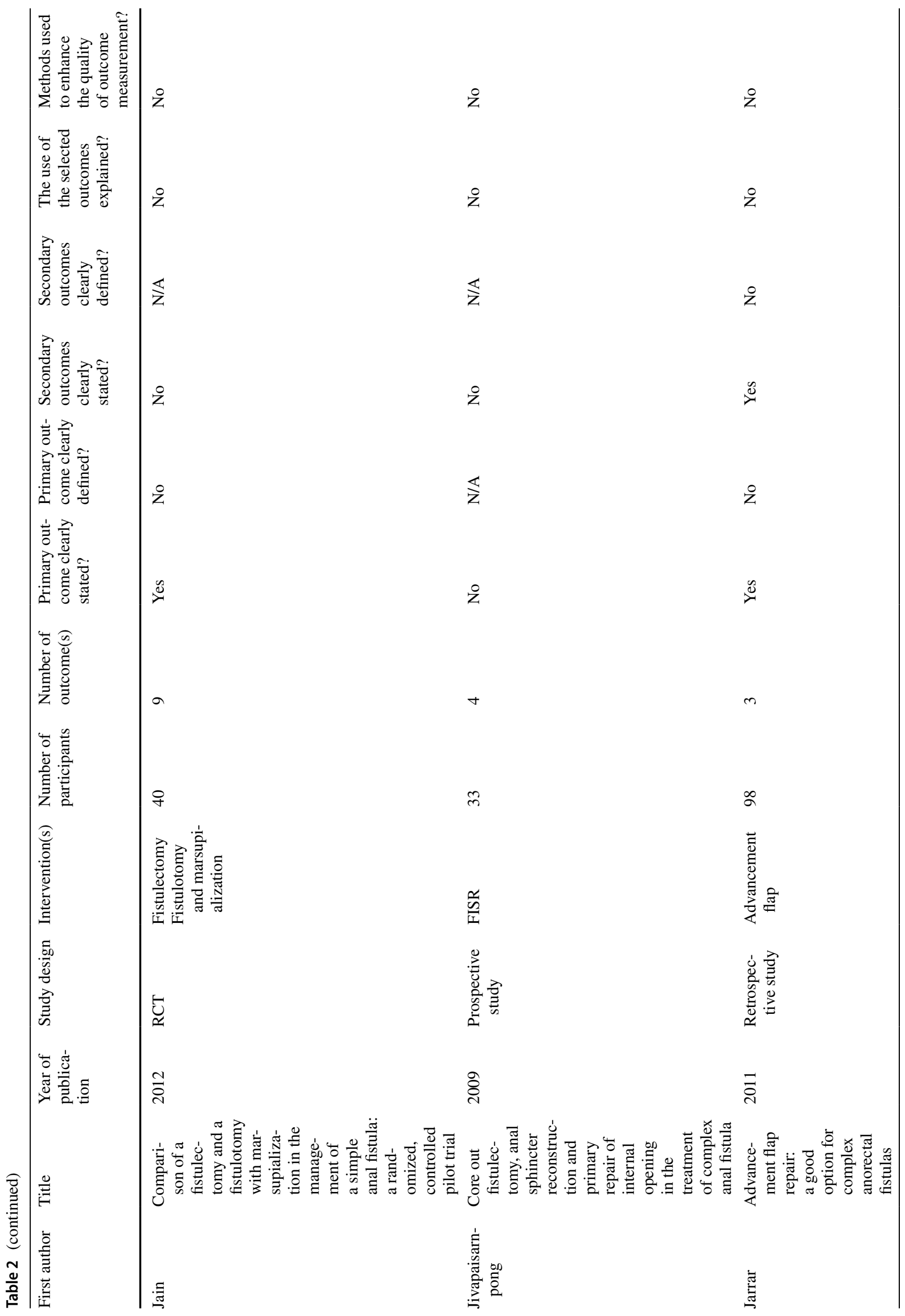




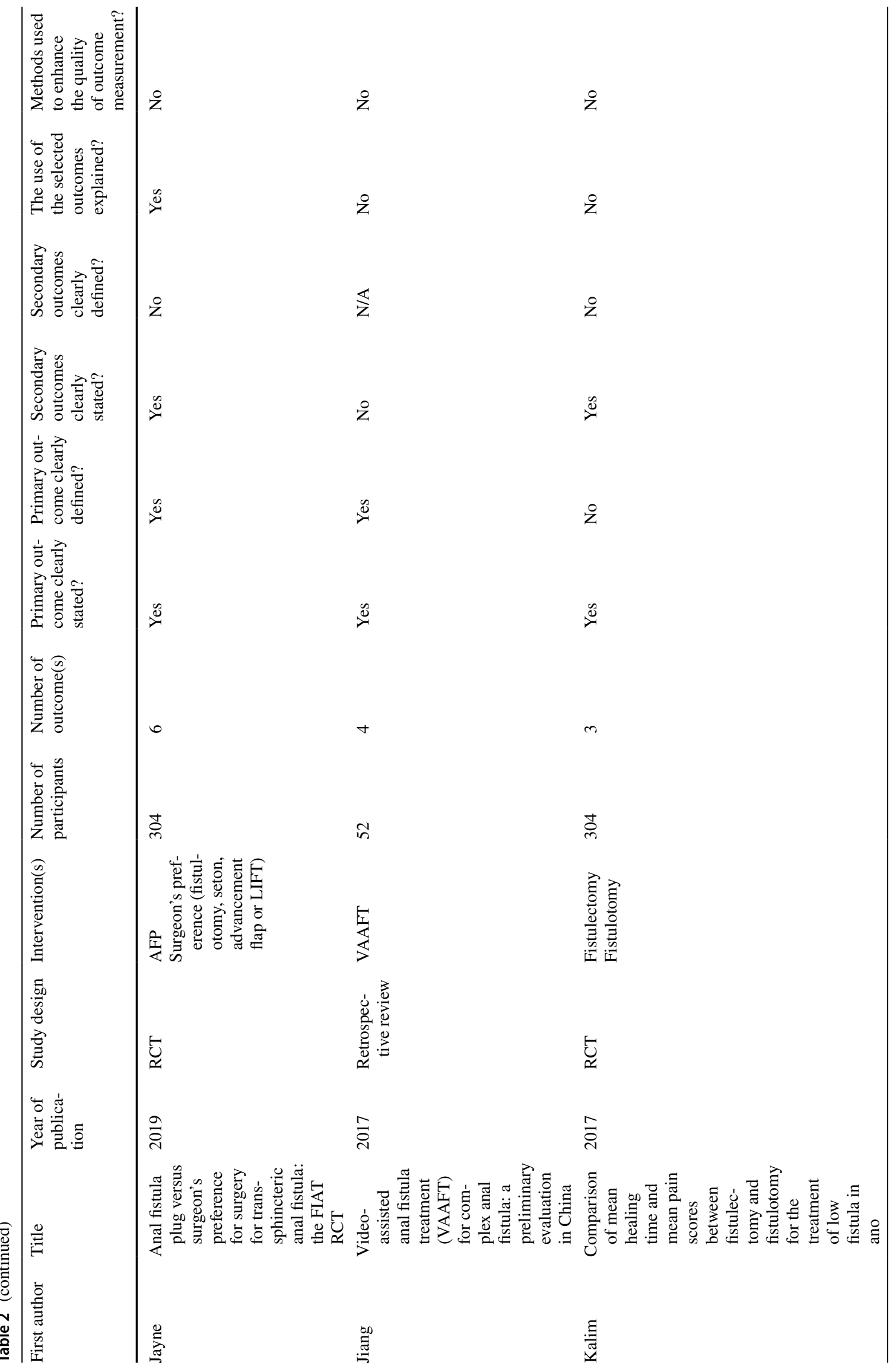




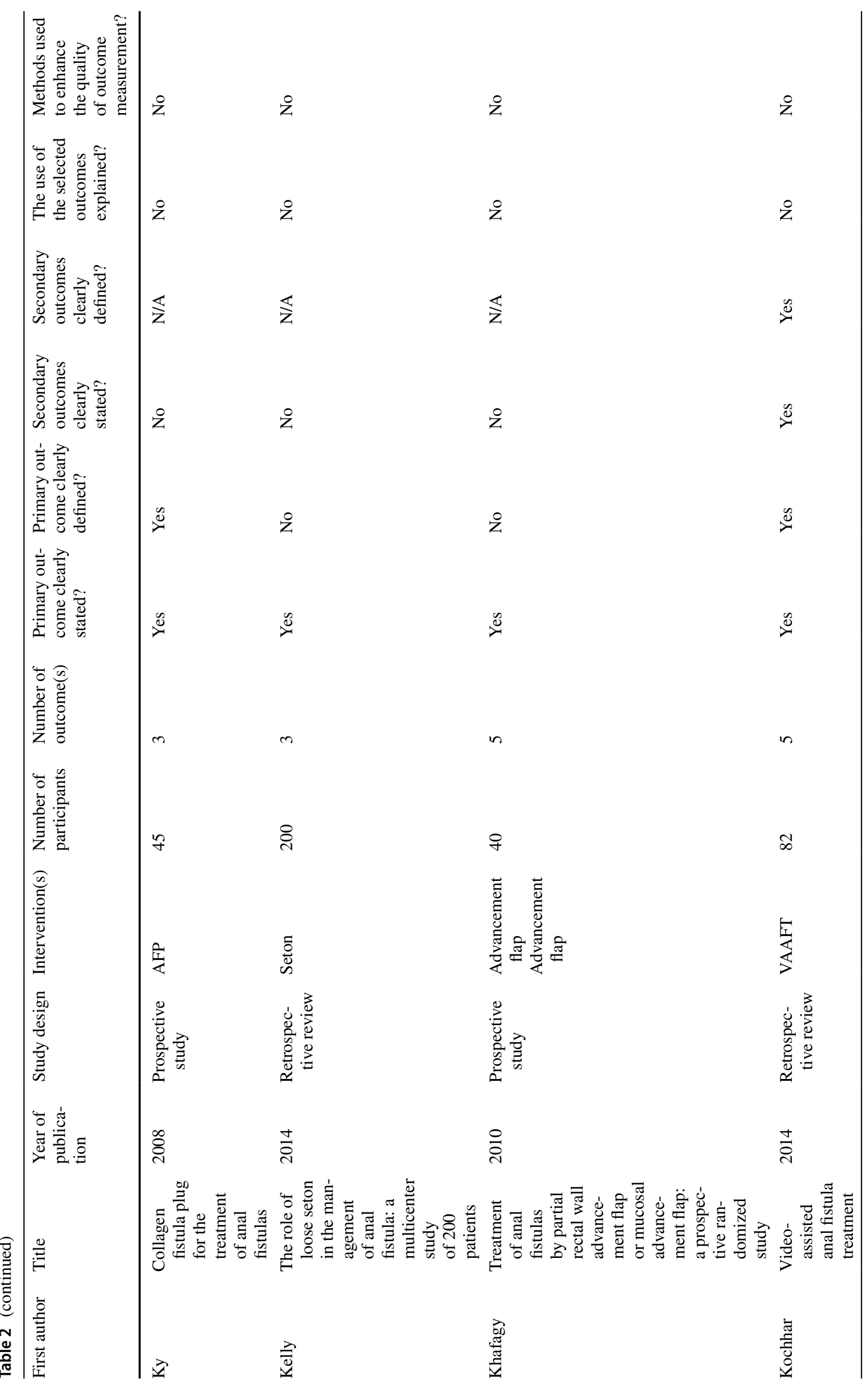




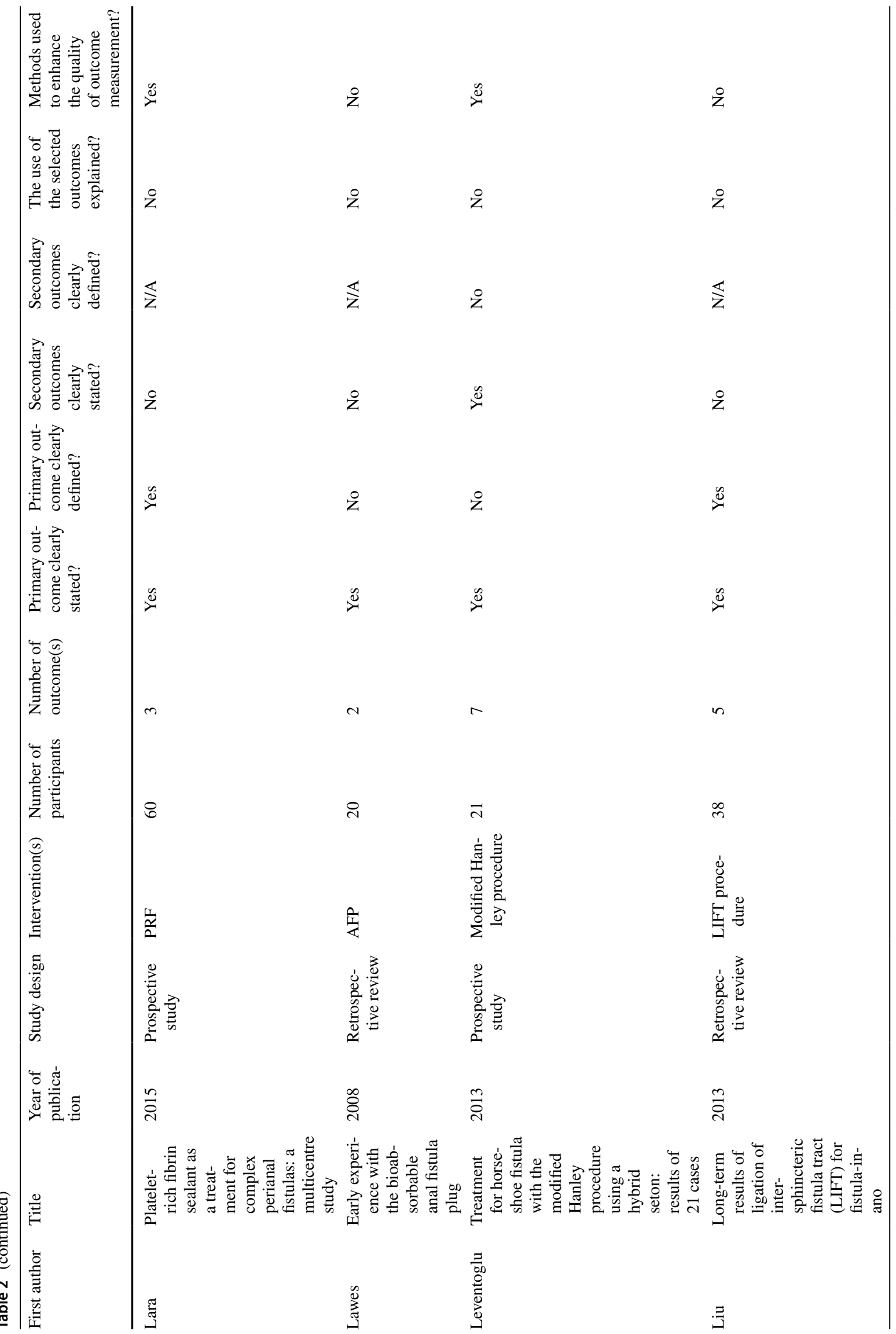




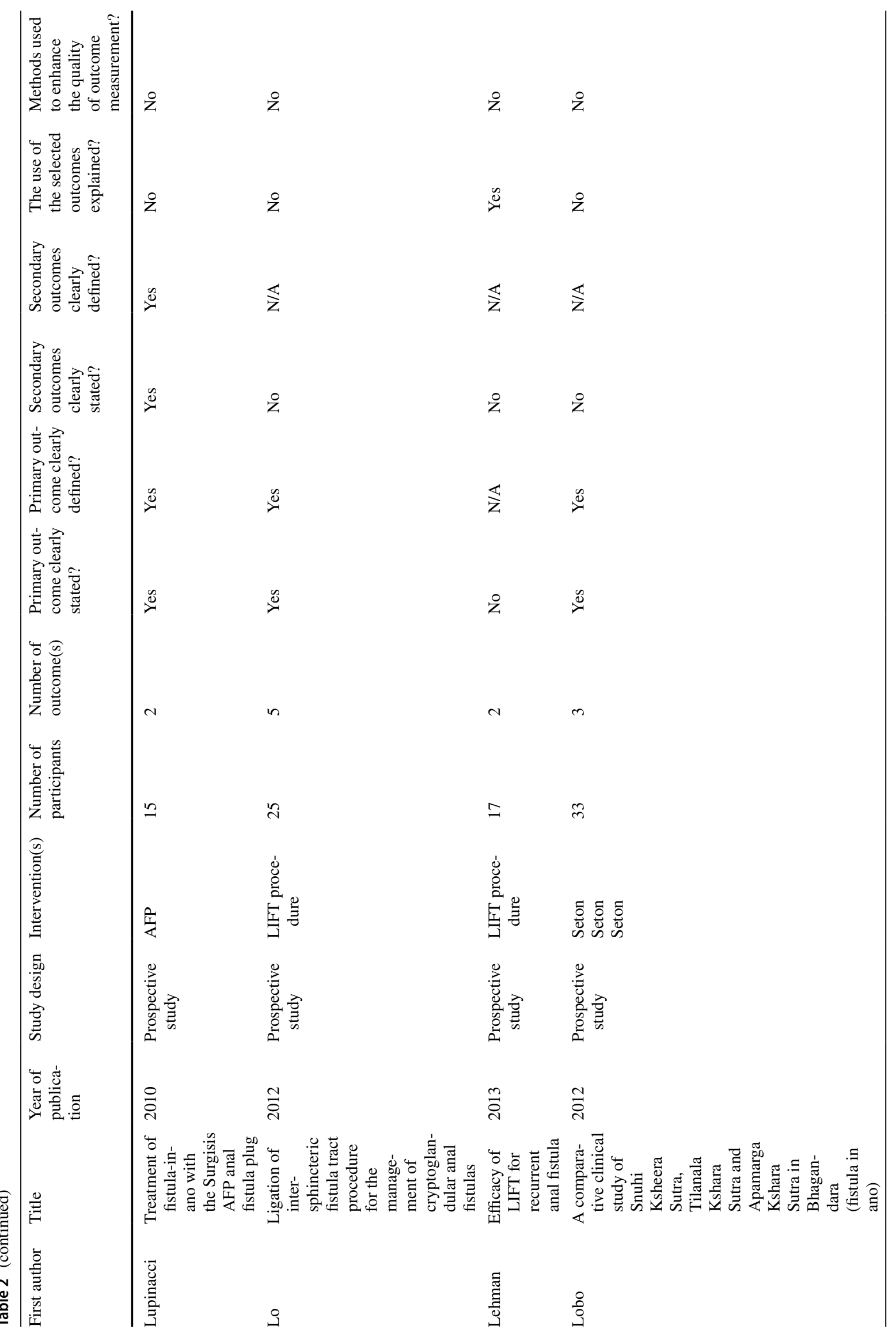




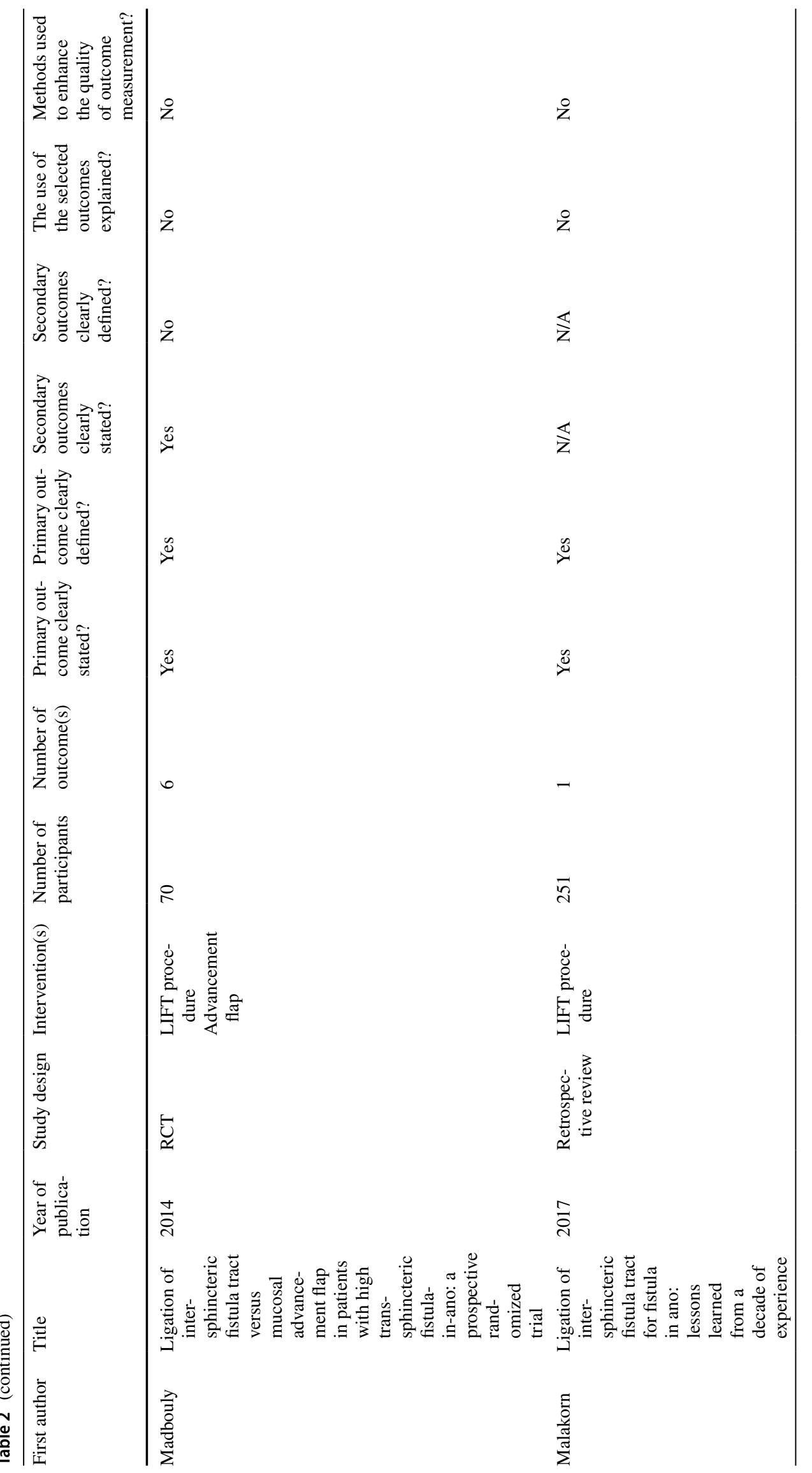




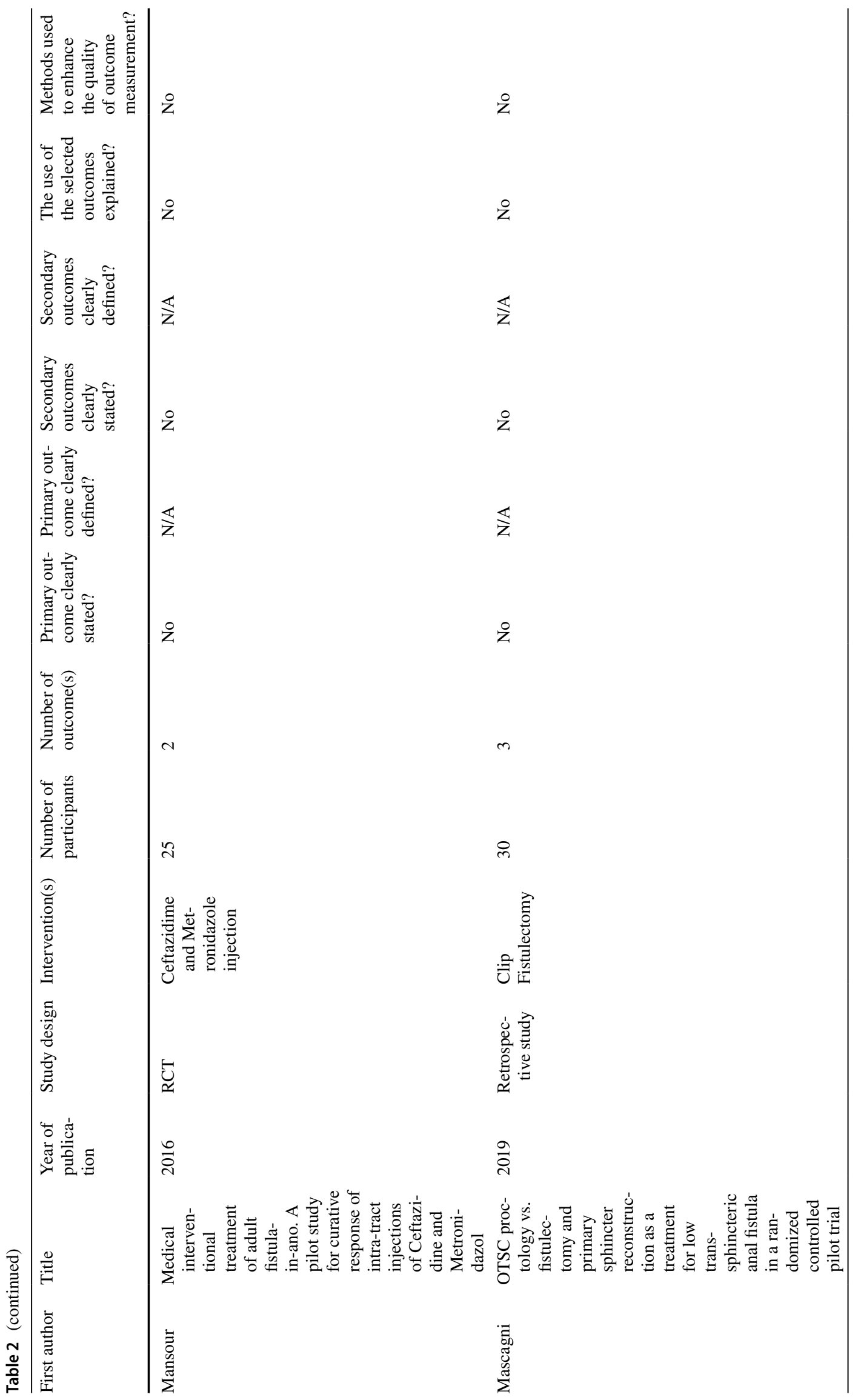




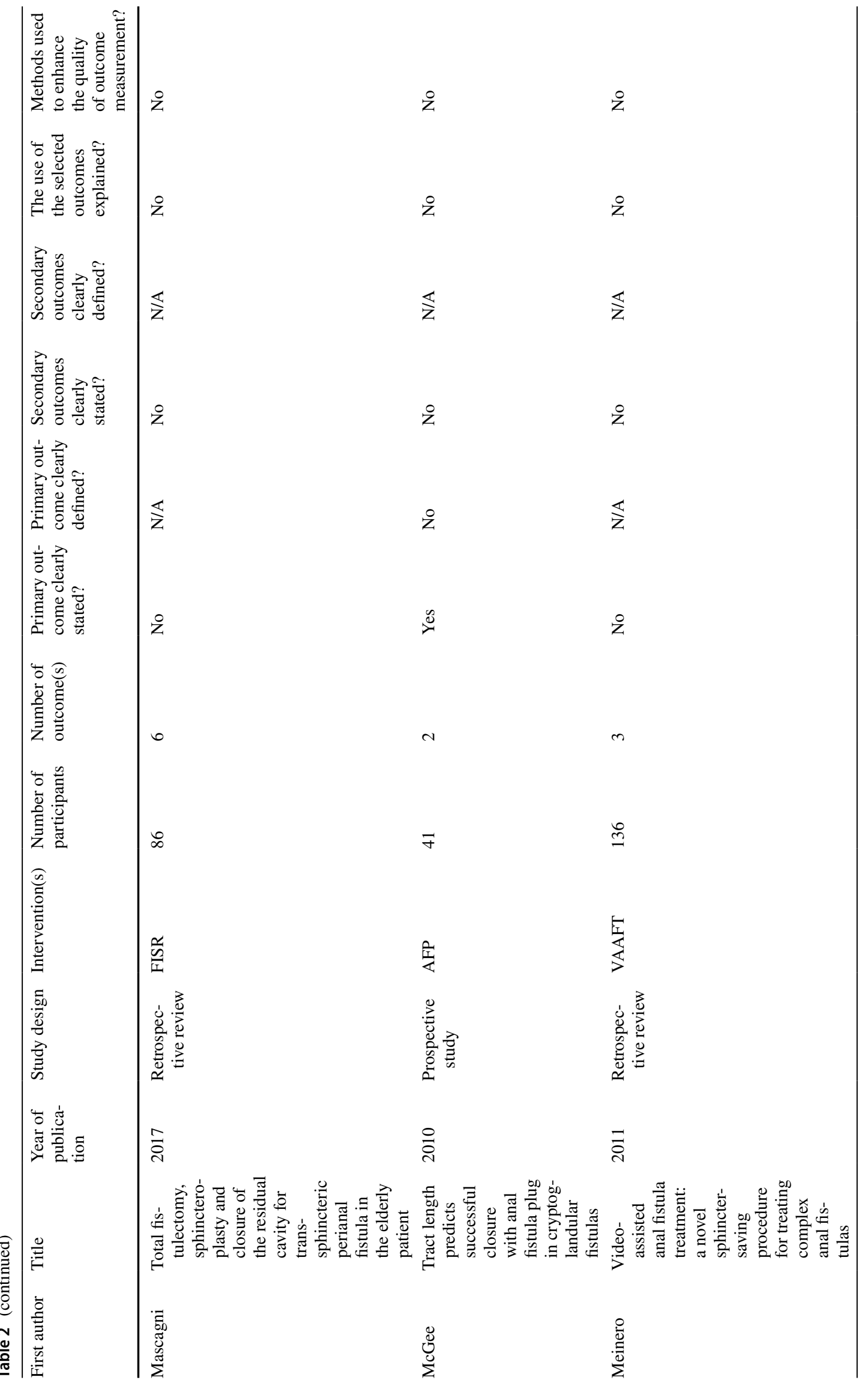




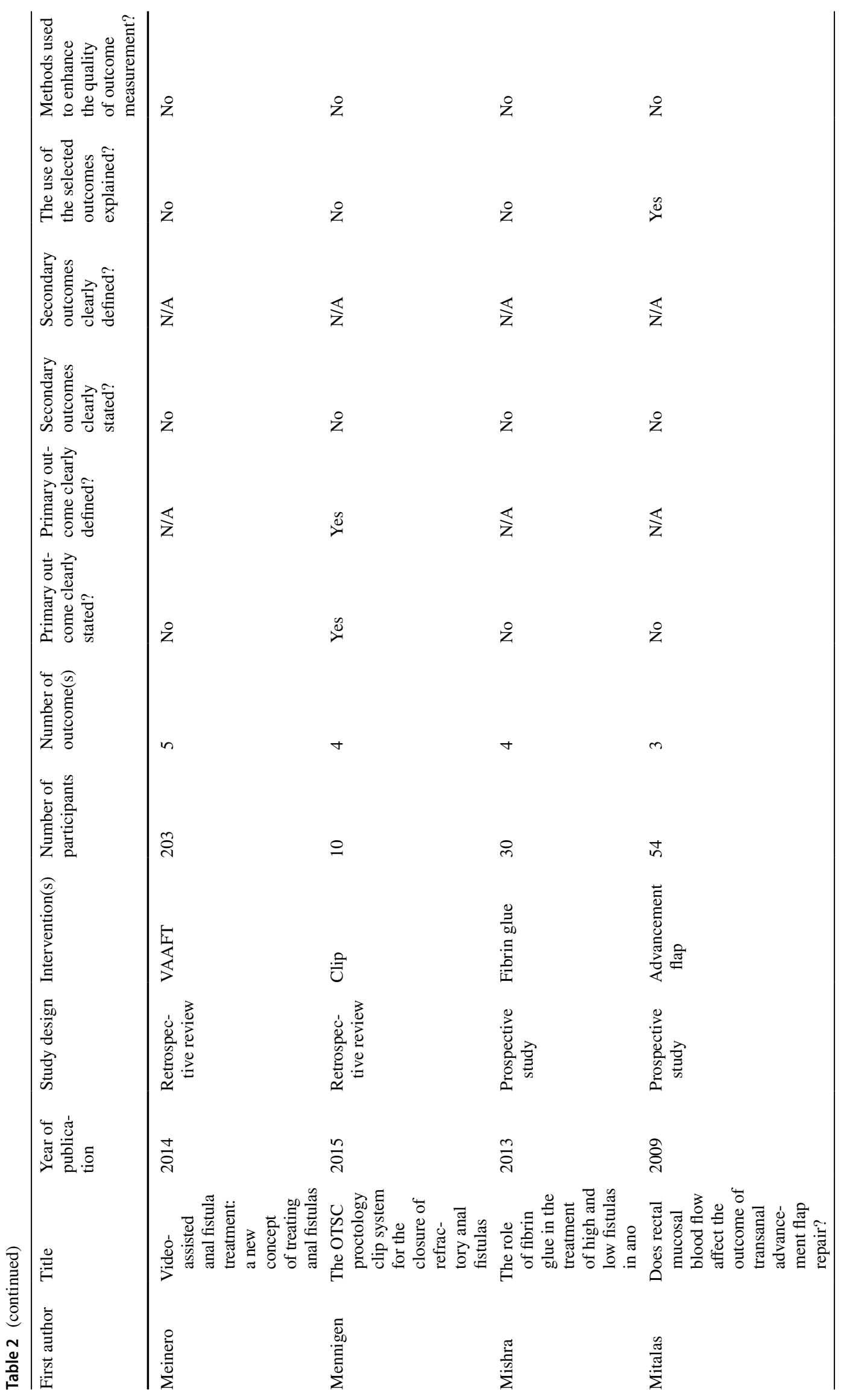




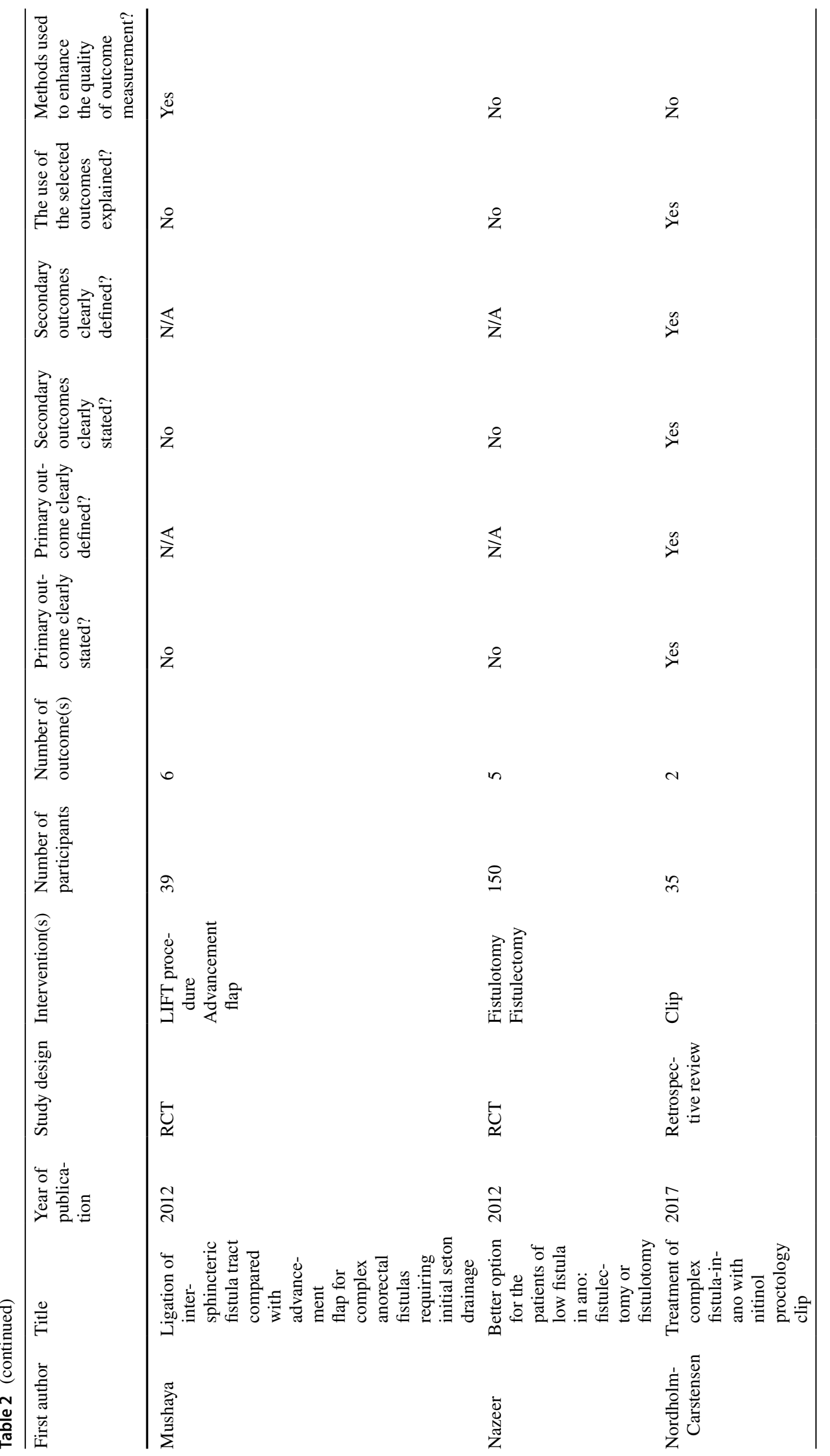




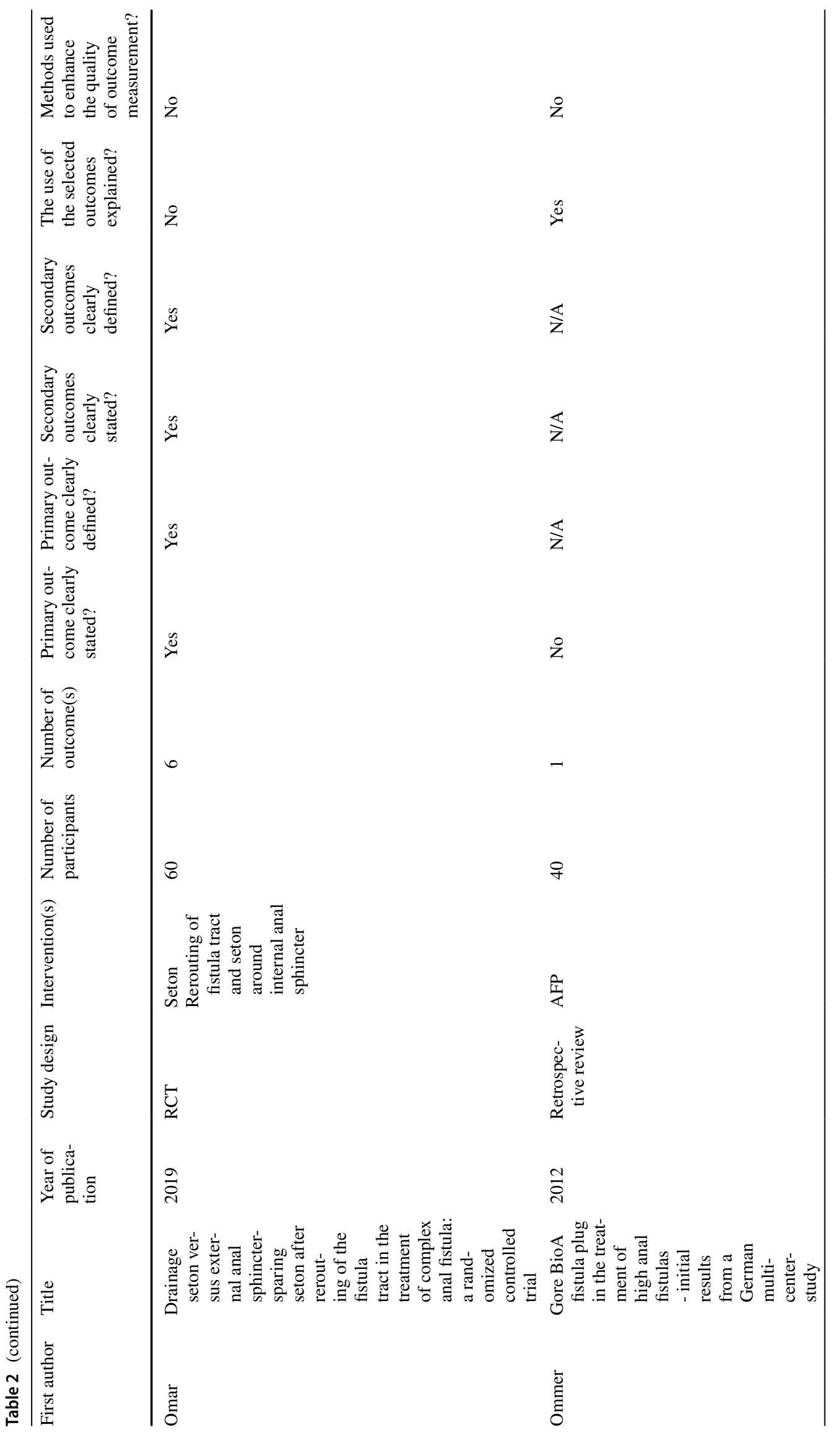




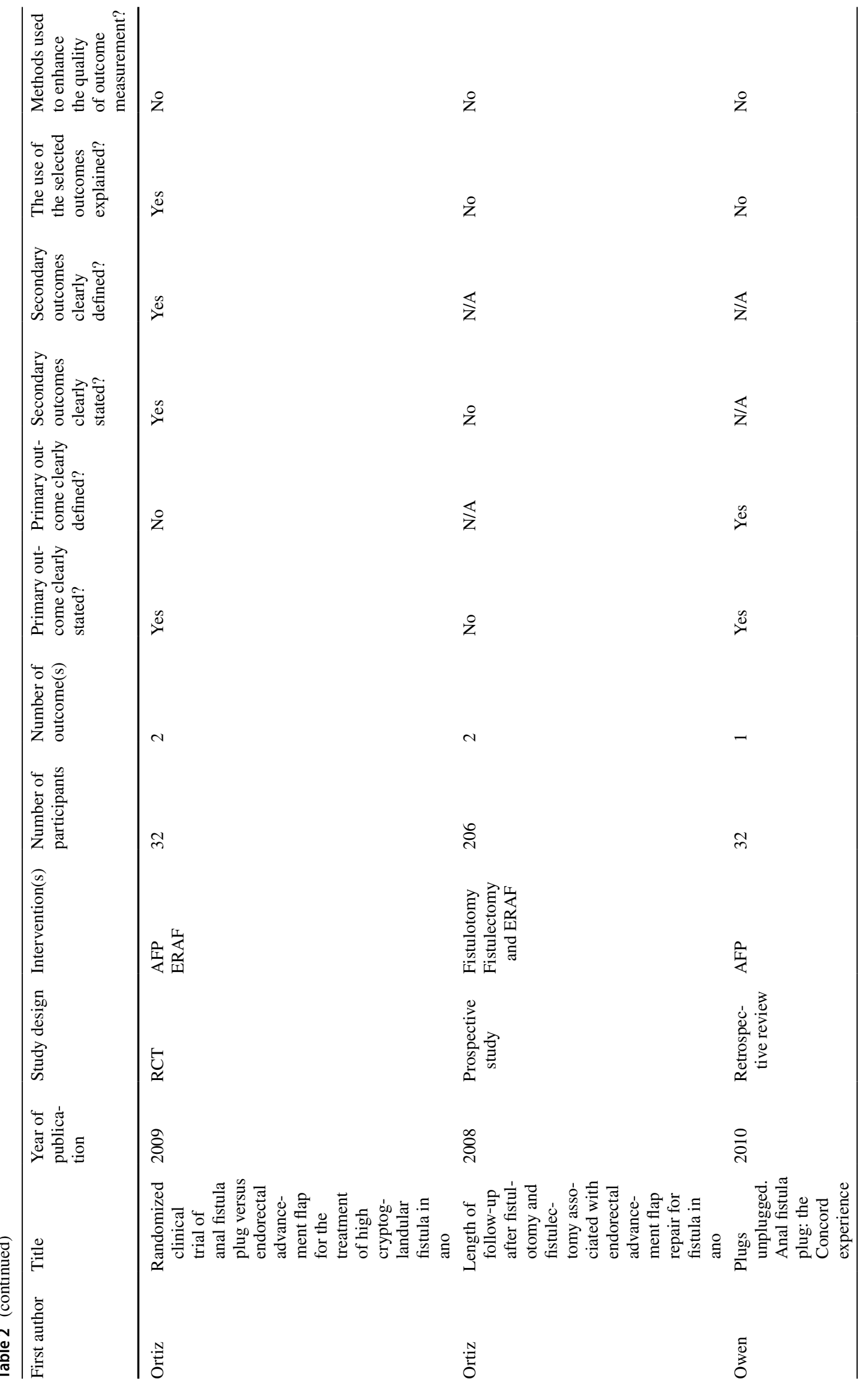




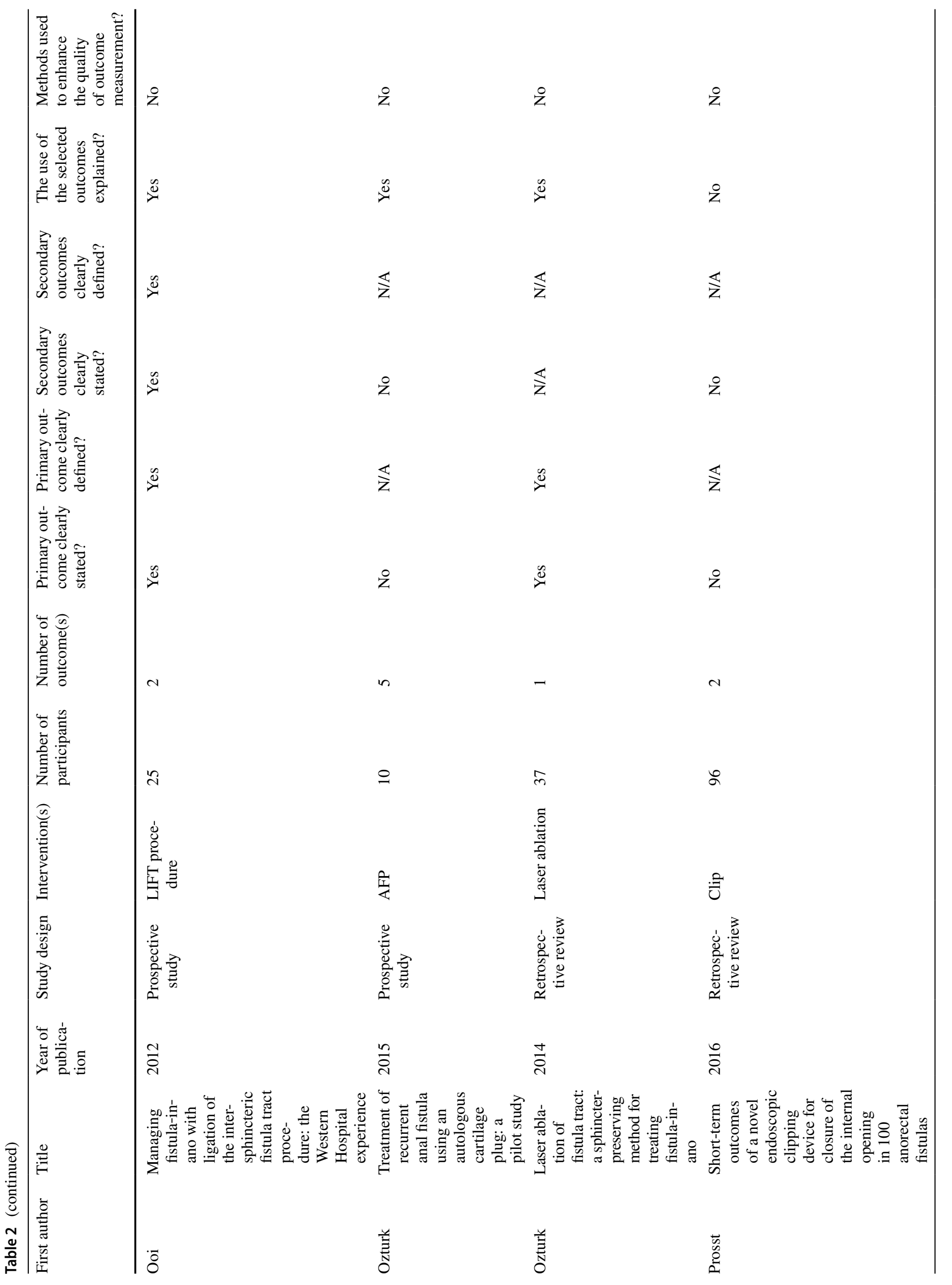




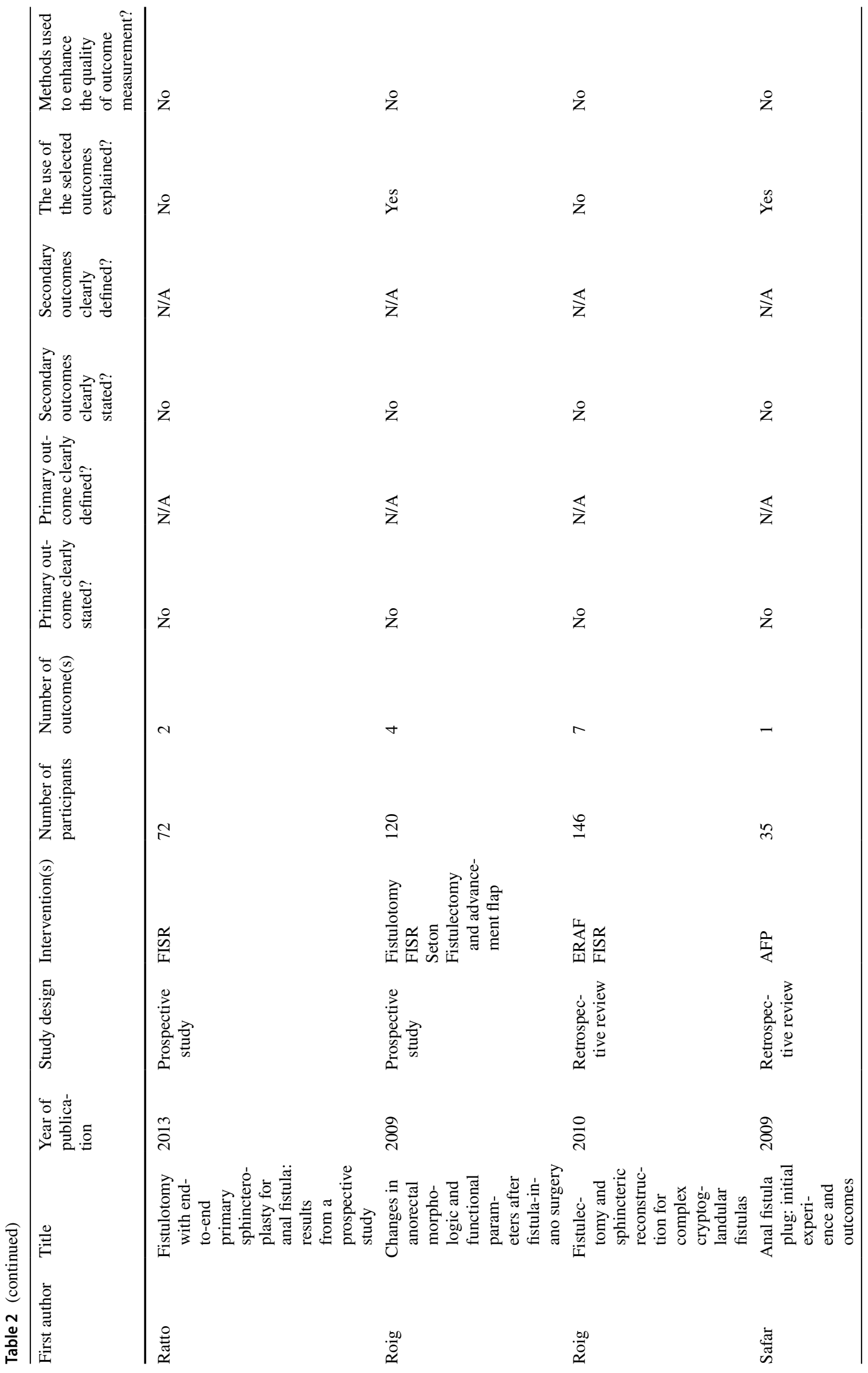




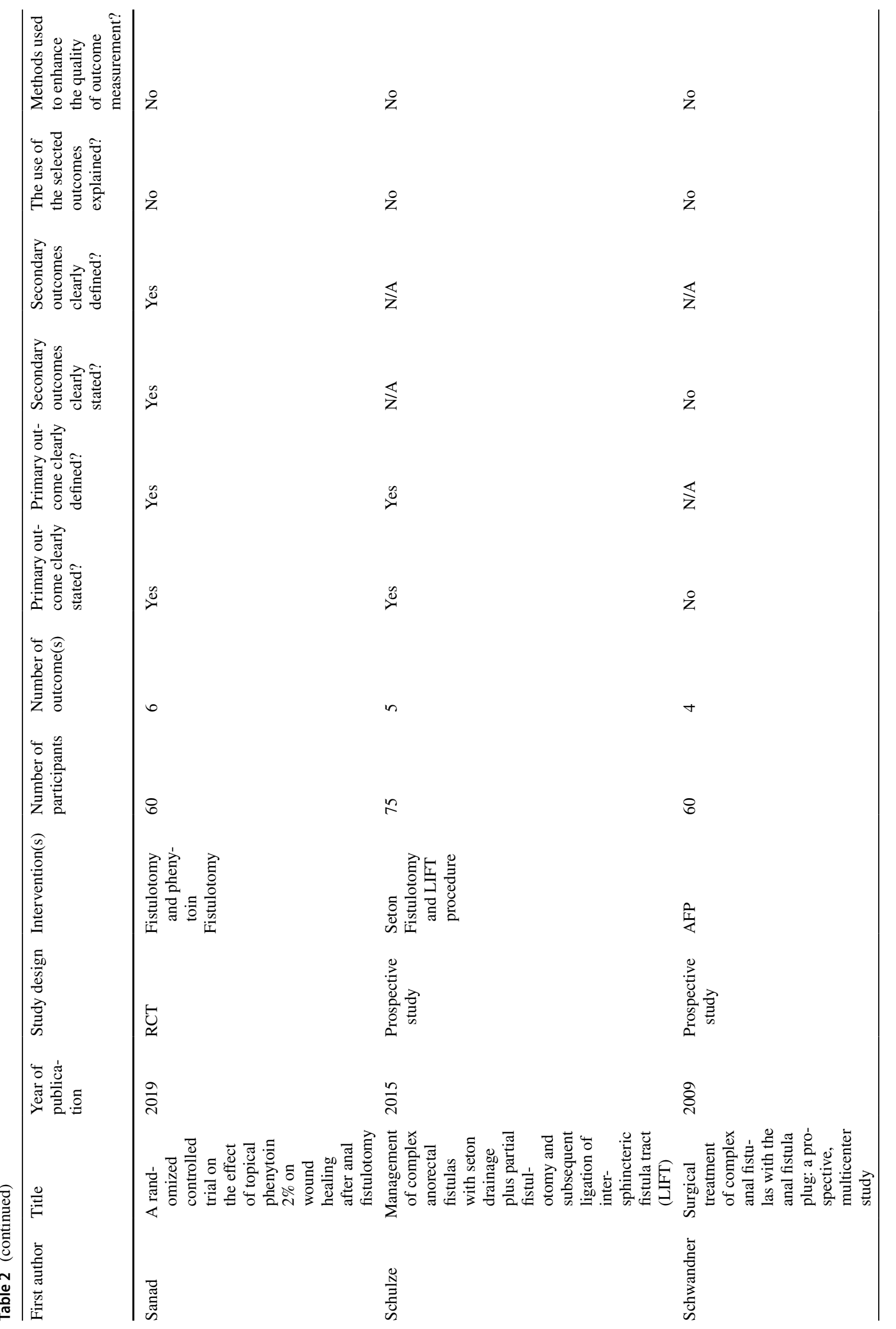




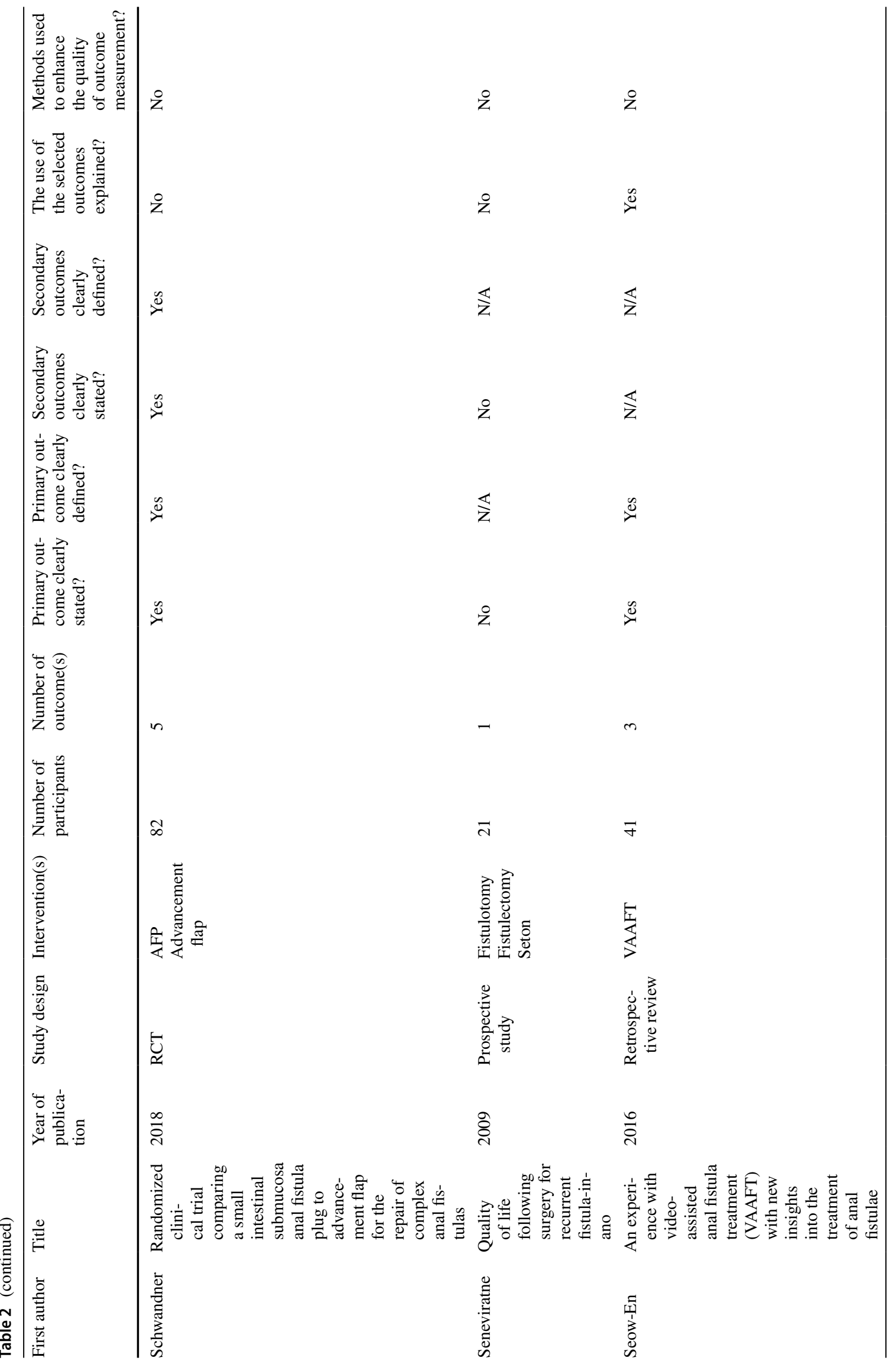




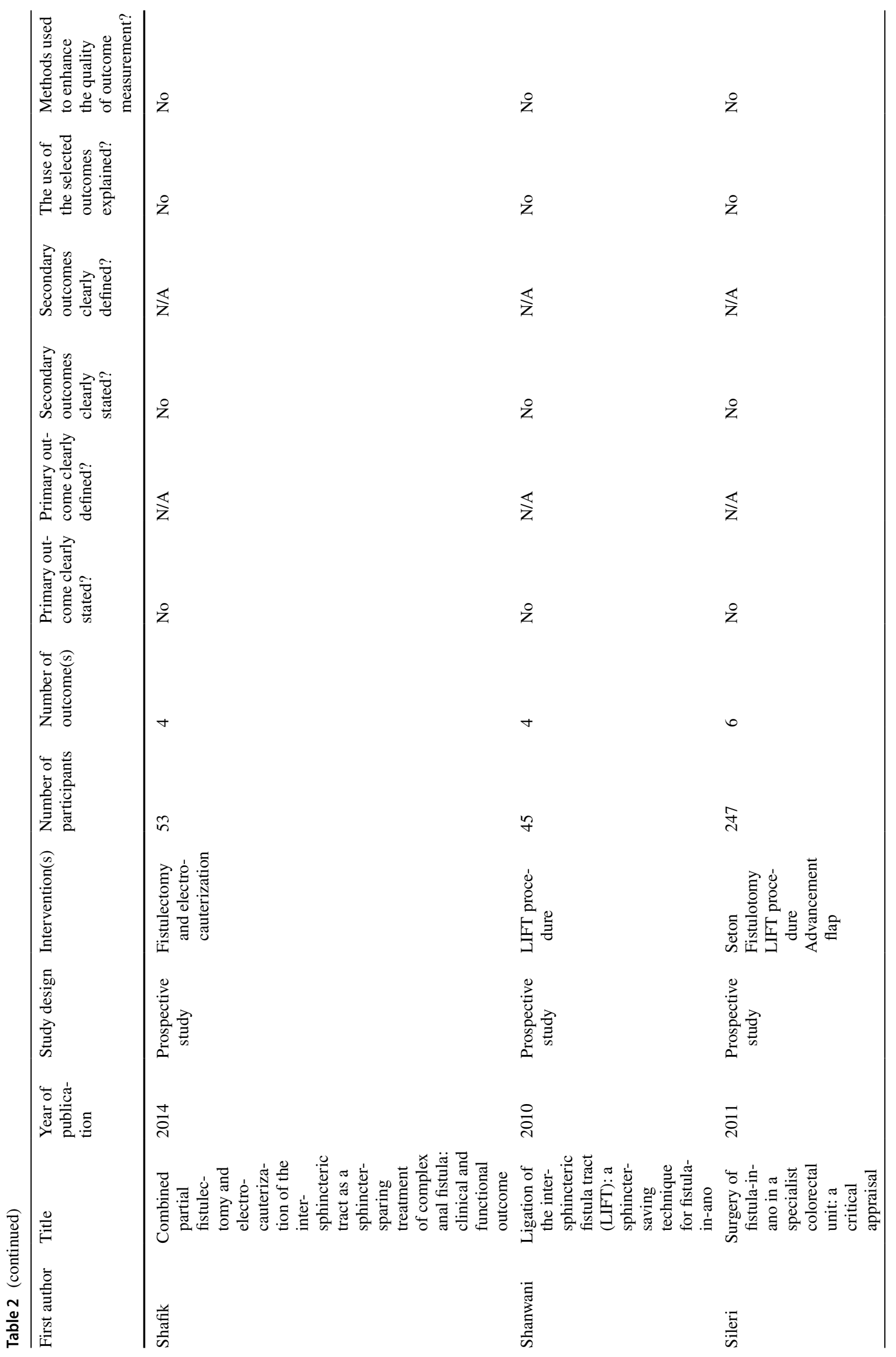




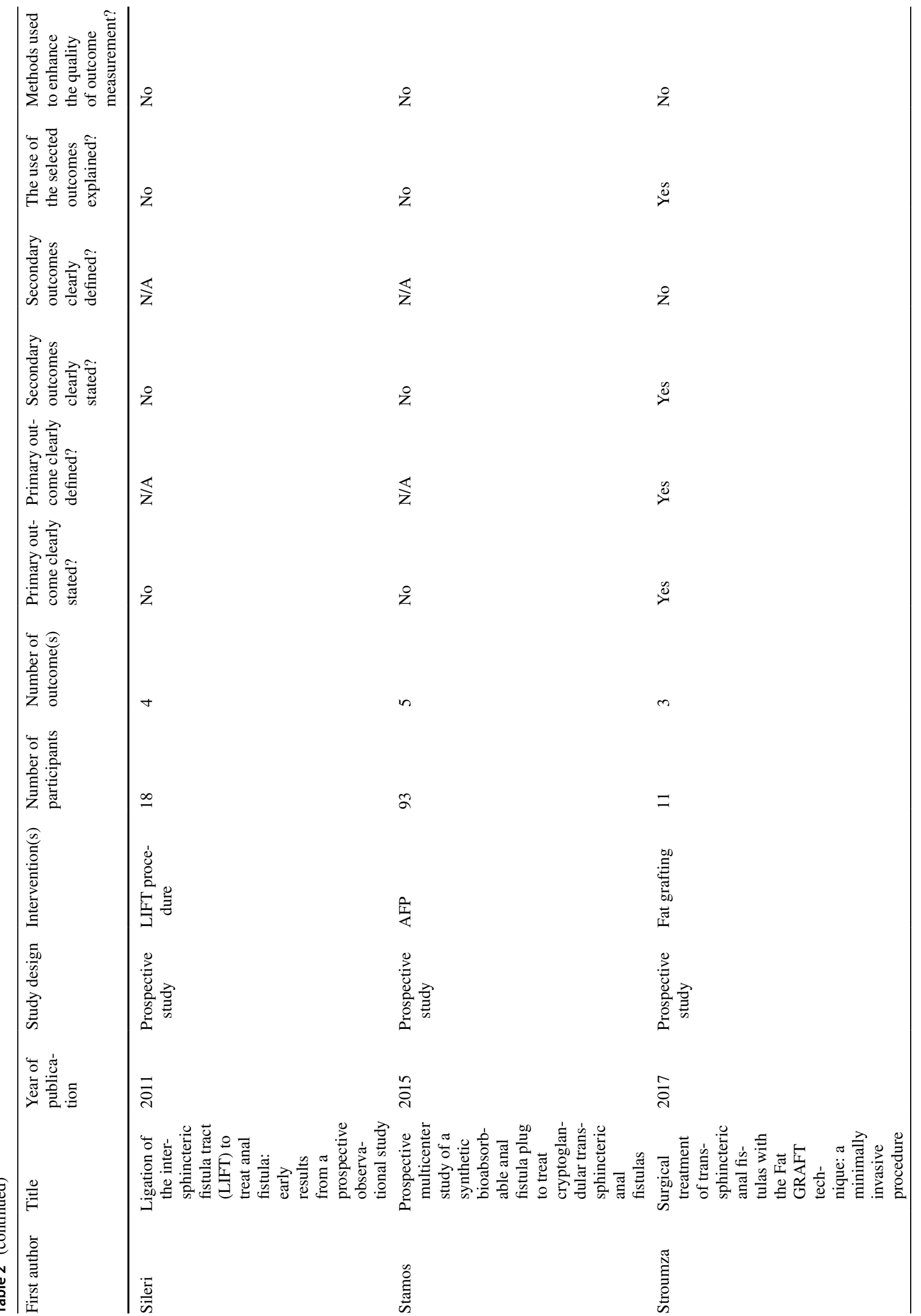




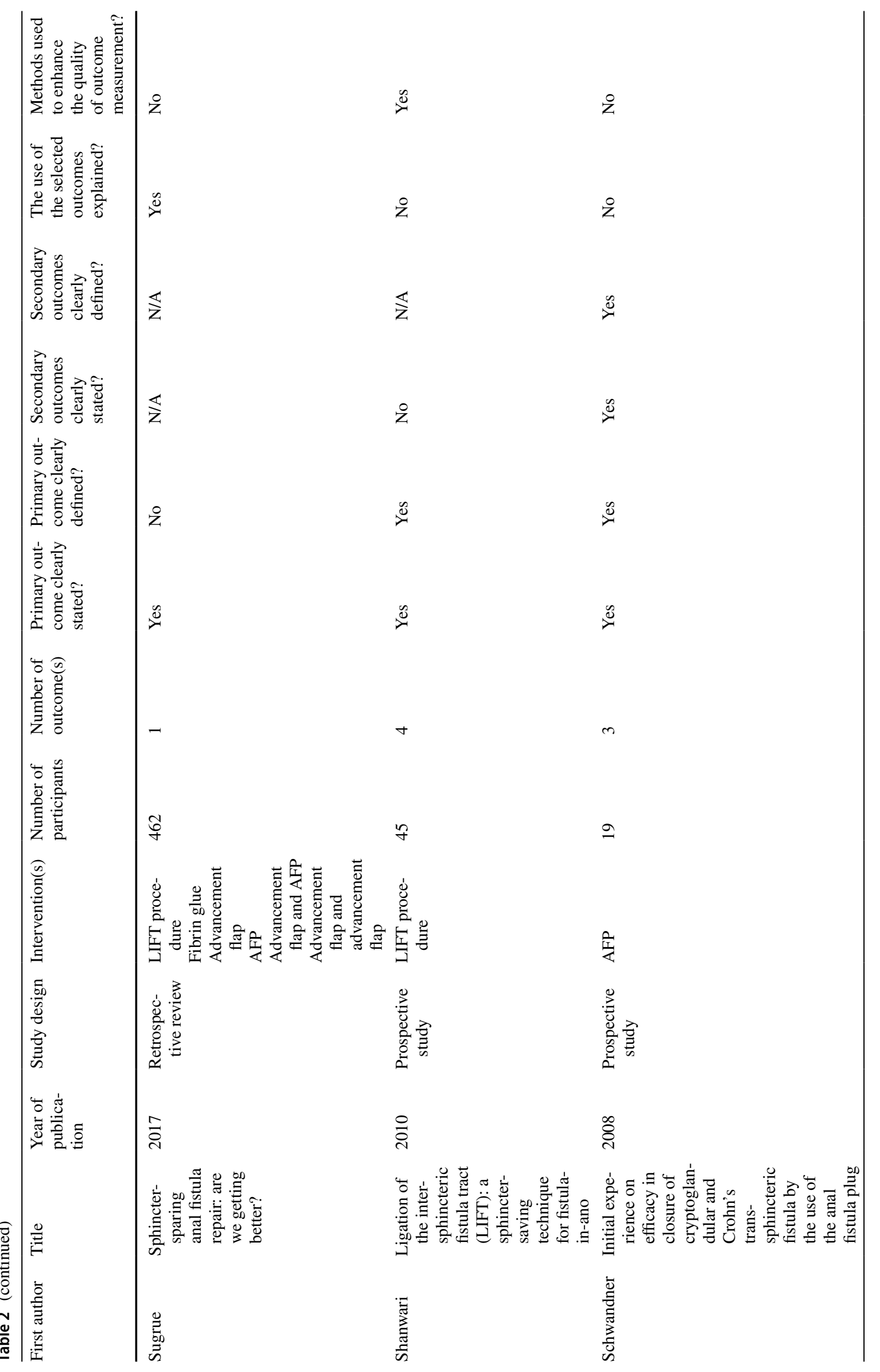




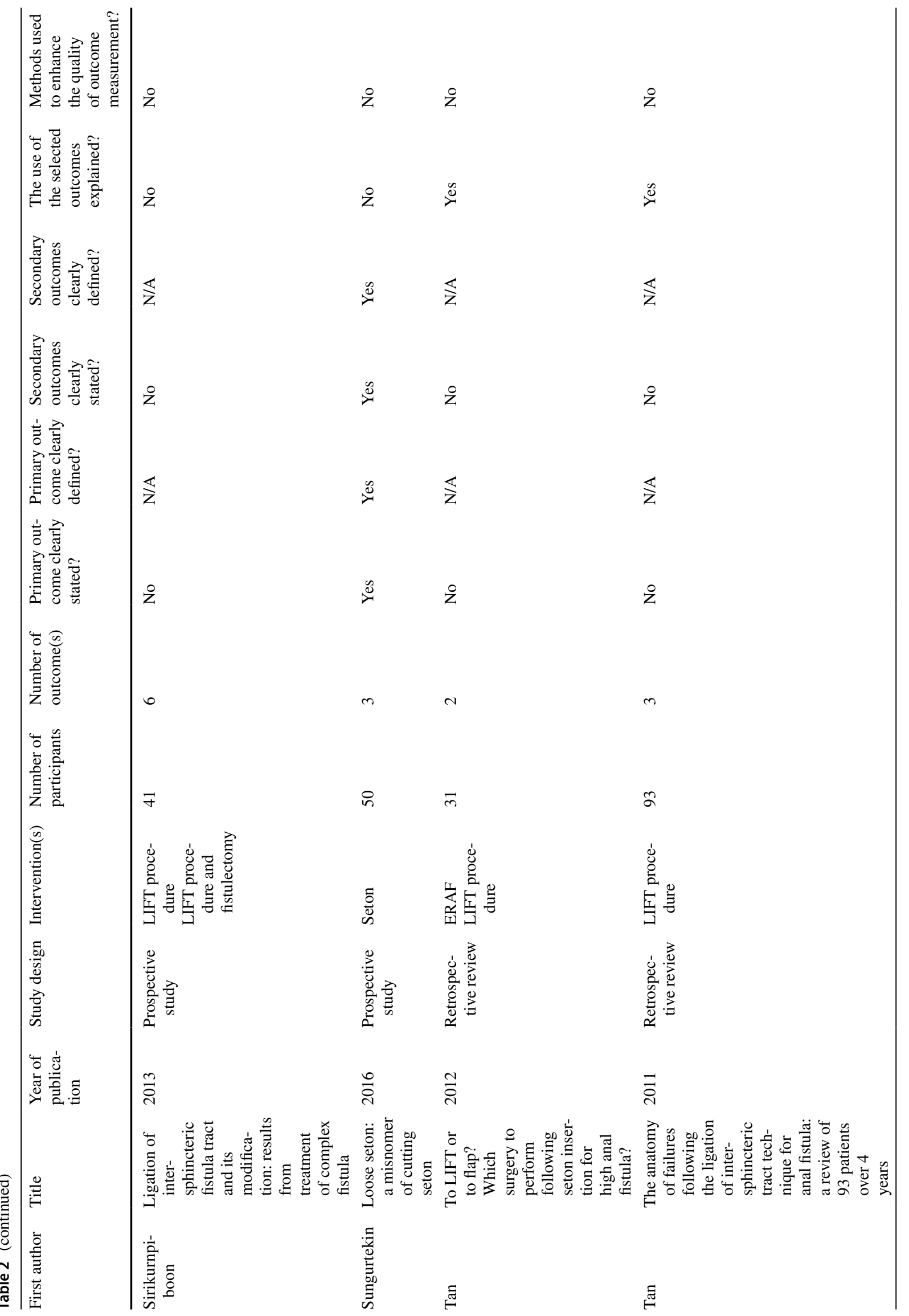




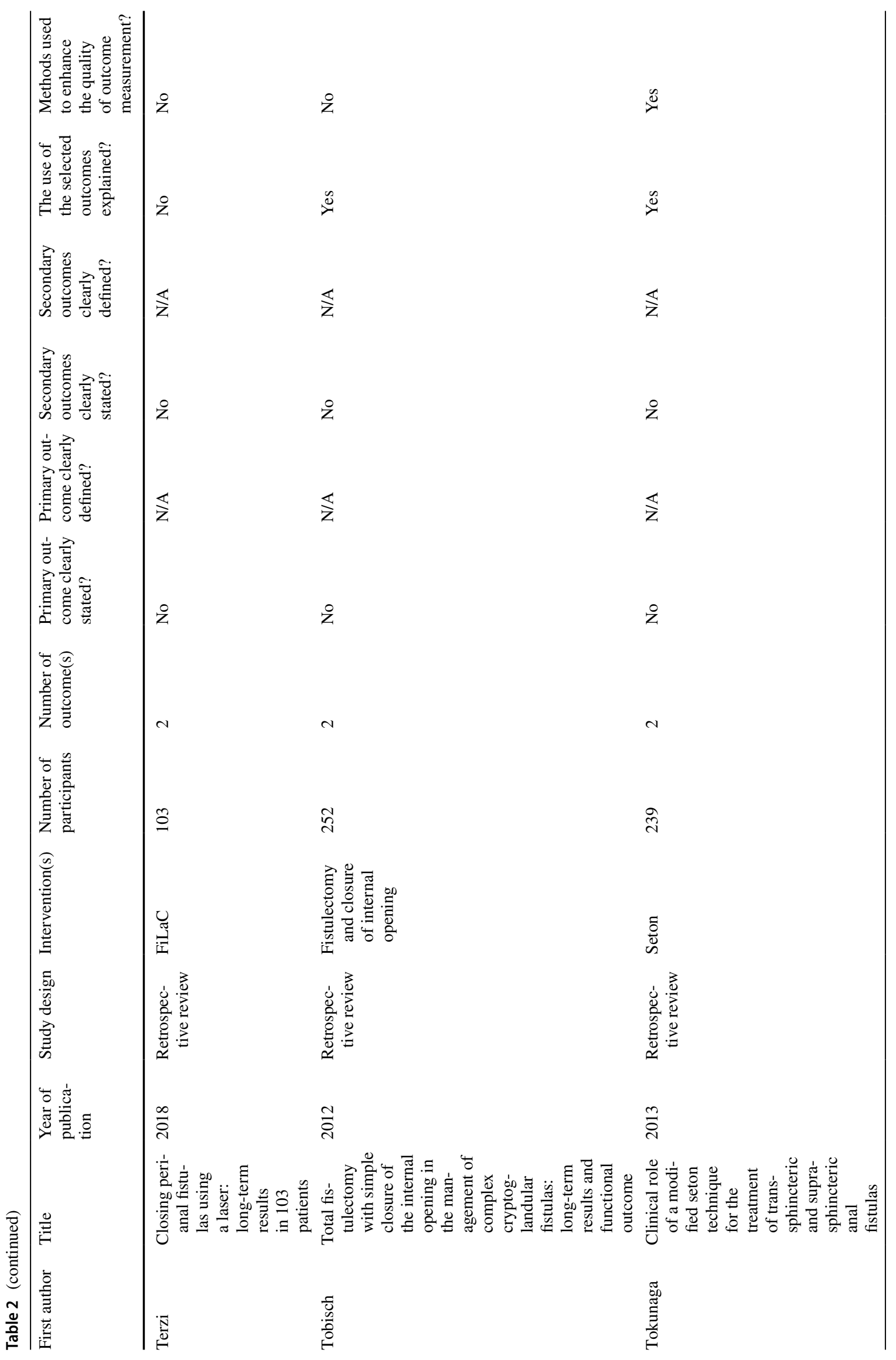




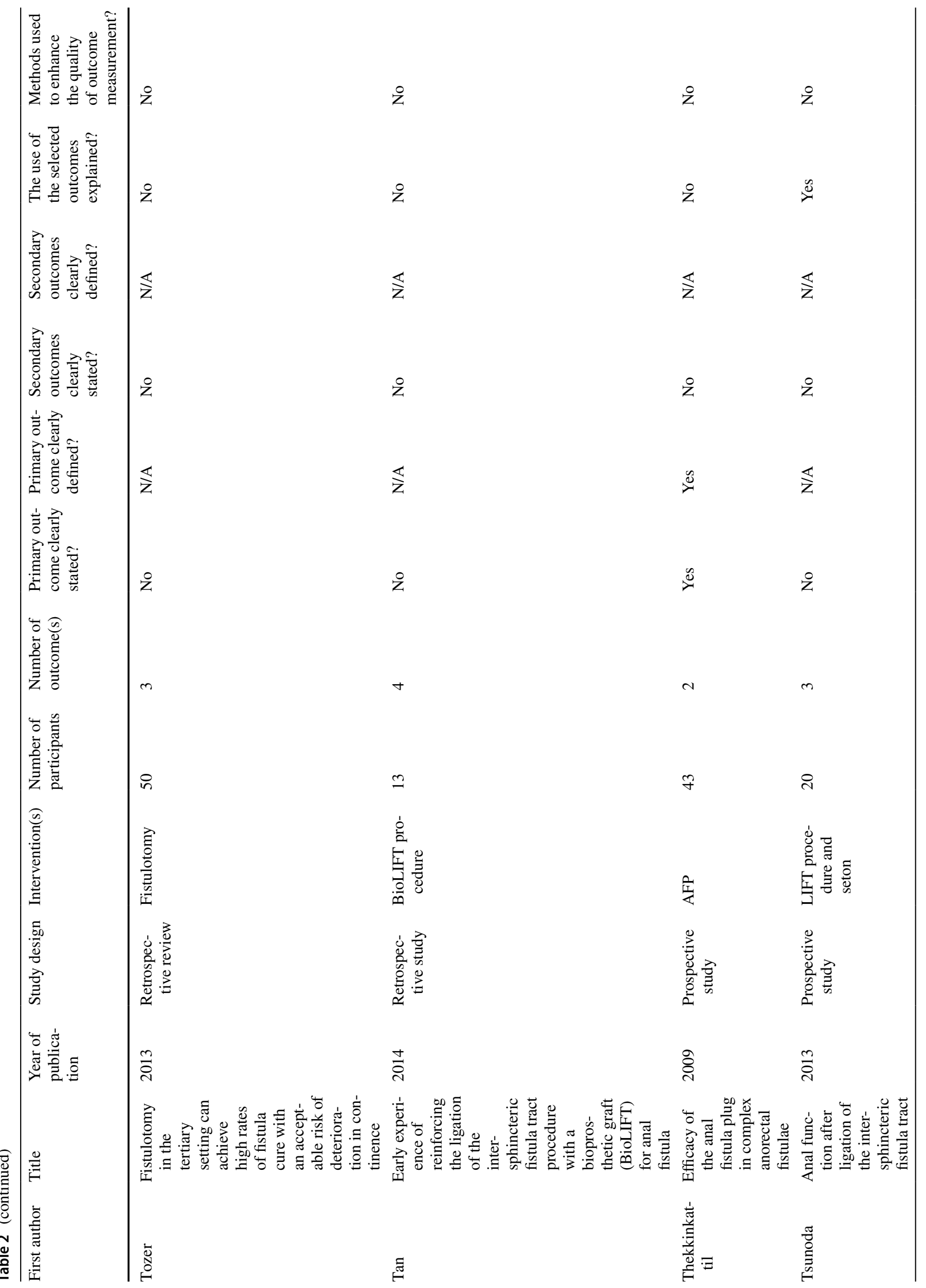




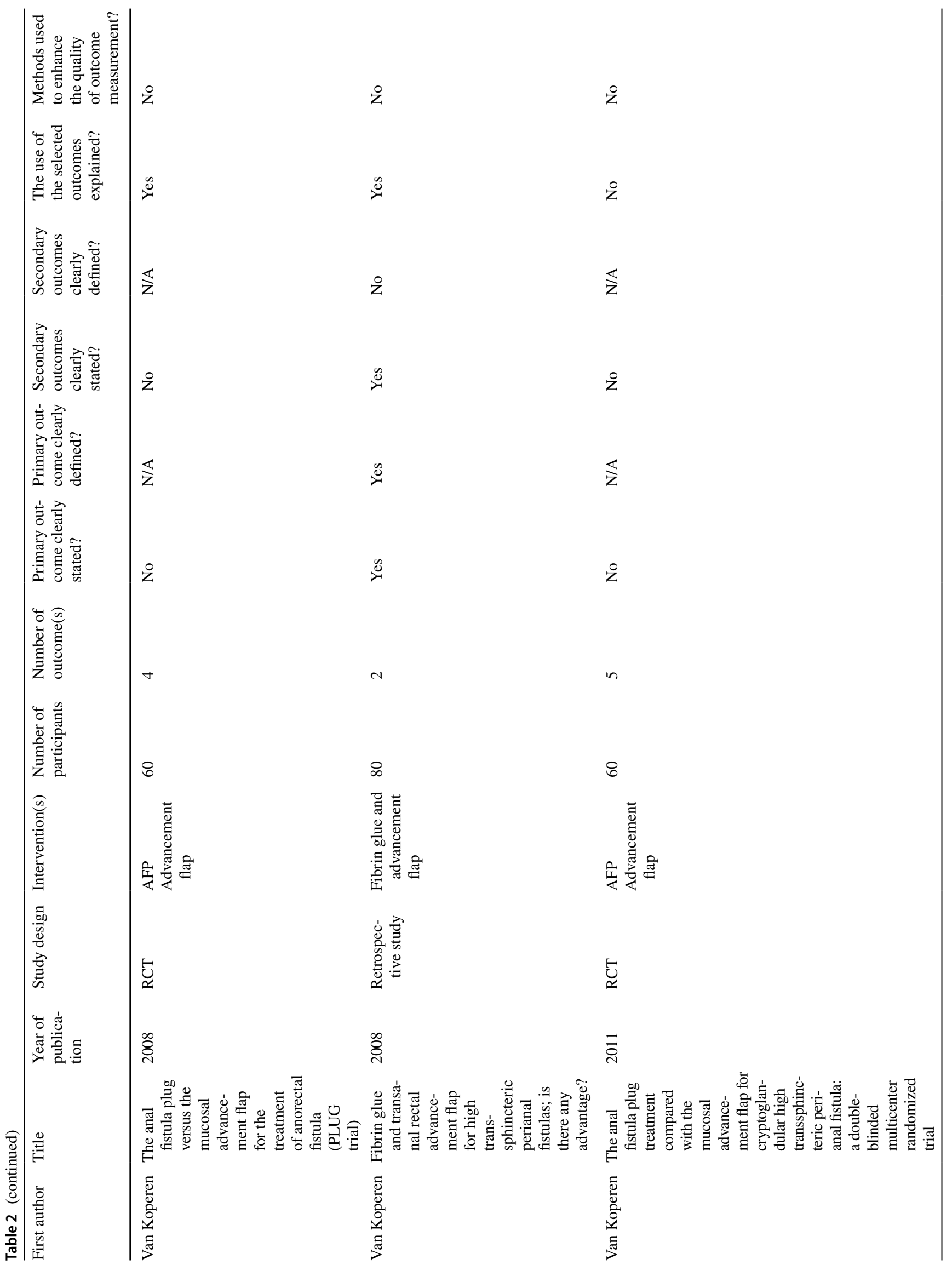




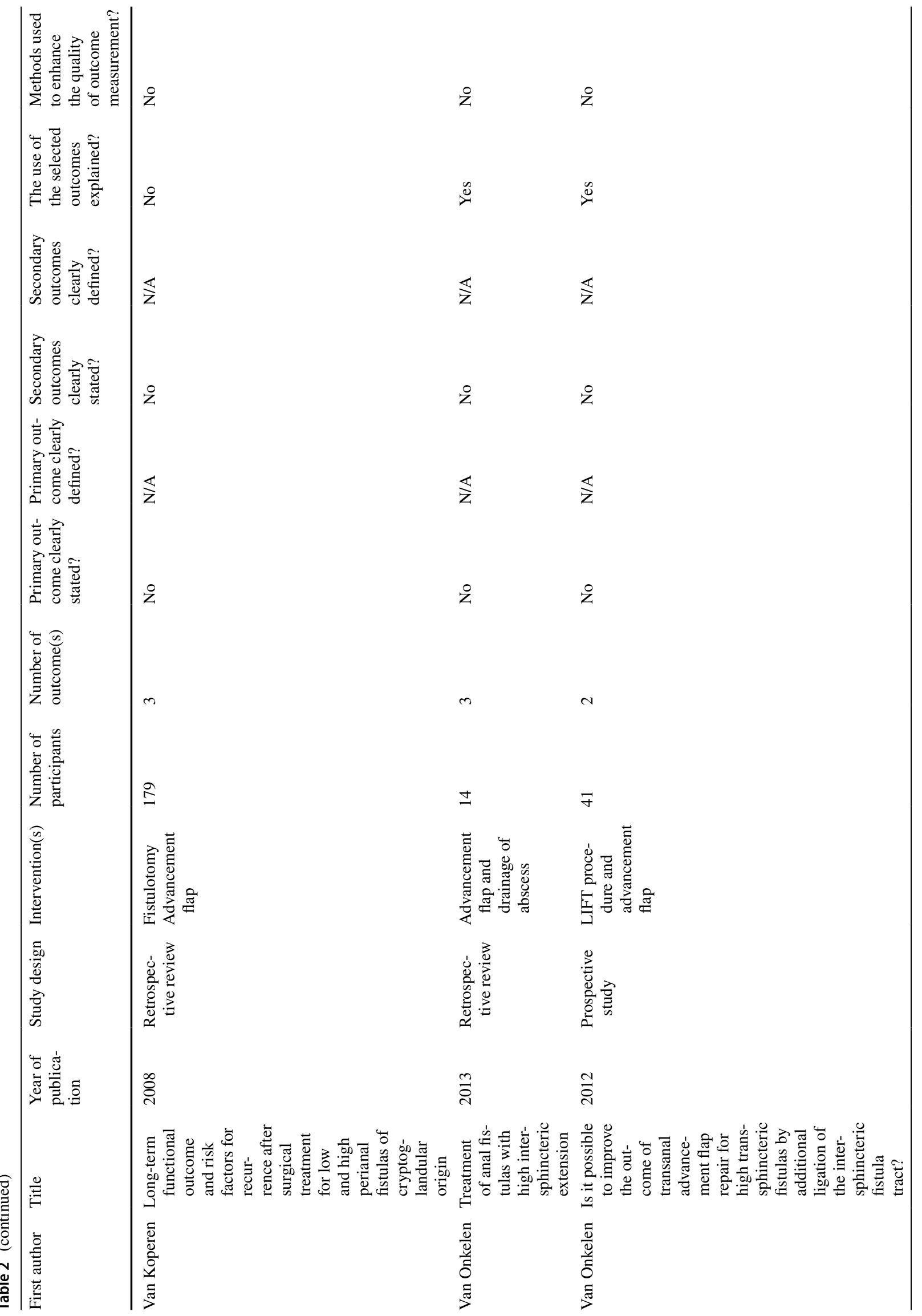




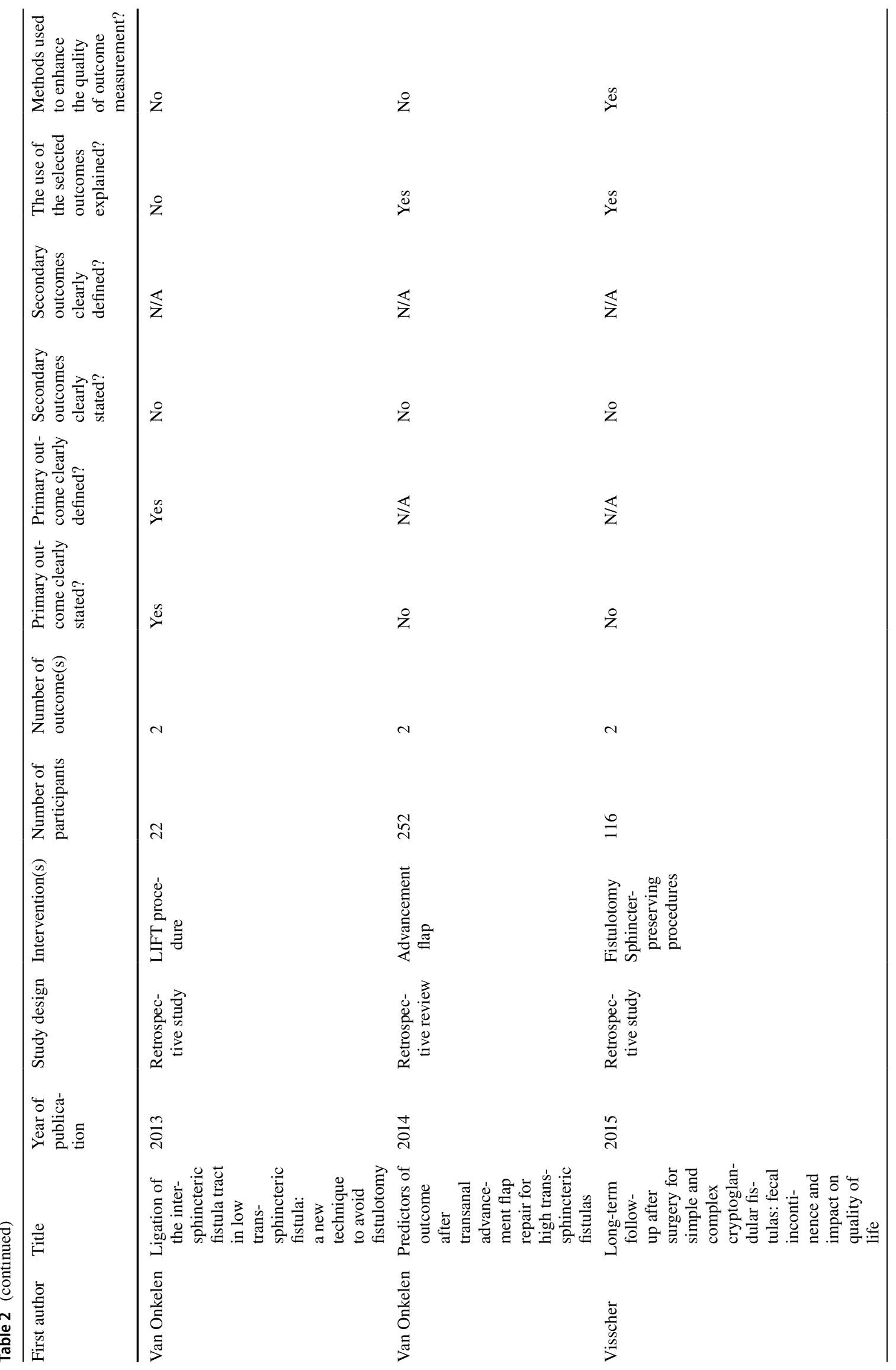




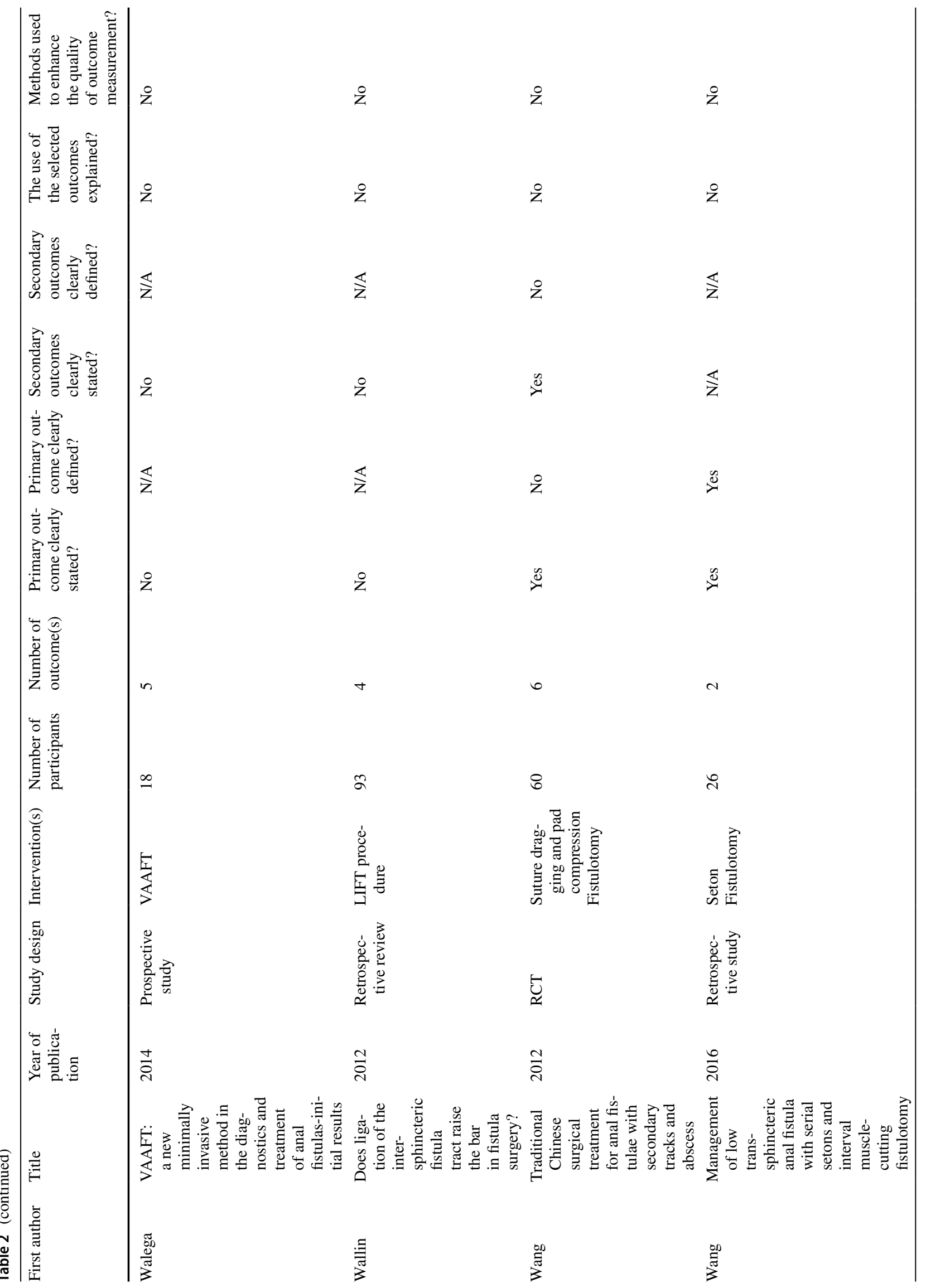




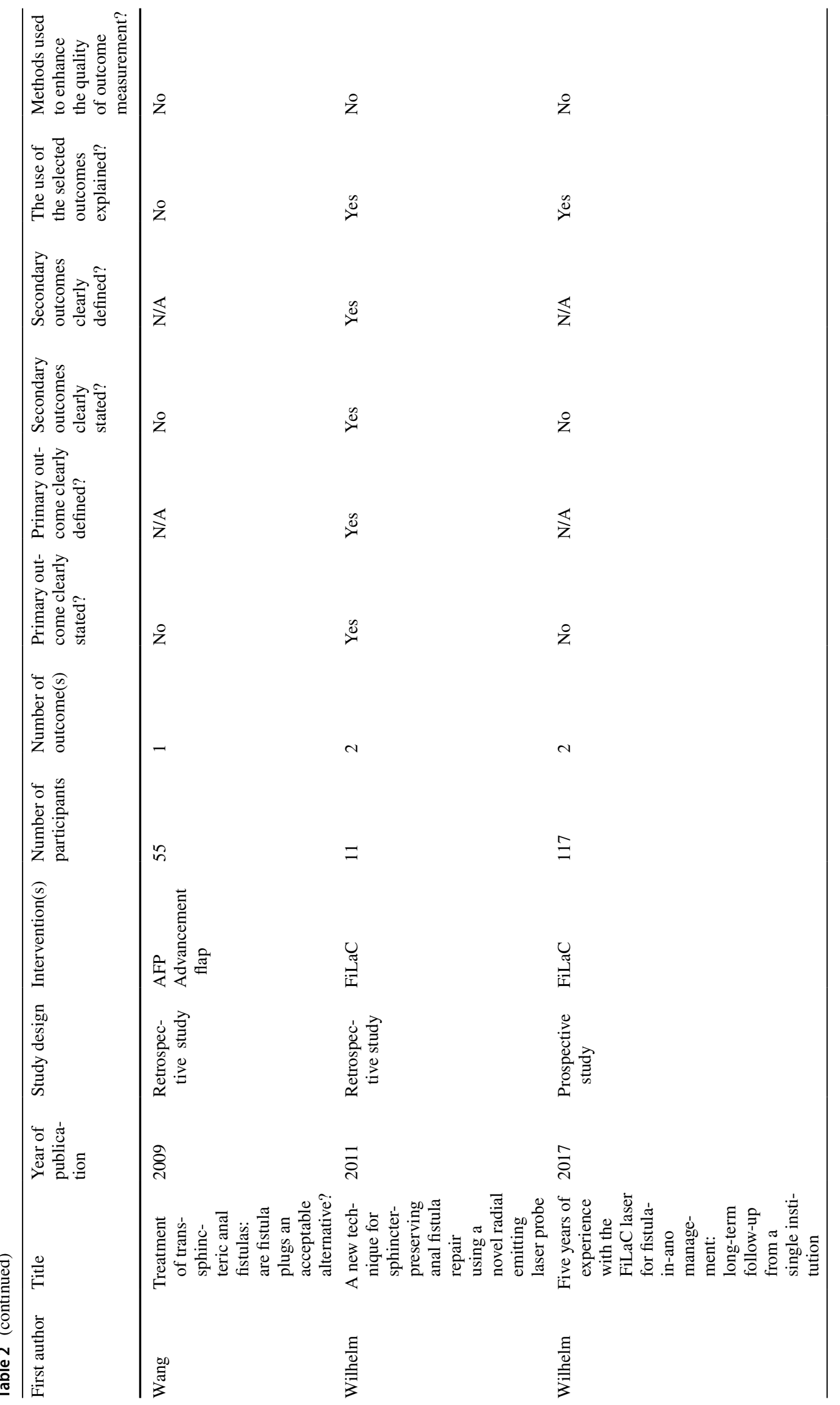




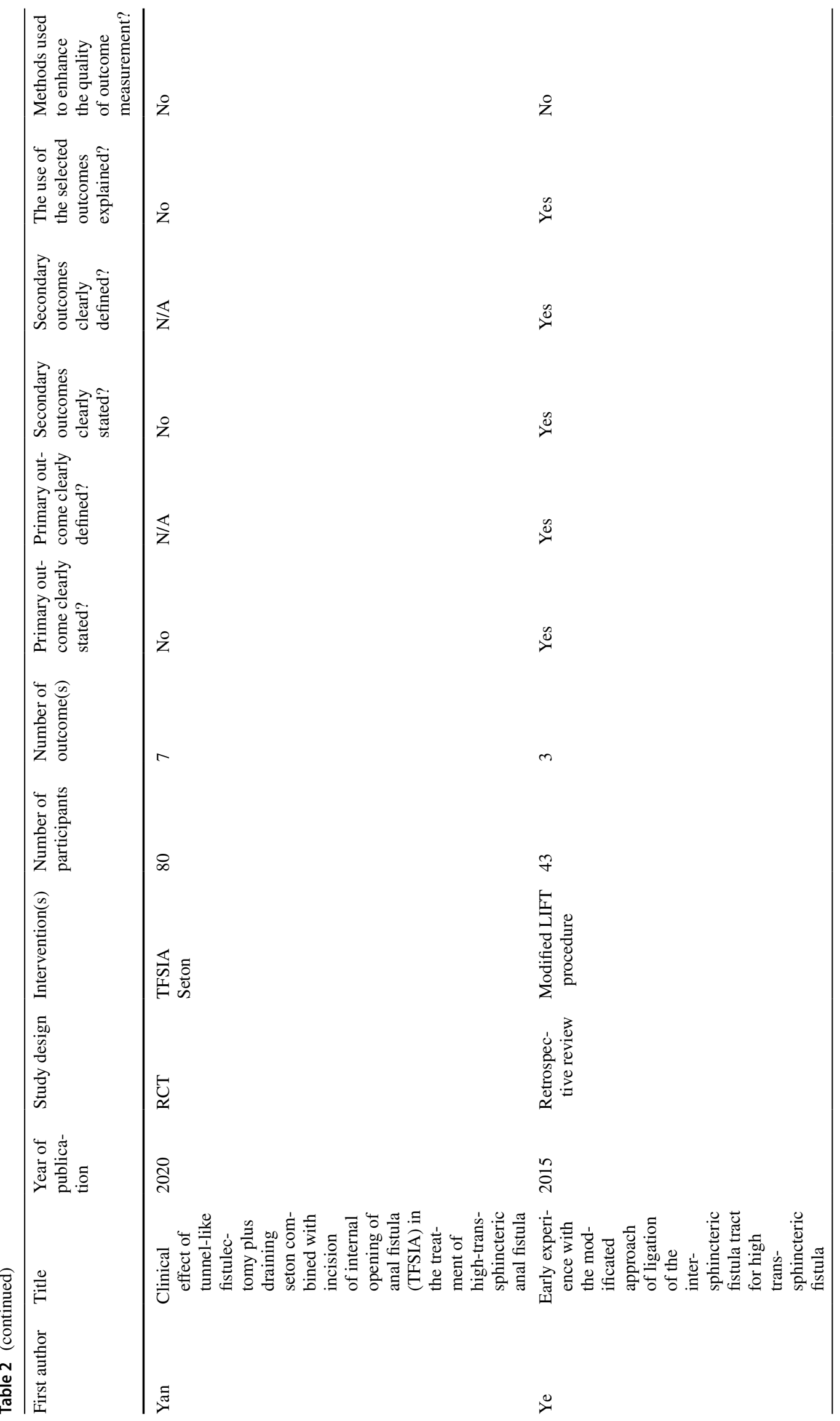




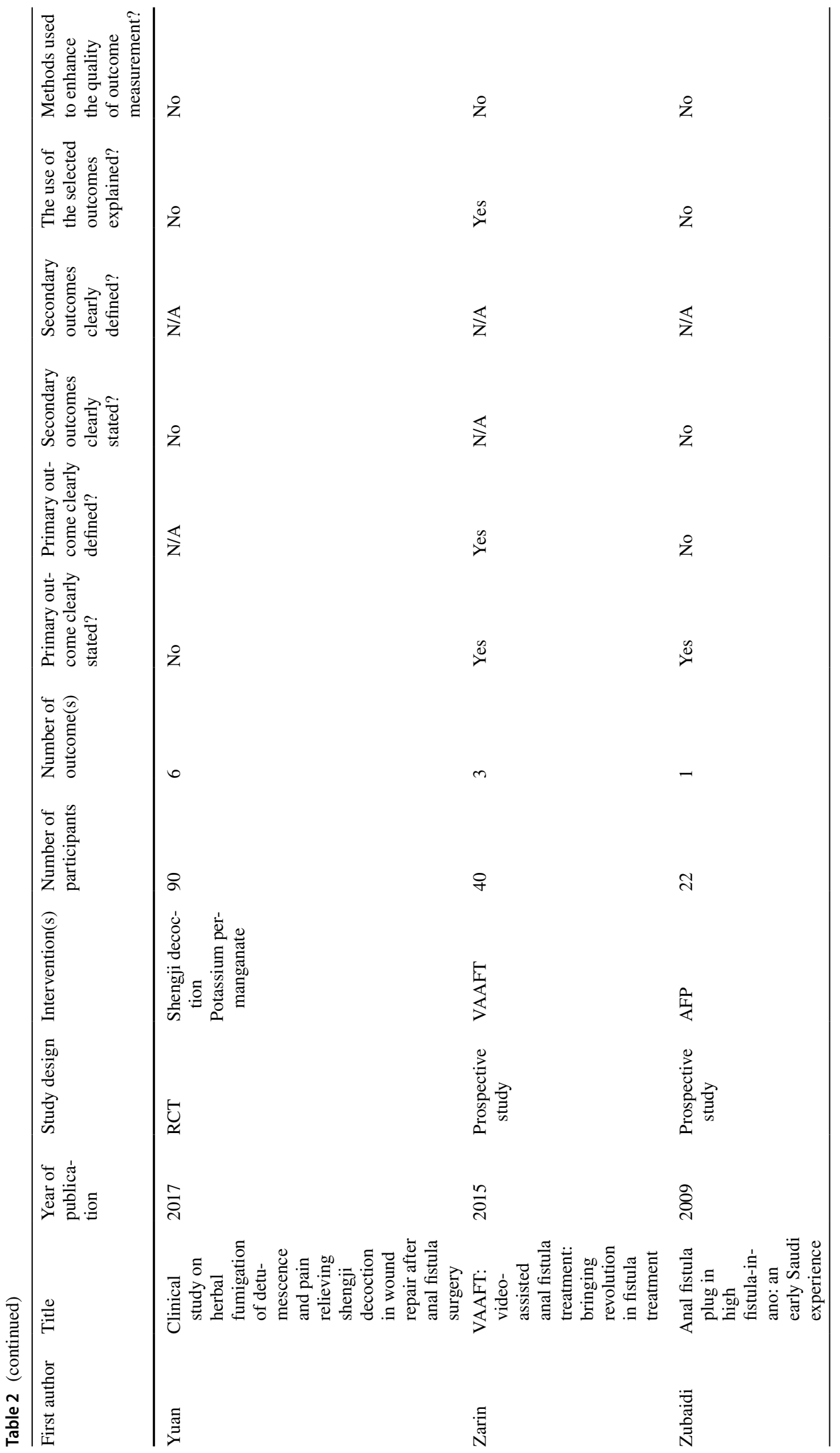




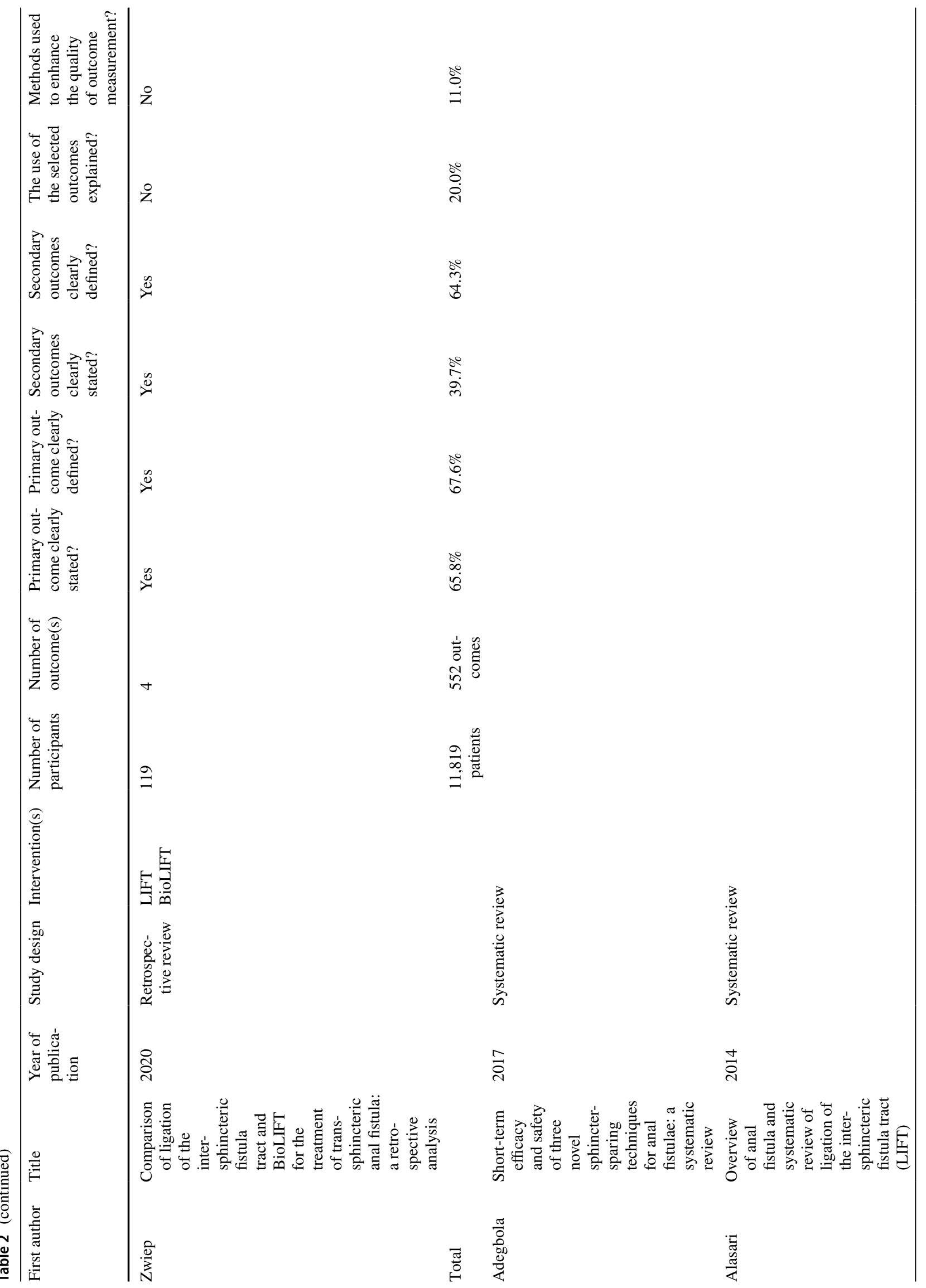




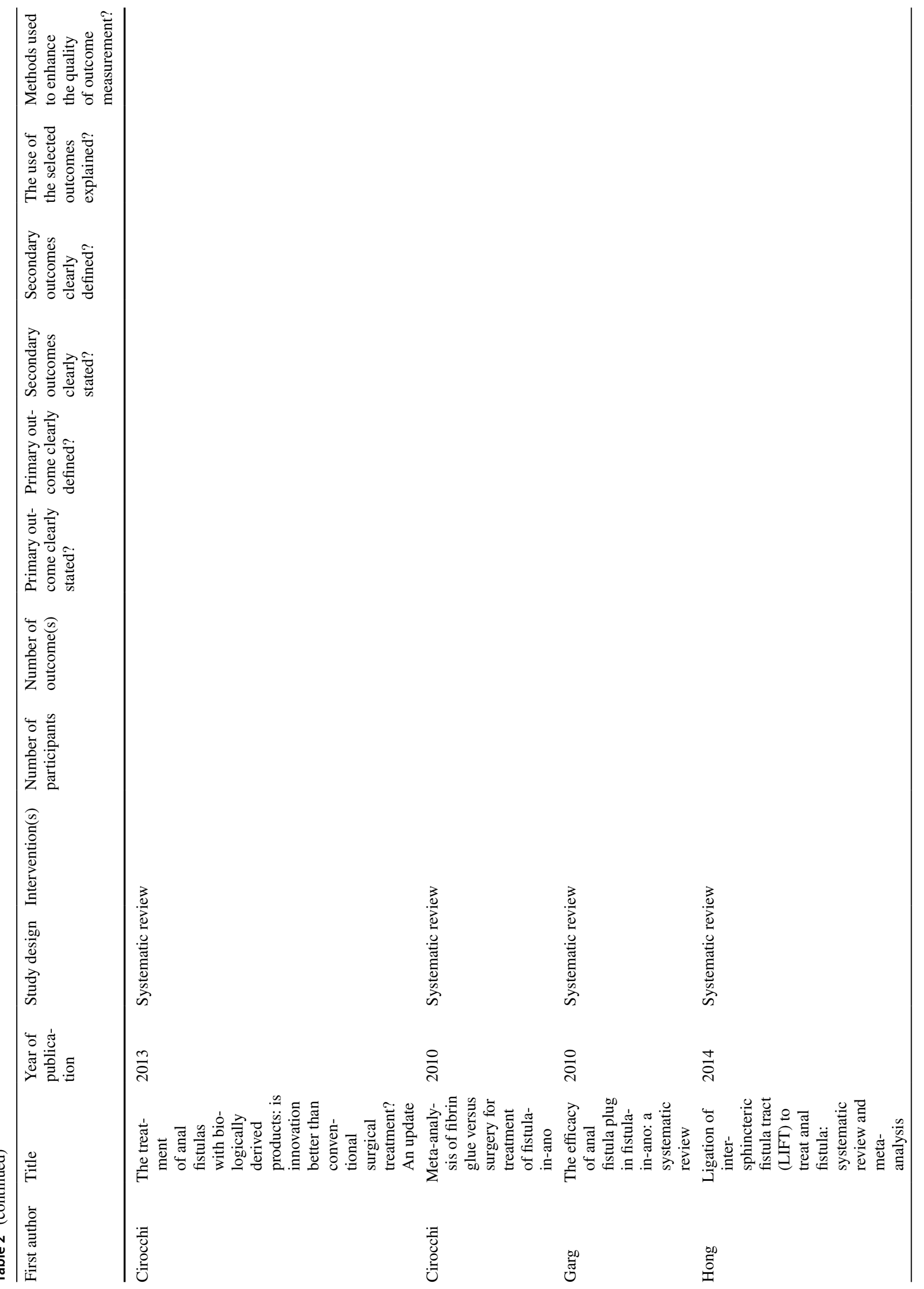




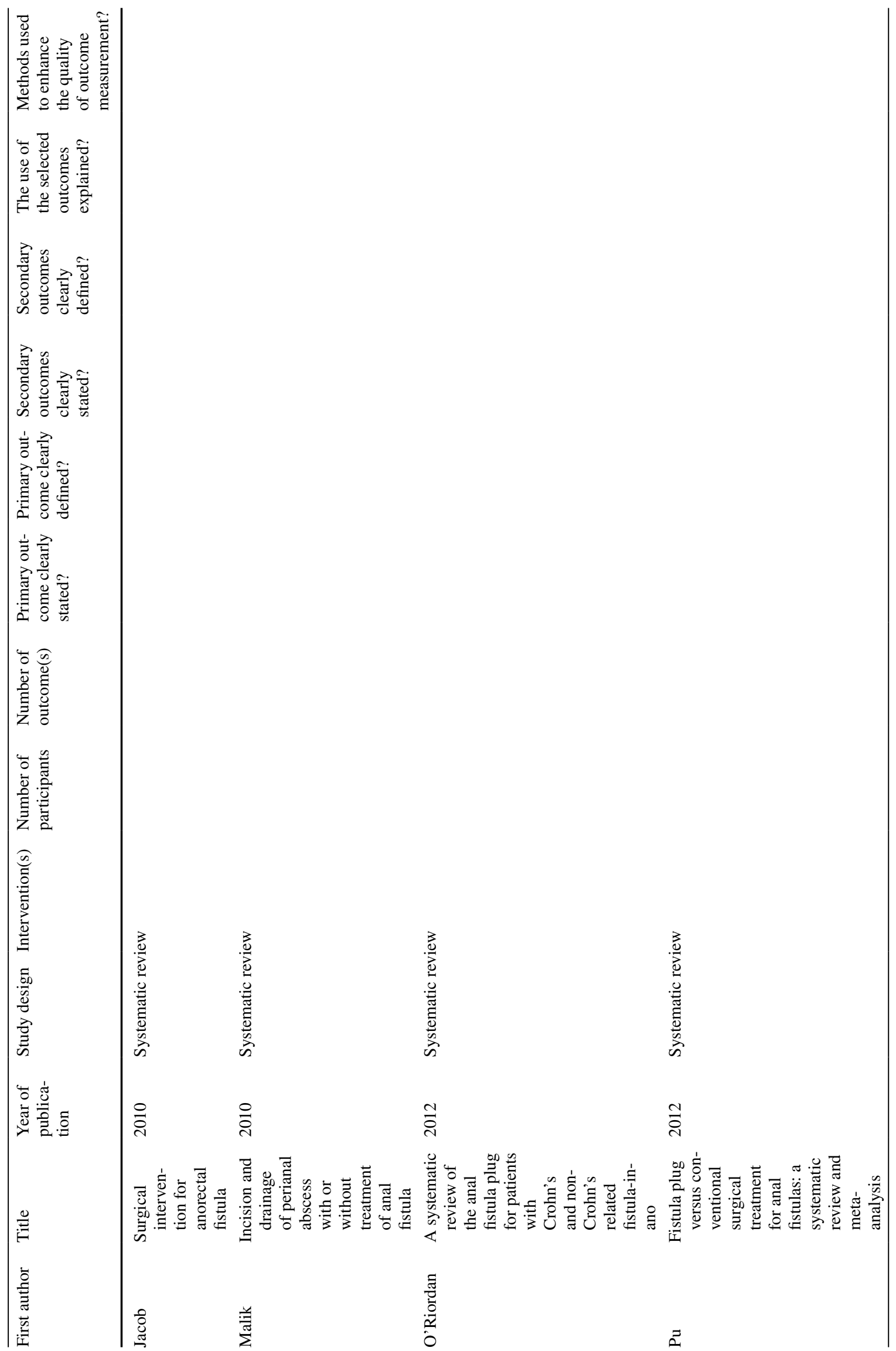




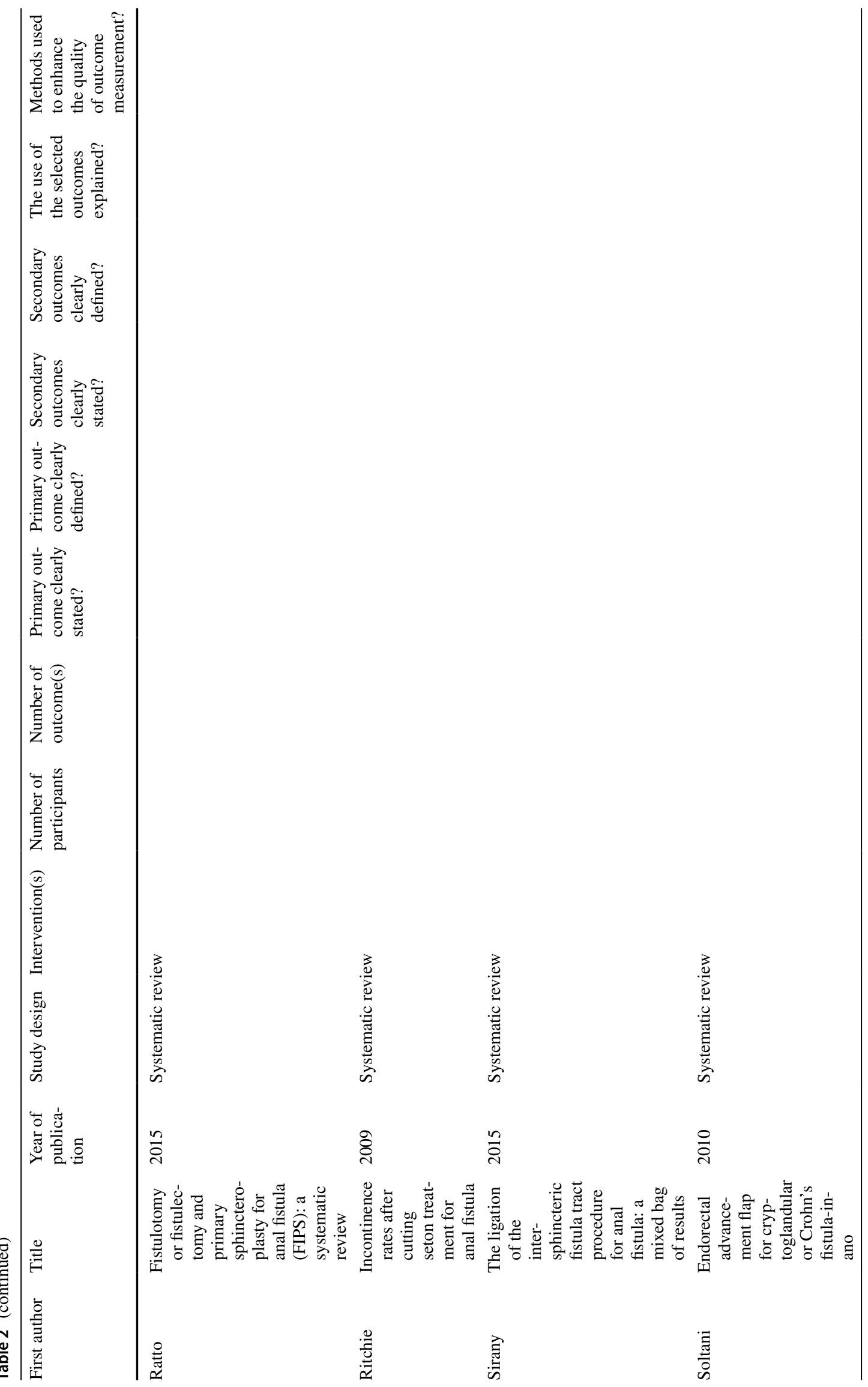




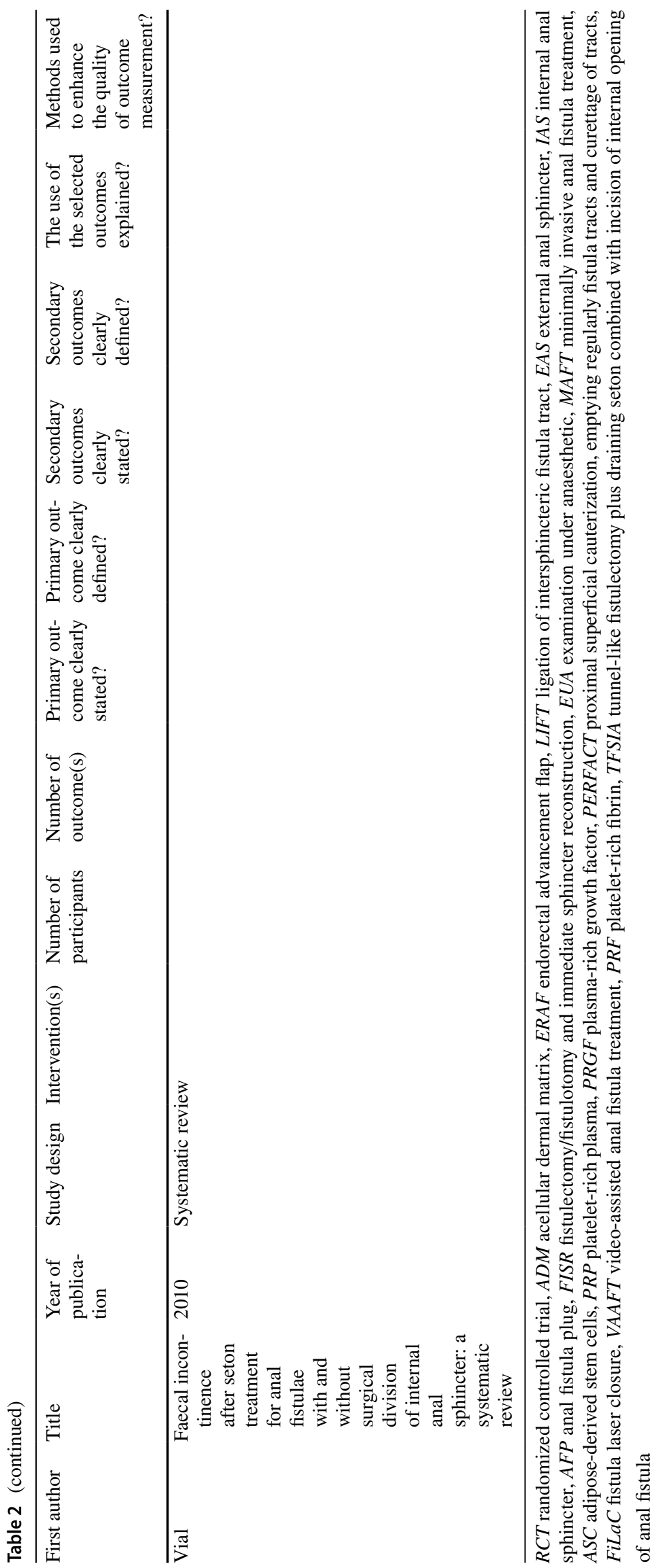


Table 3 Study characteristics

\begin{tabular}{|c|c|c|}
\hline & & $n(\%)$ \\
\hline Total included & & $155(100)$ \\
\hline \multicolumn{3}{|l|}{ Study types contributing to data synthesis } \\
\hline Retrospective studies & & $66(43)$ \\
\hline $\begin{array}{l}\text { Prospective studies } \\
(R C T)\end{array}$ & & $\begin{array}{l}89(57) \\
30(19)\end{array}$ \\
\hline \multicolumn{3}{|l|}{ Publication year } \\
\hline 2008-2010 & & $40(25)$ \\
\hline 2011-2013 & & $50(32)$ \\
\hline 2014-2016 & & $35(23)$ \\
\hline 2017-2019 & & $27(17)$ \\
\hline 2020 & & $3(2)$ \\
\hline Intervention(s) & Control(s) & $n(\%)$ \\
\hline AFP & $\begin{array}{l}\text { No control } \\
\text { Advancement flap } \\
\text { ERAF } \\
\text { Fistulotomy or cutting seton or advancement flap or LIFT }\end{array}$ & $30(19)$ \\
\hline $\begin{array}{l}\text { LIFT } \\
\text { LIFT-plug } \\
\text { BioLIFT } \\
\text { Modified LIFT } \\
\text { LIFT and seton } \\
\text { LIFT and advancement flap } \\
\text { LIFT and fistulectomy }\end{array}$ & $\begin{array}{l}\text { No control } \\
\text { LIFT-plug } \\
\text { Advancement flap } \\
\text { LIFT and fistulectomy } \\
\text { BioLIFT }\end{array}$ & $29(19)$ \\
\hline Seton & $\begin{array}{l}\text { No control } \\
\text { Seton(s) } \\
\text { Fistulotomy } \\
\text { Fistulotomy and LIFT } \\
\text { Rerouting of fistula tract and seton around internal anal sphincter }\end{array}$ & $12(8)$ \\
\hline $\begin{array}{l}\text { Fistulotomy } \\
\text { Fistulotomy and sucralfate } \\
\text { Partial fistulotomy and seton } \\
\text { Fistulotomy and phenytoin }\end{array}$ & $\begin{array}{l}\text { No control } \\
\text { Advancement flap } \\
\text { Fistulectomy } \\
\text { Fistulotomy and placebo sucralfate } \\
\text { Fistulectomy and ERAF } \\
\text { Fistulectomy and seton } \\
\text { Fistulotomy and marsupialization } \\
\text { Fistulotomy }\end{array}$ & $10(7)$ \\
\hline $\begin{array}{l}\text { Advancement flap } \\
\text { Advancement flap and platelet-rich plasma } \\
\text { Advancement flap and drainage of abscess } \\
\text { Advancement flap and drainage seton around exter- } \\
\text { nal anal sphincter }\end{array}$ & $\begin{array}{l}\text { No control } \\
\text { Advancement flap } \\
\text { Seton around internal anal sphincter }\end{array}$ & $9(6)$ \\
\hline VAAFT & No control & $8(5)$ \\
\hline $\begin{array}{l}\text { Fibrin glue } \\
\text { Fibrin glue and advancement flap }\end{array}$ & $\begin{array}{l}\text { No control } \\
\text { Seton } \\
\text { Fibrin glue and ASC }\end{array}$ & $6(4)$ \\
\hline $\begin{array}{l}\text { Fistulectomy } \\
\text { Fistulectomy and electro-cauterization } \\
\text { Fistulectomy and closure of internal fistula opening } \\
\text { TFSIA }\end{array}$ & $\begin{array}{l}\text { No control } \\
\text { Fistulotomy } \\
\text { Fistulotomy and marsupialization } \\
\text { Seton }\end{array}$ & $6(4)$ \\
\hline FISR & No control & $5(3)$ \\
\hline FiLaC or laser ablation & No control & $5(3)$ \\
\hline Clip & $\begin{array}{l}\text { No control } \\
\text { Fistulectomy }\end{array}$ & $5(3)$ \\
\hline
\end{tabular}


Table 3 (continued)

\begin{tabular}{|c|c|c|}
\hline Intervention(s) & Control(s) & $n(\%)$ \\
\hline ERAF & $\begin{array}{l}\text { AFP } \\
\text { LIFT } \\
\text { FISR }\end{array}$ & $3(2)$ \\
\hline $\begin{array}{l}\text { ASC } \\
\text { ASC and fibrin glue }\end{array}$ & $\begin{array}{l}\text { No control } \\
\text { ASC, fibrin glue, and fibrin glue } \\
\text { Fibrin glue }\end{array}$ & $3(2)$ \\
\hline $\mathrm{ADM}$ & $\begin{array}{l}\text { No control } \\
\text { ERAF }\end{array}$ & $2(1)$ \\
\hline $\begin{array}{l}\text { Modified Hanley } \\
\text { Modified Hanley, drainage, and setons }\end{array}$ & No control & $2(1)$ \\
\hline Collagen paste injection & $\begin{array}{l}\text { No control } \\
\text { Fibrin glue }\end{array}$ & $2(1)$ \\
\hline PRGF & No control & $1(1)$ \\
\hline PERFACT procedure & No control & $1(1)$ \\
\hline PRF & No control & $1(1)$ \\
\hline MAFT & No control & $1(1)$ \\
\hline Irrigation and silver nitrate & No control & $1(1)$ \\
\hline PRP & Fibrin glue & $1(1)$ \\
\hline$\geq 4$ interventions compared & & $7(5)$ \\
\hline Other & & $5(3)$ \\
\hline Total & & 155 \\
\hline
\end{tabular}

$A F P$ anal fistula plug, ERAF endorectal advancement flap, LIFT ligation of intersphincteric fistula tract, VAAFT video-assisted anal fistula treatment, $A S C$ adipose-derived stem cells, TFSIA tunnel-like fistulectomy plus draining seton combined with incision of internal opening of anal fistula, FISR fistulectomy/fistulotomy and immediate sphincter reconstruction, FiLaC fistula laser closure, ADM acellular dermal matrix, $P R G F$ plasma-rich growth factor, $P E R F A C T$ proximal superficial cauterization, emptying regularly fistula tracts and curettage of tracts, $P R F$ plateletrich fibrin, MAFT minimally invasive anal fistula treatment, $P R P$ platelet-rich plasma

\section{Outcome categorisation}

The outcomes were categorized into core areas and domains according to the COMET taxonomy, with guidance from a member of COMET. The frequency of these outcomes and their categorisation is shown in Table 5. Adverse event outcomes are categorised under their appropriate taxonomy and identified as a harm outcome [13]. Cryptoglandular AF treatment rarely impacts lifespan, therefore the core area death was excluded from categorisation. Some outcomes were categorised in multiple domains, as the study management group considered their impact to be broad. For instance, 'problems related to sexual function' was included in the domains physical, social and emotional functioning and well-being. Outcomes belonging to the core area of 'physiological or clinical' were placed in domains according to their underlying cause or affected body system [13]. Whilst categorisation highlighted the spread of outcomes across all relevant domains, the majority focused on the physiological or clinical impact, particularly in the domain of gastrointestinal outcomes ( $99 \%$ ), whereas only $12 \%$ of outcomes were related to the impact on physical, role and social functioning and emotional functioning and wellbeing (Table 5).

\section{Outcome definitions}

Significant heterogeneity in outcome definition and overlap between definitions was noted in the outcomes of 'healing', 'recurrence', and 'treatment failure'.

\section{Healing}

Healing was reported in 120 studies (77\%) and was synonymous with terms such as 'healing rate', 'fistula closure', 'success', 'cure', 'effectiveness', and 'complete clinical response'. There was considerable heterogeneity in the definitions of healing, however, overlap between the components of each definition meant that all could be defined by using one or more of the components presented in Table 6 . Considering the ways in which components could be combined, 34 different definitions were found. Healing was most frequently defined as "healing of the external fistula 
Table 4 Frequency of outcome reporting

Outcome
Reported as pri- $\quad$ Reported as secmary outcome $(n) \quad$ ondary outcome $(n)$
Unstated $(n) \quad$ Number of studies reporting outcome $(n)$ (\%)

Healing 80

Incontinence

Recurrence

Pain

Complications

Closure time

Treatment failure

Quality of life

Duration of treatment

Morbidity

Return to work

Patient satisfaction

Anorectal manometry

Pus discharge

Hospital stay

Adverse effects

Fistula persistence

Reinterventions

Safety

Plug dislodgement rates

Symptoms

Unit cutting time

Size of operative wound

Postoperative perineal sepsis

Postoperative bleeding

Cost-effectiveness

Difficulty of technique

Impact on daily life

Endoanal ultrasound

Radiological healing

Anorectal deformity rate

Burning sensation

Itching

Length of time until seton removal

Fraction of patients showing $\geq 50 \%$ decrease in fistula size

Investigator's satisfaction score

Amount of mucosal covering

Asymptomatic

Subjective parameters

Glue reaction

Median mucosal blood flow

Problems related to sexual function

Pudendal nerve terminal motor latency

Duration for return to normal activity

Duration of immobilisation

Emerging of a secondary abscess

Need for a new wave of drainage

Removal or migration of the clip

24

24

16

12

15

13

4

6

4

1

2

2

0

2

1

2

3

0

1

1

3

2

0

1

0

1

2

0

0

0

0

0

0

0

0

0

0

1

0

0

0

0

0

1

1

1

12

12

35

21

16

10

3

4

12

7

3

2

2

0

3

2

12

38
39

$120(77)$

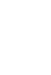

$39 \quad 98(63)$

27

62 (40)

$\begin{array}{ll}12 & 40(26) \\ 11 & 36(23)\end{array}$

$\begin{array}{rr}9 & 25(16) \\ 14 & 22(14)\end{array}$

$422(14)$

$1 \quad 12(8)$

$7 \quad 11(7)$

$3 \quad 7(5)$

$37(5)$

$6 \quad 6(4)$

$0 \quad 5(3)$

$2 \quad 5(3)$

$0 \quad 5(3)$

$0 \quad 4(3)$

$34(3)$

$0 \quad 4(3)$

$0 \quad 3(2)$

$0 \quad 3(2)$

$0 \quad 2(1)$

$0 \quad 2(1)$

$1 \quad 2(1)$

$2 \quad 2(1)$

$0 \quad 2(1)$

$0 \quad 2(1)$

$0 \quad 2(1)$

$2 \quad 2(1)$

$0 \quad 1(1)$

$0 \quad 1(1)$

$0 \quad 1(1)$

$0 \quad 1(1)$

$0 \quad 1(1)$

$0 \quad 1(1)$

$0 \quad 1(1)$

$0 \quad 1(1)$

$0 \quad 1(1)$

$0 \quad 1(1)$

$1 \quad 1(1)$

$1 \quad 1(1)$

$1 \quad 1(1)$

$1 \quad 1(1)$

$0 \quad 1(1)$

$\begin{array}{ll}0 & 1(1) \\ 0 & 1(1)\end{array}$

$0 \quad 1(1)$

$0 \quad 1(1)$ 
Table 4 (continued)

\begin{tabular}{llccc}
\hline Outcome & $\begin{array}{l}\text { Reported as pri- } \\
\text { mary outcome }(n)\end{array}$ & $\begin{array}{l}\text { Reported as sec- } \\
\text { ondary outcome }(n)\end{array}$ & $\begin{array}{l}\text { Unstated }(n) \\
\text { Number of studies } \\
\text { reporting outcome }(n) \\
(\%)\end{array}$ \\
\hline Perianal incision wound healing & 1 & 0 & 0 & $1(1)$ \\
Analgesic requirement & 0 & 0 & 1 & $1(1)$ \\
Keyhole like anomaly & 0 & 0 & 0 & $1(1)$ \\
Conversion into intersphincteric perianal fistula & 0 & 1 & $1(1)$ \\
\hline
\end{tabular}

opening and absence of symptoms' $(n=16)$. In nine studies, a radiological assessment was needed to confirm or refute healing [14-22], whereas another study identified 'radiological healing' as a separate outcome [23]. Five of these 10 studies included the radiological description required to demonstrate healing $[14,15,18,21,22]$. In 21 studies, the definition of healing was dependent upon a time period after which the fistula should be assessed, or for the duration of which the components of healing should be present, which in themselves demonstrated significant variation, ranging from 2 weeks [24] to 12 months [16, 25] after the procedure.

\section{Recurrence, treatment failure and persistence}

The terms recurrence, treatment failure, and persistence were used interchangeably to describe a spectrum of clinical manifestations, ranging from no evidence of closure or persistence of fistula and symptoms [26-29], to temporary closure followed by re-appearance of the original fistula [26], to the development of additional fistulas [20, 30-32]. Similar to healing, the definitions were broken down into components which are presented in Table 7 . The most frequently used definitions were 'persistence or recurrence of symptoms' ( $n=21)$, followed by 'persistence or reappearance of the external fistula opening' $(n=13)$. There were 19 different definitions of recurrence and treatment failure. In 10 studies, the definition was qualified by a time period at or after which the fistula had to be assessed, ranging from within the first month [20] to 12 months after treatment [33].

\section{Outcome measurement instruments}

Heterogeneity was noted amongst the measurement instruments used for the most frequently reported outcomes (Table 8). Combinations of measurement instruments were frequently used. Furthermore, the instruments for each outcome were not always clearly stated and many studies used unspecified questionnaires.

\section{Discussion}

This systematic review is the first study to provide an overview of the outcomes reported in interventional studies for AF. We identified 552 outcomes from 155 studies published in the last 12 years, which were merged into 52 unique outcomes, of which healing was reported most frequently (77\%). Our results demonstrate heterogeneity in outcome definition and measurement, making the use of such studies to supplement current understanding of fistula management and guide treatment pathways much more challenging.

The lack of consistency and clarity in definitions of success, treatment failure, and recurrence after fistula treatment has been previously noted [34]. Despite being one of the most frequently reported outcomes, healing was variably defined in terms of anatomical features, absence of a specific set of symptoms or healing of the (surgical) wound. This highlights the difficulty of data synthesis across different studies, particularly when a fistula has healed in one study simply by closure of the external fistula opening [35], but would be considered persistent in another, where both the external and internal fistula openings, and an absence of symptoms are required [36]. The addition of radiological healing provides additional complexity, as it is well documented that deep tissue healing of perianal fistula as assessed on magnetic resonance imaging lags behind clinical healing by a period of months [37-39]. Nevertheless, radiological outcomes and objective measures of the disease have been frequently used in studies of AF, and their potential inclusion in a COS warrants further discussion and involvement of radiological expertise.

The various definitions of recurrence, persistence, and treatment failure demonstrated overlap, however, in line with previous suggestions [34], we determined that treatment failure and persistence of the fistula, i.e. no change in the morphology and symptomatology of the original fistula, should be differentiated from fistula recurrence, which describes reappearance of the fistula after a period of resolution, and 
Table 5 Outcome categorisation and frequency of outcome reporting according to the COMET taxonomy

\begin{tabular}{|c|c|c|c|}
\hline Core area & Domain & Outcomes & $\begin{array}{l}\text { No. studies } \\
\text { reporting out- } \\
\text { comes }(\%)\end{array}$ \\
\hline \multirow[t]{4}{*}{ Physiological or clinical } & Gastrointestinal outcomes & $\begin{array}{l}\text { Healing } \\
\text { Incontinence (harm) } \\
\text { Recurrence (harm) } \\
\text { Pain } \\
\text { Treatment failure (harm) } \\
\text { Closure time } \\
\text { Pus discharge } \\
\text { Anorectal manometry } \\
\text { Fistula persistence (harm) } \\
\text { Plug dislodgement rates (harm) } \\
\text { Unit cutting time } \\
\text { Symptoms } \\
\text { Radiological healing } \\
\text { Anorectal deformity rate (harm) } \\
\text { Burning sensation } \\
\text { Itching } \\
\text { Fraction of patients showing } \geq 50 \% \text { decrease in fistula size } \\
\text { Amount of mucosal covering } \\
\text { Asymptomatic } \\
\text { Subjective parameters } \\
\text { Glue reaction (harm) } \\
\text { Endoanal ultrasound } \\
\text { Pudendal nerve terminal motor latency } \\
\text { Removal or migration of the clip (harm) } \\
\text { Perianal incision wound healing } \\
\text { Conversion into intersphincteric fistula (harm) } \\
\text { Keyhole like anomaly (harm) }\end{array}$ & $154(99)$ \\
\hline & General outcomes & Morbidity (harm) & $11(7)$ \\
\hline & Infection and infestation outcomes & $\begin{array}{l}\text { Postoperative perineal sepsis (harm) } \\
\text { Emerging of a secondary abscess (harm) }\end{array}$ & $3(2)$ \\
\hline & Vascular outcomes & $\begin{array}{l}\text { Median mucosal blood flow } \\
\text { Postoperative bleeding (harm) }\end{array}$ & $2(1)$ \\
\hline
\end{tabular}


Table 5 (continued)

\begin{tabular}{|c|c|c|c|}
\hline Core area & Domain & Outcomes & $\begin{array}{l}\text { No. studies } \\
\text { reporting out- } \\
\text { comes }(\%)\end{array}$ \\
\hline \multirow[t]{18}{*}{ Life impact } & Physical functioning & Problems related to sexual functioning & $5(3)$ \\
\hline & & Duration for return to normal activity & \\
\hline & & Duration of immobilisation & \\
\hline & & Impact daily life & \\
\hline & Social functioning & Problems related to sexual functioning & $3(2)$ \\
\hline & & Impact daily life & \\
\hline & Role functioning & Return to work & $8(5)$ \\
\hline & & Impact daily life & \\
\hline & Emotional functioning or well-being & Problems related to sexual functioning & $3(2)$ \\
\hline & & Impact daily life & \\
\hline & Global quality of life & Quality of life & $22(14)$ \\
\hline & Delivery of care & Treatment failure & $32(22)$ \\
\hline & & Duration of treatment & \\
\hline & & Patient satisfaction & \\
\hline & & Size of operative wound & \\
\hline & & Length of time until seton removal & \\
\hline & & Investigator's satisfaction score & \\
\hline & & Difficulty of technique & \\
\hline \multirow[t]{5}{*}{ Resource use } & Economic & Cost-effectiveness & $2(1)$ \\
\hline & Hospital & Hospital stay & $5(3)$ \\
\hline & Need for further intervention & Reinterventions & $6(4)$ \\
\hline & & Need for a new wave of drainage & \\
\hline & & Analgesic requirement & \\
\hline \multirow[t]{3}{*}{ Adverse events } & Adverse events and/or effects & Complications & $44(28)$ \\
\hline & & Adverse effects & \\
\hline & & Safety & \\
\hline
\end{tabular}

Table 6 Components used, in varying combinations, to define the outcome 'healing'

\begin{tabular}{ll}
\hline Component & Times used \\
\hline Absence of symptoms & 70 \\
Closure of the external fistula opening & 61 \\
Absence of abscess or infection or inflammation or & 27 \\
$\quad$ sepsis & 24 \\
Closure of the (surgical) wound & 15 \\
Closure of the internal fistula opening & 14 \\
Closure of the fistula tract & 8 \\
No additional intervention required & 8 \\
Absence of recurrence or persistence or treatment failure & 1 \\
Absence of anal sphincter injury &
\end{tabular}

Table 7 Components used, in varying combinations, to define the outcomes 'recurrence' and 'treatment failure'

\begin{tabular}{ll}
\hline Component & Times used \\
\hline Persistence or recurrence of symptoms & 21 \\
Reappearance of the fistula after healing & 16 \\
Persistence or reappearance of the external fistula & 13 \\
$\quad$ opening & 8 \\
Absence of wound healing & 6 \\
Abscess or infection & 6 \\
Absence of fistula closure or persistence & 3 \\
Non-healing fistula & 3 \\
Additional intervention required & 2 \\
Additional fistula & \\
\hline
\end{tabular}


that development of new fistulas should be considered separately. However, persistence and recurrence of fistulas could simply be the same problem viewed at different time points, and from a patient's perspective 1 year after the intervention, the difference is probably minimal. This would be an interesting area to explore during the generation of the COS.

The quality of studies eligible for data extraction was assessed using Harman's criteria [12], however, only a quarter of the studies demonstrated high-quality outcome reporting using this method. Whilst the majority of studies clearly stated their measured outcomes, few went as far as defining whether the outcomes were primary or secondary. Only $20 \%$ of the studies explained their reasoning for selecting their outcomes. This may be due to the fact that healing, incontinence, and recurrence, the most commonly reported outcomes, require little explanation for their selection to fistula surgeons or patients, as the ultimate aim of any fistula treatment is frequently cited as healing with minimal impact on continence, and minimal risk of recurrence.

The outcomes summarised in this systematic review were categorised according to the COMET taxonomy. Although all relevant domains are represented, the vast majority of outcomes are related to the pathophysiology of disease and treatment. Only $10 \%$ of the outcomes reported by all studies in the last 12 years were related to the impact of disease in terms of its influence on patients' physical, social and role functioning, in other words their quality of life. Whilst the inclusion of outcomes such as these is encouraging and should be recognised, their use is infrequent and gives a narrow reflection of the wide-ranging impact that fistula symptoms or treatments have for patients. For example, whilst the impact on sexual functioning has been recognised, the wider effects on personal and social relationships have not been recorded, as well as the influence of symptoms on non-workrelated activities. Whilst the pathophysiological aspects of the disease are inevitably interrelated with life impact and use of resources, focusing only on the physical symptoms fails to address adequately the wider impact of living with AF. Earlier studies have identified that patients and surgeons allocate importance to different aspects of quality of life associated with anal fistula and its treatment. Surgeons rated continence, leakage, pain, cure and sepsis, whereas patients identified independent activity, good health, pain, continence, psychological health and leakage as their most important aspects of quality of life [40]. We are currently conducting further qualitative work to explore patients' experiences of disease further, and patient involvement in deciding the final COS and how these outcomes should be prioritised is crucial to ensure that the COS remains representative of all stakeholders [7] and centred around relevance to patients.

The current study reported the range of outcome measurement instruments used for the most frequently reported outcomes. Validated measures were largely used for outcomes such as incontinence and quality of life, allowing the benefit of comparison across studies, as well as with other chronic health conditions [41]. However, the broad range of validated measures across studies for AF makes it difficult to compare these specific outcomes across interventions. This supports the need for a systematic method of selecting appropriate Outcome Measurement Instruments (OMIs) once the final COS is established [7, 42]. Furthermore, most measurement instruments of quality of life were generic. Disease-specific measures are known to be more sensitive to change and can directly detect the specific concerns of particular clinical groups, which may be underrepresented in generic measurement instruments [43]. Planned qualitative work will help to determine whether the concerns of patients with AF are adequately addressed by these instruments, or whether the development of a disease-specific PatientReported Outcome Measure (PROM) is needed.

The strength of this systematic review is that with the range of studies reviewed, it is well placed to inform a long list of items for the development of a COS. However, it is limited by the lack of outcomes related to the quality of life, suggesting that the additional qualitative feedback from patients required by COMET to supplement this longlist is crucial. Although it is possible that not all relevant studies have been captured due to the eligibility criteria used, the sheer number of outcomes extracted from the included studies make it likely that saturation has been reached and that any additional outcomes would be procedure specific, and, therefore, not eligible for a generic COS representing a minimum set of outcomes to be adopted by all studies, regardless of intervention used. A further limitation is the English language inclusion criterion, although no abstracts or full texts were excluded based on the language criterion alone, rather they studied the wrong population or were review articles or commentaries. The lack of non-English papers may limit the generalisability of these findings across cultural and ethnic groups. This may be effectively countered through the subsequent longlisting and consensus processes, which will include a broad ethnic and cultural diversity.

\section{Conclusions}

This systematic review highlights the need for consensus amongst researchers and clinicians regarding the outcomes that are essential in determining successful fistula treatment, and how they should be defined and measured. The underrepresentation of outcomes relating to the quality of life needs to be challenged, and qualitative exploration of the patient experience, as well as active engagement of patients in determining a COS are crucial. 
Table 8 Measurement instruments used, in varying combinations, to assess the most frequently reported outcomes

\begin{tabular}{|c|c|c|}
\hline Outcome & Instruments (used in various combinations) & Times used \\
\hline \multirow[t]{11}{*}{ Healing } & Clinical examination, including digital rectal examination & 88 \\
\hline & (Telephone) interview & 16 \\
\hline & MRI & 9 \\
\hline & (3D) endoanal ultrasound & 7 \\
\hline & Medical record review & 7 \\
\hline & Anoscopy or proctoscopy or rectoscopy & 7 \\
\hline & (Un)specified questionnaire & 6 \\
\hline & Digital photograph of the external fistula opening & 2 \\
\hline & Transanal ultrasound & 1 \\
\hline & Examination under anaesthetic & 1 \\
\hline & Anal endosonography & 1 \\
\hline \multirow{15}{*}{$\begin{array}{l}\text { Incontinence/sphincter } \\
\text { function }\end{array}$} & Wexner Cleveland Clinic Florida incontinence score & 48 \\
\hline & Patient-reported & 9 \\
\hline & Vaizey incontinence score & 9 \\
\hline & Fecal Incontinence Quality of Life Scale & 6 \\
\hline & (Un)specified questionnaire & 5 \\
\hline & Anorectal manometry & 5 \\
\hline & Endoanal ultrasound & 4 \\
\hline & Specified grading system & 3 \\
\hline & Clinical examination, including digital rectal examination & 3 \\
\hline & Colorectal functional outcome questionnaire & 3 \\
\hline & (Telephone) interview & 3 \\
\hline & Medical record review & 2 \\
\hline & German Society of Coloproctology score & 1 \\
\hline & Williams grade & 1 \\
\hline & Fecal Incontinence Severity Index & 1 \\
\hline \multirow{10}{*}{$\begin{array}{l}\text { Recurrence } \\
\text { Treatment failure }\end{array}$} & Clinical examination & 43 \\
\hline & (Telephone) interview & 7 \\
\hline & MRI & 6 \\
\hline & Medical record review & 6 \\
\hline & (Un)specified questionnaire & 3 \\
\hline & Endorectal ultrasound & 2 \\
\hline & Anoscopy or proctoscopy & 2 \\
\hline & 3D endoanal ultrasound & 1 \\
\hline & Anal endosonography & 1 \\
\hline & Patient-reported & 1 \\
\hline \multirow[t]{10}{*}{ Quality of life } & Fecal Incontinence Quality of Life Scale & 6 \\
\hline & Short Form-36 health survey (SF-36) & 6 \\
\hline & EQ-5D & 4 \\
\hline & Short Form-12 health survey (SF-12) & 2 \\
\hline & Cleveland global quality of life & 2 \\
\hline & Gastrointestinal Quality of Life Index & 2 \\
\hline & (Un)specified questionnaire & 2 \\
\hline & Quality of Life Scale & 1 \\
\hline & Visual Analogue Scale (VAS) & 1 \\
\hline & Fecal Incontinence Severity Index & 1 \\
\hline \multirow[t]{5}{*}{ Pain } & VAS & 31 \\
\hline & Patient-reported & 2 \\
\hline & Specified grading system & 1 \\
\hline & Medical record review & 1 \\
\hline & Number of analgesics used & 1 \\
\hline
\end{tabular}

$M R I$ magnetic resinance imaging, VAS Visual Analogue Scale, EQ-5D EuroQol five-dimensions questionnaire 
Funding NI is supported by a Royal College of Surgeons of England Research Fellowship.

Data availability Registered protocol is available on Prospero (CRD42018102778).

Code availability Not applicable.

\section{Declarations}

Conflict of interest The authors have no relevant financial or non-financial interests to disclose.

Open Access This article is licensed under a Creative Commons Attribution 4.0 International License, which permits use, sharing, adaptation, distribution and reproduction in any medium or format, as long as you give appropriate credit to the original author(s) and the source, provide a link to the Creative Commons licence, and indicate if changes were made. The images or other third party material in this article are included in the article's Creative Commons licence, unless indicated otherwise in a credit line to the material. If material is not included in the article's Creative Commons licence and your intended use is not permitted by statutory regulation or exceeds the permitted use, you will need to obtain permission directly from the copyright holder. To view a copy of this licence, visit http://creativecommons.org/licenses/by/4.0/.

\section{References}

1. Owen HA, Buchanan GN, Schizas A, Cohen R, Williams AB (2016) Quality of life with anal fistula. Ann R Coll Surg Engl 98(5):334-338

2. Tozer P, Sala S, Cianci V, Kalmar K, Atkin GK, Rahbour G et al (2013) Fistulotomy in the tertiary setting can achieve high rates of fistula cure with an acceptable risk of deterioration in continence. J Gastrointest Surg 17(11):1960-1965

3. Garg P (2018) Is fistulotomy still the gold standard in present era and is it highly underutilized?: An audit of 675 operated cases. Int J Surg 56:26-30

4. Ratto C, Grossi U, Litta F, Di Tanna GL, Parello A, De Simone V et al (2019) Contemporary surgical practice in the management of anal fistula: results from an international survey. Tech Coloproctol 23(8):729-741

5. Gottgens KWA, Smeets RR, Stassen LPS, Beets G, Breukink SO (2015) Systematic review and meta-analysis of surgical interventions for high cryptoglandular perianal fistula. Int J Colorectal Dis 30(5):583-593

6. Jayne D, Phillips R, Ahmad A, Maxwell-Armstrong C, Williams A, Tozer P et al (2018) The treatment of anal fistula: second ACPGBI position statement-2018. Colorectal Dis 20(Suppl 3):5-31

7. Williamson PR, Altman DG, Bagley H, Barnes KL, Blazeby JM, Brookes ST et al (2017) The COMET handbook: version 1.0. Trials 18(Suppl 3): 1-50

8. Dwan K, Gamble C, Williamson PR, Kirkham JJ (2013) Systematic review of the empirical evidence of study publication bias and outcome reporting bias-an updated review. PLoS ONE 8(7):e66844

9. Page MJ, McKenzie JE, Kirkham J, Dwan K, Kramer S, Green, Forbes A (2014) Bias due to selective inclusion and reporting of outcomes and analyses in systematic reviews of randomised trials of healthcare interventions. Cochrane Database Syst Rev
1(10):MR000035. https://doi.org/10.1002/14651858.MR000035. pub2

10. Chan A, Song F, Vickers A, Jefferson T, Dickersin K, Gotzsche $P$ et al (2014) Increasing value and reducing waste: addressing inaccessible research. Lancet 383(9913):257-266

11. Machielsen AJHM, Iqbal N, Kimman ML, Sahnan K, Adegbola SO, Kleijnen J, Vaizey CJ, Grossi U, Tozer PJ, Breukink SO (2020) The development of a cryptoglandular anal fistula core outcome set (AFCOS): an international Delphi study protocol. United Eur Gastroenterol J 8(2):220-226

12. Harman NL, Bruce IA, Callery P, Tierney S, Sharif MO, O'Brien $\mathrm{K}$ et al (2013) MOMENT-management of otitis media with effusion in cleft palate: protocol for a systematic review of the literature and identification of a core outcome set using a Delphi survey. Trials 14(1):70

13. Dodd S, Clarke M, Becker L, Mavergames C, Fish R, Williamson PR (2018) A taxonomy has been developed for outcomes in medical research to help improve knowledge discovery. J Clin Epidemiol 96:84-92

14. Herreros MD, Garcia-Arranz M, Guadalajara H, De-La-Quintana P, Garcia-Olmo D (2012) Autologous expanded adipose-derived stem cells for the treatment of complex cryptoglandular perianal fistulas: a phase III randomized clinical trial (FATT 1: fistula advanced therapy trial 1) and long-term evaluation. Dis Colon Rectum 55(7):762-772

15. Nordholm-Carstensen A, Krarup P-M, Hagen K (2017) Treatment of complex fistula-in-ano with a nitinol proctology clip. Dis Colon Rectum 60(7):723-728

16. Wilhelm A, Fiebig A, Krawczak M (2017) Five years of experience with the FiLaCTM laser for fistula-in-ano management: long-term follow-up from a single institution. Tech Coloproctol 21(4):269-276

17. Boenicke L, Karsten E, Zirngibl H, Ambe P (2017) Advancement flap for treatment of complex cryptoglandular anal fistula: prediction of therapy success or failure using anamnestic and clinical parameters. World J Surg 41(9):2395-2400

18. Heydari A, Attina GM, Merolla E, Piccoli M, Fazlalizadeh R, Melotti G (2013) Bioabsorbable synthetic plug in the treatment of anal fistulas. Dis Colon Rectum 56(6):774-779

19. Lara FJ, Serrano AM, Moreno JU, Carmona JH, Marquez MF, Perez LR et al (2015) Platelet-rich fibrin sealant as a treatment for complex perianal fistulas: a multicentre study. J Gastrointest Surg 19(2):360-368

20. Ozturk E (2015) Treatment of recurrent anal fistula using an autologous cartilage plug: a pilot study. Tech Coloproctol 19(5):301-307

21. Doizois EJ, Lightner A, Mathis KL et al (2019) Early results of a phase I trial using an adipose-derived mesenchymal stem cell-coated fistula plug for the treatment of transsphincteric cryptoglandular fistulas. Dis Colon Rectum 62(5):615-622

22. De la Portilla F, Munoz-Cruzado MVD, Maestre MV et al (2019) Platelet-rich plasma (PRP) versus fibrin glue in cryptogenic fistula-in-ano: a phase III single-center, randomized, double-blind trial. Int J Colorectal Dis 34(6):1113-1119

23. Attaallah W, Tuney D, Gulluoglu BM, Ugurlu MU, Gunal O, Yegen C (2014) Should we consider topical silver nitrate irrigation as a definitive nonsurgical treatment for perianal fistula? Dis Colon Rectum 57(7):882-887

24. Gupta PJ, Heda PS, Shrirao SA, Kalaskar SS (2011) Topical sucralfate treatment of anal fistulotomy wounds: a randomized placebo-controlled trial. Dis Colon Rectum 54(6):699-704

25. Altomare DF, Greco VJ, Tricomi N, Arcana F, Mancini S, Rinaldi $M$ et al (2011) Seton or glue for trans-sphincteric anal fistulae: a prospective randomized crossover clinical trial. Colorectal Dis 13(1):82-86 
26. Garg P (2009) To determine the efficacy of anal fistula plug in the treatment of high fistula-in-ano: an initial experience. Colorectal Dis 11(6):588-591

27. Eitan A, Koliada M, Bickel A (2009) The use of the loose seton technique as a definitive treatment for recurrent and persistent high trans-sphincteric anal fistulas: a long-term outcome. J Gastrointest Surg 13(6):1116-1119

28. Abcarian AM, Estrada JJ, Park J, Corning C, Chaudhry V, Cintron J et al (2012) Ligation of intersphincteric fistula tract: early results of a pilot study. Dis Colon Rectum 55(7):778-782

29. Daodu OO, O'Keefe J, Heine JA (2018) Draining setons as definitive management of fistula-in-ano. Dis Colon Rectum 61(4):499-503

30. Gottgens KW, Vening W, van der Hagen SJ, van Gemert WG, Smeets RR, Stassen LP et al (2014) Long-term results of mucosal advancement flap combined with platelet-rich plasma for high cryptoglandular perianal fistulas. Dis Colon Rectum 57(2):223-227

31. Leventoglu S, Ege B, Mentes BB, Yorubulut M, Soydan S, Aytac B (2013) Treatment for horseshoe fistulas with the modified Hanley procedure using a hybrid seton: results of 21 cases. Tech Coloproctol 17(4):411-417

32. Ege B, Leventoglu S, Mentes BB, Yilmaz U, Oner AY (2014) Hybrid seton for the treatment of high anal fistulas: results of 128 consecutive patients. Tech Coloproctol 18(2):187-193

33. Garcia-Olmo D, Herreros D, Pascual I, Pascual JA, Del-Valle E, Zorrilla J et al (2009) Expanded adipose-derived stem cells for the treatment of complex perianal fistula: a phase II clinical trial. Dis Colon Rectum 52(1):79-86

34. Amato A, Bottini C, De Nardi P, Giamundo P, Lauretta A, Realis Luc A et al (2020) Evaluation and management of perianal abscess and anal fistula: SICCR position statement. Tech Coloproctol 24:127-143

35. Schwandner T, Roblick MH, Kierer W, Brom A, Padberg W, Hirschburger M (2009) Surgical treatment of complex anal fistulas with the anal fistula plug: a prospective, multicenter study. Dis Colon Rectum 52(9):1578-1583
36. Van Koperen PJ, Bemelman WA, Gerhards MF, Janssen LWM, van Tets WF, van Dalsen AD et al (2011) The anal fistula plug treatment compared with the mucosal advancement flap for cryptoglandular high transsphincteric perianal fistula: a double-blinded multicenter randomized trial. Dis Colon Rectum 54(4):387-393

37. Van Assche G, Vanbeckevoort D, Bielen D, Coremans G, Aerden I, Noman M et al (2003) Magnetic resonance imaging of the effects of infliximab on perianal fistulizing Crohn's disease. Am J Gastroenterol 98(2):332-339

38. Tozer P, Ng SC, Siddiqui MR, Plamondon S, Burling D, Gupta A et al (2012) Long-term MRI-guided combined anti-TNF- $\alpha$ and thiopurine therapy for Crohn's perianal fistulas. Inflamm Bowel Dis 18(10):1825-1834

39. Garg P (2019) Comparison of preoperative and postoperative MRI after fistula-in-ano surgery: lessons learnt from an audit of 1323 MRI at a single centre. World J Surg 43(6):1612-1622

40. Wong S, Solomon M, Crowe P, Ooi K (2008) Cure, continence and quality of life after treatment for fistula-in-ano. ANZ J Surg 78(8):675-682. https://doi.org/10.1111/j.1445-2197.2008.04616.x (PMID: 18796027)

41. Black N (2013) Patient reported outcome measures could help transform healthcare. BMJ 346(7896):f167

42. Prinsen CAC, Vohra S, Rose MR, Boers M, Tugwell P, Clarke M et al (2016) How to select outcome measurement instruments for outcomes included in a "core outcome set"- a practical guideline. Trials 17(1):1-10

43. Patrick DL, Deyo RA (1989) Generic and disease-specific measures in assessing health status and quality of life. Med Care 27(3 Suppl):S217-S232

Publisher's Note Springer Nature remains neutral with regard to jurisdictional claims in published maps and institutional affiliations.

\section{Authors and Affiliations}

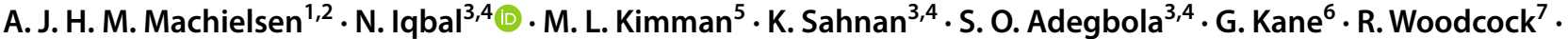 J. Kleijnen ${ }^{8} \cdot$ U. Grossi ${ }^{9} \cdot$ S. O. Breukink ${ }^{10} \cdot$ P. J. Tozer $^{3,4}$}

\author{
A. J. H. M. Machielsen \\ ajhmmachielsen@gmail.com
}

1 Department of Surgery and Colorectal Surgery, Maastricht University Medical Centre+, Maastricht, The Netherlands

2 Faculty of Health, Medicine and Life Sciences, Maastricht University, Maastricht, The Netherlands

3 Robin Phillips' Fistula Research Unit, St Mark's Hospital, London, UK

4 Department of Surgery and Cancer, Imperial College London, London, UK

5 Department of Clinical Epidemiology and Medical Technology Assessment, Care and Public Health Research Institute (CAPHRI), Maastricht University Medical Centre+, Maastricht, The Netherlands
6 Belfast, UK

7 London, UK

8 Department of Family Medicine, Care and Public Health Research Institute (CAPHRI), Maastricht University, Maastricht, The Netherlands

9 Tertiary Referral Pelvic Floor and Incontinence Centre, Regional Hospital Treviso, Treviso, Italy

10 Department of Surgery and Colorectal Surgery, Nutrim School of Nutrition and Translational Research in Metabolism, Maastricht University Medical Centre+, Grow School for Oncology and Developmental Biology, Maastricht, The Netherlands 